Submitted to Advances in Applied Mechanics, March 2009

Revised version, June 2009

\title{
A probabilistic damage model of the dynamic fragmentation process in brittle materials
}

\author{
Pascal FORQUIN ${ }^{1, *}$ and François HILD ${ }^{2}$ \\ ${ }^{1}$ LPMM / CNRS-FRE 3236 / Université Paul Verlaine - Metz \\ Ile du Saulcy, F-57045 Metz Cedex 1, France \\ ${ }^{2}$ LMT-Cachan, ENS de Cachan / CNRS-UMR 8535 / UPMC / PRES UniverSud \\ 61 avenue du Président Wilson, F-94235 Cachan Cedex, France
}

*to whom correspondence should be addressed.

Fax: +33 3873153 66, Email: pascal.forquin@univ-metz.fr 


\title{
A probabilistic damage model of the dynamic fragmentation
}

\author{
process in brittle materials
}

by

Pascal FORQUIN and François HILD

\begin{abstract}
Dynamic fragmentation is observed in brittle materials such as ceramics, concrete, glass or rocks submitted to impact or blast loadings. Under such loadings, high-stress-rate tensile fields develop within the target, and produce fragmentations characterized by a high density of oriented cracks. To improve industrial processes such as blast loadings in open quarry or ballistic efficiencies of armours or concrete structures against impact loadings, it is essential to understand the main properties of such damage processes (namely, characteristic time of fragmentation, characteristic density, orientation and extension of cracking, ultimate strength) as functions of the loading rate, the size of the structure (or the examination volume), and the failure properties of the brittle material concerned. In the present contribution, the concept of probability of non-obscuration is developed and extended to predict the crack density for any size, shape of the loaded volume, stress gradients, and stress-rates. A closed-form solution is used to show how a brittle and random behaviour under quasi-static loading becomes deterministic and stress-rate-dependent with increasing loading rates. Two definitions of the tensile strength of brittle materials are proposed. As shown by Monte-Carlo simulations, for brittle materials, the "ultimate macroscopic strength" applies under high loading rate or in a large domain whereas the "mean obscuration stress" applied in a small domain or under low stress rate. Next, a multi-scale model is presented and used to simulate damage processes
\end{abstract}


observed during edge-on impact tests performed on an ultra-high strength concrete. Last, the fragmentation properties predicted by modelling of six brittle materials (dense and porous $\mathrm{SiC}$ ceramics, a micro-concrete, an ultra-high strength concrete, a limestone rock and a soda-lime silicate glass) are compared.

Keywords: Single / multiple fragmentation process, Probability of obscuration, Weakest-link hypothesis, Anisotropic damage model, Dynamic tensile strength, Edge-On Impact tests. 


\section{Introduction}

Fragile, easily breakable, difficult to machine, expansive, weakly tough, "brittle materials" do

not have the best reputation in the world of industry, materials science or mechanical engineering. However, under extreme loading situations such as high temperatures, high confining pressures or dynamic loads, brittle materials may appear as very attractive in comparison with metals, polymers or some composite materials. Ceramics have been known since antiquity as heat-resistant materials and are used very often under high temperature conditions [Kingery et al., 1976]. For example, the tensile or compressive strength of ceramics such as silicon carbide or alumina is virtually constant for temperatures as high as 1000 to $1200 \mathrm{~K}$ [Lankford, 1981; 1991]. Concrete materials are also very popular in civil engineering applications for their low conductivity and residual strength after exposure to high temperatures up to 700-900 K [Saad et al., 1996; Ghan et al., 1999; Xiao and König, 2004; Savva et al., 2005; Arioz, 2007].

The quasi-static confined strength of brittle materials has been extensively studied during the last three decades. In particular, triaxial compression tests were developed to provide an evaluation of the strength of geomaterials under different confinement pressures. During these tests, a purely hydrostatic pressure is first applied on a cylindrical specimen. Afterwards, an axial compression is added. The strength, in a von Mises sense, is taken as the maximum axial stress on withdrawal of the pressure applied by the confinement fluid. These tests have been carried out for several decades on concretes [Bridgman, 1952; Zimmerman, 1972; Palaniswamy and Shah, 1974; Kotsovos and Newman, 1980], on rocks [Hoek and Franklin, 1968; Cagnoux and Don, 1994] (limestone and quartzite), and on ceramics [Heard and Cline, 1980] (alumina-type ceramics, aluminium nitride, and beryllium or magnesium oxide). All these works show that these materials known for their brittleness or quasi- 
brittleness under uniaxial compression undergo a change to a more ductile behaviour under high pressure with an increase of strength under pressures of about few hundreds of MPa that may exceed ten times those under unconfined or nearly unconfined loading.

The increase of strength and ductility with confining pressure is particularly spectacular in brittle materials; the same remark can be made concerning their strain-rate sensitivity. Influence of strain rate on the failure stress of brittle materials has been investigated extensively during the two last decades. For example, quasi-static and dynamic uniaxial compression tests were performed on ordinary or high-strength concretes. A review proposed by Bischoff and Perry [1991] shows that above a strain rate of $10^{-5} \mathrm{~s}^{-1}$, a smooth and linear (in a log-log plot) increase of strength with strain rate is observed up to $20-30 \mathrm{~s}^{-1}$. This increase of strength is due to the free water within the specimens of concrete since this phenomenon totally disappears with dry concretes [Gary et al., 1991; Gary and Klepaczko, 1992]. Rossi [1988] showed a significant influence of free water on the toughness of concretes. Therefore, the strain rate sensitivity is certainly the result of the viscosity of internal fluid that impedes the opening of micro-cracks [Mangis, 1988; Rossi, 1991]. Above the strain-rate level of transition (i.e., 20-30 s $\mathrm{s}^{-1}$ for concretes [Bischoff and Perry, 1991]), the increase of strength in dynamic uniaxial compression is more pronounced. This time free water is not the main reason of the phenomenon since it is also observed in dry concretes [Gary et al., 1991]. According to Gorham [1989] and Weerheijm [1992], this increase of ultimate stress is the consequence of inertia effects that restrain the lateral expansion associated with compression. As reported above, brittle materials are very sensitive to any lateral pressure, and the inertia of the specimen is acting as an artificial confinement that explains the apparent strain-rate sensitivity that is observed in concrete-like materials under such loading rates. A confirmation of this interpretation, namely, no strain-rate sensitivity, was observed in dynamic quasi-oedometric compression tests for which the radial 
displacement is considerably reduced by a metallic confinement cell that surrounds the concrete specimen [Forquin, 2003; Forquin et al., 2008a; 2009].

As discussed above, the increase of failure stress in concrete samples under dynamic compression is mainly due to free water in the material or inertia effects. However, strain-rate sensitivity of brittle materials is also observed in dynamic tensile loadings for which no inertia confinement occurs. A review of results obtained with concretes was proposed by Klepaczko and Brara [2001]. As in uniaxial compression, a low increase of strength with loading rate is observed up to about $1 \mathrm{~s}^{-1}$. Above this transition, a sharp increase of strength is reported. Free water within concrete samples may explain the sensitivity at low strain rates. Toutlemonde [1994] performed direct tensile tests for strain rates in the range of $\left(2.5 \times 10^{-6} \mathrm{~s}^{-1}\right.$ $-2.5 \mathrm{~s}^{-1}$ ). Significant strain-rate sensitivity was observed in wet concretes for a maximum aggregate size ranging from 2 to $10 \mathrm{~mm}$, and for water to cement ratios varying from 0.3 to 0.7. Conversely, a very limited influence of loading rate was detected in dry specimens. Spall tests performed by Klepaczko and Brara [2001] on a dried or water-saturated microconcrete revealed a spectacular increase of dynamic tensile strength in the strain-rate range of $\left(20 \mathrm{~s}^{-1}-120 \mathrm{~s}^{-1}\right)$. Other results for the "Dynamic Increase Factor" (i.e., ratio between the dynamic and quasi-static strengths) were obtained in the strain-rate range of $\left(10-100 \mathrm{~s}^{-1}\right)$ by Weerheijm [1992], Wu et al. [2005], Schuler et al. [2006], Weerheijm and Van Doormaal [2007], Erzar and Forquin [2009] on ordinary and high-strength concretes.

To summarize, it is puzzling to observe that most brittle materials show attractive properties under extreme conditions such as high temperatures, high pressures or high loading rates but ironically these materials are not popular in the field of engineering mechanics. The present study is focused on the modelling of the fragmentation process of brittle materials under dynamic tensile loading. In particular it is shown that when the stress rate is "sufficiently" increased, the well-known brittle and probabilistic behaviour of these materials 
becomes deterministic and is characterized by an increase of ultimate failure stress and strain with loading rate. Moreover, the ubiquitous weakest link hypothesis [Freudenthal, 1968] does no longer apply and the failure is not controlled by a unique initiation site but is the consequence of a large number of oriented cracks.

In this study, six brittle materials are selected to compare their fragmentation behaviour under dynamic tensile loading. The first two materials are a dense $\mathrm{SiC}$ ceramic and a porous $\mathrm{SiC}$ ceramic (infiltrated or not by an aluminium alloy). The third material is a sodalime silicate glass. As geomaterials, two concretes are chosen, namely, an ultra-high strength concrete (Ductal ${ }^{\circledR}$ ) and a micro-concrete (MB50), and a limestone rock is selected as the last material. The first part gives examples of the use of such brittle materials under impact or blast loadings. Their damage pattern is illustrated by means of macrographs and micrographs. In the second part, based on the weakest-link hypothesis, the Weibull model is used to describe single fragmentation in brittle materials. The Weibull parameters and the basic properties of the six reference materials are presented. Results of edge-on impact tests performed with each material are shown in the third part. Open or sarcophagus configurations are used to analyze the main properties of fragmentation in the targets (density, orientation, extension of cracking). In the fourth part, based on a concept of "local" weakest-link hypothesis, a description of the obscuration phenomenon is proposed for any fragmentation process (single or multiple). The meaning of the probability of obscuration is discussed depending on the applied loading rate and the size of the examination domain. In the last part, the multi-scale fragmentation model is used to simulate the damage process during edge-on impact tests. An analytical solution is also used to deduce the fragmentation properties near the surface of targets for the six brittle materials. 


\section{Damage of brittle materials under impact or blast loadings}

Fragmentation processes are commonly observed in targets made of concrete, rock, ceramic or glass when they are submitted to impact or blast loadings. In this part, four examples of brittle materials under such conditions are detailed. A silicon carbide ceramic is utilized as a front face of multilayered armour. Next, the fragmentation of a limestone rock under blast loading is shown. Ballistic results obtained with an ultra-high strength concrete $\left(\right.$ Ductal $\left.^{\mathbb{R}}\right)$ are shown afterwards. This type of concrete combines low porosity levels and high compressive strengths that makes it interesting as a material for protective structures against impact loads. The last brittle material loaded under a projectile impact is a soda-lime silicate glass used in transparent armoured windshields.

\section{II.1. Fragmentation of ceramic tiles used as front face of multilayered armour}

Bilayered armours using hard materials such as ceramics (e.g., alumina, silicon carbide, quartz) as front plate and ductile materials (e.g., steel, aluminium alloy, composite or polycarbonate) as backing face have been studied for several years to improve the efficiency of light or medium armours against small-to-medium piercing calibres (e.g., AP $7.62 \mathrm{~mm}$ or AP $12.7 \mathrm{~mm}$ [den Reijer, 1991]). The high hardness of ceramic materials favours projectile blunting and / or failure and spreads the kinetic energy on a large surface of the ductile backing. The weight of the armour is then reduced in comparison to those made of steel only [Forquin et al., 2003]. Figure 1 shows a block of armour made of three tiles of infiltrated ceramic as front face and of $15 \mathrm{~mm}$ thick aluminium layer as backing. A steel casing that maintains the three tiles in position during squeeze casting and constrains the ceramic during impact surrounds the ceramic tiles. An AP $12.7 \mathrm{~mm}$ projectile travelling at $880 \mathrm{~m} / \mathrm{s}$ impacted the block (Figure 1). One notes no penetration even though a bending deformation 
of the target is observed. An intense fragmentation made of dense and oriented micro-cracks occurred mainly in the first layer (see micrographs of Figure 1). This anisotropic damage is due to high tensile stresses that spread out in the target following the incident compressive wave [Denoual et al., 1996; Forquin et al., 2003a]. The projectile was found totally pulverized after impact. During impact, damage in the target and of the projectile develops simultaneously during few microseconds that follow impact. They reduce respectively the strength of the target to be penetrated and the penetrating capability of the projectile. This is why the fragmentation properties of the target (i.e., the characteristic time to damage, the density and orientation of cracking or the dynamic strength of the material) need to be predicted and modelled; the role of the microstructure of the ceramic tile being an important point to be understood.

\section{II.2. Fragmentation of a limestone rock submitted to blast loading}

Detonating explosives are currently used in geomechanics to blast rocks to build roads, tunnels, bridges or dams. They are also extensively used in open quarries to produce blocks, aggregates and gravel. In such situations, fragmentation of rocks needs to be controlled to limit the extension of cracking, to obtain the required size of blocks and to adjust as well as possible the quantity of explosives, their power, the number and position of the charges. The distinct zones resulting from rock blasting were identified by Kutter and Fairhurst [1971], namely a comminuted area (or crushing zone) in the vicinity of the explosive followed by a damaged zone in which dense microcracking is observed and finally a zone where few long cracks develop. Later, it was recognized that inherent flaws are activated, grow and eventually coalesce to form macrocracks [Shockey et al., 1974]. For example, the picture of Figure 2 (left) shows the synchronized detonation of eight charges in an open quarry. The 
pressure of gas, the spacing of the charges and the chronology of the pyrotechnic system directly influence the fragmentation process of the blasted rock. Figure 2 (right) shows the result of a unique blast loading of a Beaucaire limestone slab. The material is reduced in debris in an area close to the explosive. Furthermore, numerous radial and hoop cracks have propagated in the whole block. Compressive damage and compaction in the first zone probably limited the crack density in the volume.

\section{II.3. Damage of Ultra-High Strength Concrete due to impact by a kinetic striker}

During the two last decades, performances of concretes have seen a spectacular and continuous evolution. First, super-plasticizers were used in the ' 80 s to reduce the proportion of water in the mix, keeping at the same time a sufficient malleability. This has led to highperformance concretes with compressive strengths ranging from -40 to $-60 \mathrm{MPa}$, instead of $-20 \mathrm{MPa}$ to $-30 \mathrm{MPa}$ generally obtained with ordinary concretes. Addition of silica fume in the mix led in the '90s to very-high performance concretes (failure stress under simple compression down to -120 MPa [Malier, 1992]). Next, ultra-high strength concretes (UHSC) also called RPC (reactive powder concretes) were developed during the last decade with failure stresses that may reach at least $-200 \mathrm{MPa}$ in simple compression. These concretes benefit from a reduced grain size (maximum size $<600 \mu \mathrm{m}$ ) and an optimal granular skeleton that enables one to homogenize the elastic properties of the grains and the matrix, and to decrease internal stresses [Richard and Cheyrezy, 1995; Cheyrezy et al., 1995]. For example, a micrograph of an UHSC $\left(\right.$ Ductal $^{\circledR}$ ) with no small fibres is shown in Figure 3. Its microstructure is made of fine-sand grains whose size is a few hundreds of micrometers, followed by cement grains and crushable quartz grains whose size is in the tens of micrometers. A compact arrangement is obtained by using silica fumes (few micrometer- 
sizes). The amount of water used in the mix [water $/$ (cement + silica fumes $)=0.17$ in weight] enables one to minimize the porosity (few \%). In its commercial composition, the $\operatorname{Ductal}^{\circledR}$ matrix is reinforced by steel fibres (length: $13 \mathrm{~mm}$, diameter: $0.2 \mathrm{~mm}$, strength: $2400 \mathrm{MPa}$ [Bayard, 2003]).

At the same time, military laboratories have investigated whether the ballistic performances of concretes had grown in proportion to their quasi-static strength. This is why laboratory-scale tests of projectile impact were carried out on ordinary, high-performance concretes [Forrestal et al., 1994; Forrestal et al., 1996, Frew et al., 1998; Gómez and Shukla, 2001] and on ultra-high performance concretes [Darrigade and Buzaud, 1999]. These studies allowed for a derivation of analytical solutions of the depth of penetration of a projectile into a thick concrete target, in normal impact, knowing the geometry and the velocity of the projectile. This type of dimensionless analysis was proposed, for example, by Kennedy [1976] and Barr [1990], and was applied to ordinary and high-performance concretes [Forrestal et al., 1996, Frew et al., 1998]. Li et al. [2005] recently proposed a synthesis of analytical solutions to predict the depth of penetration of a projectile into a concrete target.

To illustrate the different types of cracking that develop in a target made of UHSC subjected to the impact of a kinetic striker, two pictures are shown in Figure 3. The target is made of two 30-mm thick concrete blocks perfectly glued and a $10-\mathrm{mm}$ thick aluminium backing that is used to prevent any spalling on the rear face of the second concrete tile. The projectile is an Armour-Piercing AP $7.62 \mathrm{~mm}$ (hard steel core) bullet fired at $840 \mathrm{~m} / \mathrm{s}$. As detailed by Li et al. [2005], one may observe distinct damage zones illustrated on the sketch on right-hand side of Figure 3:

- scabbing on the front face (i.e., conical cracks that emerge on the front surface) due to unconfined compression in the direction orthogonal to the projectile trajectory, 
- cracking around the tunnel region due to hoop stresses generated by the swelling of the tunnel during projectile penetration,

- spalling on the rear face (i.e., conical cracks on the rear surface) due to axial punching of the projectile,

- fragmentation of the target made of numerous oriented cracks with respect to the impact point due to tensile hoop stresses induced by the incident compressive wave,

- Microcracking parallel to the tunnel corresponding to shear stresses ahead of the projectile (confined compression in front of the projectile).

Similar damage patterns were observed in targets made of two mortars when impacted by cylindrical projectiles $(5.3 \mathrm{~mm}$ diameter) of rolled $100 \mathrm{C} 6$ steel, fired at about $750 \mathrm{~m} / \mathrm{s}$ [Forquin et al., 2008b]. In particular, scabbing on the front face (referred to as saucer-shaped cracking), radial and hoop cracking in the bulk of the targets as well as micro-cracking around the tunnel were observed. The damage patterns of Figure 3 correspond to several dynamic tensile and compressive loadings at distinct instants and locations after impact. Here again, the fragmentation process needs to be understood and modelled (especially the time to form damage, the dynamic strength as function of the loading rate and the mechanical properties of the damaged target).

\section{II.4. Damage of glass during impact against transparent armoured windshields}

Glass is usually employed to make transparent armoured windshields. Figure 4 shows a typical result of impact (in this case, a 44 magnum bullet) against a multilayered glass / polycarbonate target. A complex crack pattern is observed. It is made of: 
- a zone fully pulverized and reduced in debris close to the impact point,

- a second area that surrounds the first one. This area, referred to as 'zone of visionloss,' is made of dense and oriented cracks,

- long radial cracks that propagate far away from the impact point and that are intersected by hoop cracks.

In this situation, the main issues are to prevent the perforation of the target by single or multiple hits, to reduce the extension of the area of vision loss and to limit as much as possible the weight of the windshield. A better understanding of the origin and kinetics of fragmentation may allow the designer to improve the efficiency of such transparent armours.

In this introduction, few examples of damage in brittle materials due to impact or blast loadings were shown. The mere knowledge of the dynamic strength of these materials is not sufficient since the projectile (in a case of impact) or gas (in a case of blasting) are still acting against the damaged target a long time after the initiation of cracking. The origin of cracking (i.e., microdefects in the material), the growth and extension of damage, and the crack densities are also essential points to be understood and modelled. In the following part, the Weibull model is detailed and mechanical properties of the six reference materials are presented.

\section{Weibull parameters and basic properties of six reference materials}

\section{III.1. Weibull model}

The single fragmentation in brittle materials is first analyzed. Single fragmentation (i.e., a single crack initiation event leading to the failure of the whole structure) is observed in many brittle materials under tensile loading when the stress rate is low. It follows that a weakest 
link hypothesis is made [Freudenthal, 1968] and a Weibull model [1951] is used to fit experimental data,

$$
P_{F}=1-\exp \left[-Z_{\text {eff }} \lambda_{t}\left(\sigma_{F}\right)\right] \text { with } \lambda_{t}\left(\sigma_{F}\right)=\lambda_{0}\left(\frac{\sigma_{F}}{S_{0}}\right)^{m}
$$

where $P_{F}$ denotes the failure probability, $\lambda_{t}$ the defect density, $m$ the Weibull modulus, $S_{0}$ a scale parameter relative to a reference density $\lambda_{0}$. The constant $S_{0}^{m} / \lambda_{0}$ is the Weibull scale parameter. In the following, when no special mention is made, the development is valid for any space dimension $n$ (i.e., 1, 2 or 3). Otherwise, it will be explicitly stated for which space dimension the results are valid. The failure stress $\sigma_{F}$ is defined as

$$
\sigma_{F}=\max _{\Omega} \sigma_{1}
$$

where $\sigma_{1}$ is the local maximum principal stress. The effective volume, surface or length [Davies, 1973], $Z_{\text {eff }}$, is expressed as

$$
Z_{\text {eff }}=Z H_{m}
$$

where $Z$ is the size of the whole volume, surface or length and $H_{m}$ is the stress heterogeneity factor [Hild et al., 1992] expressed as

$$
H_{m}=\frac{1}{Z} \int_{\Omega}\left(\frac{\left\langle\sigma_{1}\right\rangle}{\sigma_{F}}\right)^{m} d Z \text { when } \sigma_{F}>0
$$

The stress heterogeneity factor characterizes the effect of the load pattern on the cumulative failure probability. Last, the average failure stress $\sigma_{w}$ and the corresponding standard deviation $\sigma_{s d}$ are written as 


$$
\sigma_{w}=S_{0}\left(\lambda_{0} Z H_{m}\right)^{-1 / m} \Gamma\left(1+\frac{1}{m}\right)
$$

and

$$
\sigma_{s d}=S_{0}\left(\lambda_{0} Z H_{m}\right)^{-1 / m} \sqrt{\Gamma\left(1+\frac{2}{m}\right)-\Gamma^{2}\left(1+\frac{1}{m}\right)}
$$

where $\Gamma$ is the Euler function of the second kind [Spanier and Oldham, 1987]

$$
\Gamma(1+x)=\int_{0}^{\infty} \exp (-u) u^{x} d u
$$

Figure 5 shows the change of the stress deviation divided by the average failure stress as function of the Weibull modulus (Equations (5) and (6)). The coefficient of variation $\sigma_{s d} / \sigma_{w}$ is bounded by the functions $1 / m$ and $\pi / \sqrt{6} m$. Therefore the Weibull modulus gives a direct indication on the scatter in failure stresses, namely, the higher the Weibull modulus, the lower the standard deviation and the scatter of failure stresses with respect to the average value.

\section{III.2. Weibull parameters of the six reference materials}

Bending tests (at least a dozen) were performed for each reference materials and a distribution of failure stresses $\sigma_{F}$ was deduced. According to Equation (1), the failure probability of a structure $\Omega$ is function of the two Weibull parameters, namely, the Weibull scale parameter $\left(S_{0}^{m} / \lambda_{0}\right)$ and the Weibull modulus $(m)$. One way to obtain these parameters is to deduce the Weibull modulus for example from Figure 5 knowing the average failure stress and the standard deviation of failure stresses (Equations (5) and (6)). It is then possible to compute the stress heterogeneity factor (Equation (4)) knowing the stress field in the structure $\Omega$. The 
Weibull scale parameter $\left(S_{0}^{m} / \lambda_{0}\right)$ is deduced afterwards from Equation (5) or (6). A classical alternative is to resort to the so-called Weibull [1939] diagram in which $\ln \left[-\ln \left(1-P_{F}\right)\right]$ vs. $\ln \left(\sigma_{F}\right)$ is interpolated by a linear function, the slope of which is the Weibull modulus $m$.

Three-point flexure tests were carried out on SiC-100, R-SiC ceramics, MB50 and Ductal $^{\circledR}$ concretes, and crinoidal limestone samples. The sizes of the latter and the number of tests performed are given in Table 1. The Weibull modulus, the average failure stress and the effective volume are also reported. For the five studied materials, the Weibull parameters are significantly different. The Weibull parameters are representative of the material microstructure, and more precisely of the defect distribution and local toughness properties [Jayatilaka and Trustrum 1977; Hild et al., 1992]. For example, Figure 6 (right) shows the load / displacement curves obtained from bending tests carried out on Ductal ${ }^{\circledR}$ concrete without fibres. The behaviour is perfectly elastic-brittle (i.e. no loss of linearity is observed until the maximum load is reached). Consequently, the distribution of maximum loads allows one to characterize the population of defects (in terms of activation stresses) that induce the failure of specimens. The pictures of Figure 6 (left) show two failure causes. A large porosity $(0.6 \mathrm{~mm}$ and $2 \mathrm{~mm}$ in diameter respectively for $\mathrm{B} 1$ and $\mathrm{B} 5)$ is observed close to the tensile surface of each specimen (upper surfaces of Figure 6 (left)). The largest porosities in the bulk of the specimens are the likely cause of failure. Concerning the specimens made of crinoidal limestone, ceramics and glass, the analysis of failure patterns did not always allow one to identify the actual defect from which each failure originated. The failure of R-SiC specimens is probably due to a pore as those visible in Figure 1 . The failure of limestone specimens may originate from inclusions made of silica, magnesia, sulphur, ferrous sulphide, or potassium oxides that are present in the material. As demonstrated by Brajer et al. [2003], the failure of specimens made of soda-lime silicate glass is due to surface defects (such as 
micro-scratches). Therefore an effective surface is computed instead of an effective volume (Table 1).

The Weibull modulus is mainly related to the decay for large defect sizes of the corresponding probability density function [Jayatilaka and Trustrum 1977; Hild et al., 1992], which is usually described by a power law whose exponent is a linear function of the Weibull modulus. Consequently, different Weibull moduli, as observed for the studied materials, are an indication of different defect populations, in particular for the largest defect sizes, i.e., the ones likely to initiate failure under quasi-static loading conditions. For a given reference density $\lambda_{0}$, different stresses $S_{0}$ are mainly induced by different toughnesses and average defect sizes. Different defect populations will therefore lead to different Weibull parameters. Conversely, different Weibull parameters are indicators of different defect distributions. When dealing with dynamic fragmentation, the Weibull model itself can no longer be used since a weakest link hypothesis does not apply, however, the following microstructure model using Weibull parameters is still considered.

A microstructure model is now introduced to account for random distributions of defects. It has to be valid for describing single and multiple fragmentation regimes. Its advantage then lies in the fact that quasi-static experiments may be used to identify the material parameters. Once they are determined, they may be used in a situation where single fragmentation no longer occurs (e.g., dynamic fragmentation). The material is assumed to contain point defects of density $\lambda_{t}$. Such hypotheses are those of a Poisson point process of intensity $\lambda_{t}$ [Gulino and Phoenix, 1991; Jeulin, 1991; Denoual and Hild, 2000]. Consequently, the probability of finding $\delta$ defects within a uniformly loaded domain $\Omega$ of size $Z$ reads

$$
P(\delta, \Omega)=\frac{\Lambda_{t}^{\delta}}{\delta !} \exp \left[-\Lambda_{t}\right]
$$


so that $\Lambda_{t}$ corresponds to the average number of defects within $\Omega$. By definition, $\Lambda_{t}$ is related to the density $\lambda_{t}$ by $\Lambda_{t}=Z \lambda_{t}$ for a uniformly loaded domain. Let us now assume that $\lambda_{t}$ is a function of the applied stress $\sigma_{1}$. The larger the applied stress, the greater the number of defects that will initiate cracks. One possible choice to account for this trend is given by a power law function of the maximum principal stress

$$
\lambda_{t}\left(\sigma_{1}\right)=\lambda_{0}\left(\frac{\left\langle\sigma_{1}\right\rangle}{S_{0}}\right)^{m}
$$

where $m$ and $S_{0}^{m} / \lambda_{0}$ are interpreted as the Weibull parameters when single fragmentation occurs. By using the weakest link hypothesis, the failure probability $P_{F}$ is the probability of finding at least one defect within $\Omega$ when $\sigma_{F}=\sigma_{1}>0$

$$
P(\delta \geq 1, \Omega)=1-P(\delta=0, \Omega)=1-\exp \left[-Z \lambda_{0}\left(\frac{\sigma_{F}}{S_{0}}\right)^{m}\right]
$$

when a uniform stress is applied. If the stress field is heterogeneous, $\Lambda_{t}$ is related to $\lambda_{t}$ by

$$
\Lambda_{t}=\int_{\Omega} \lambda_{t} d Z
$$

and the failure probability reduces to Equation (1), and describes the fact that the larger the volume the smaller the mean failure stress. The Poisson-Weibull model allows one to relate the Weibull parameters to microstructural properties describing the population of initiation sites. The latter is the key for understanding probabilistic features related to the fragmentation of brittle materials. 


\section{III.3. Other mechanical properties}

In addition to the Weibull parameters, several mechanical properties are reported in Table 1. Elastic properties (Young's modulus and Poisson's ratio) are obtained from ultra sound measurements and knowing the mass density of the materials. The Young's modulus of the two ceramic materials is much higher than that of Ductal ${ }^{\circledR}$ and MB50 concretes, limestone and soda-lime glass. However, the densities of the five materials are very similar. Consequently, the wave speed is higher in $\mathrm{SiC}$ ceramics (about 10 to $11 \mathrm{~km} / \mathrm{s}$ for the $1 \mathrm{D}$

wave speed, $\sqrt{E / \rho}$ ) than in the three other material types (about $5 \mathrm{~km} / \mathrm{s}$ ).

Data about the compressive strength of the five materials are also reported in Table 1. Simple compression tests performed with hourglass specimens on two dense silicon carbide grades ( $\mathrm{SiC}-\mathrm{B}$ and the $\mathrm{SiC}-100)$ showed a sudden failure with an average failure stress of about $-6 \mathrm{GPa}$ and $-7 \mathrm{GPa}$ [Forquin et al., 2003b]. The compressive strength of the R-SiC grade was not measured. Simple compression tests were also performed with hourglass $\operatorname{Ductal}^{\circledR}$ specimens and cylindrical specimens with crinoidal limestone. The average ultimate strength measured was $-220 \mathrm{MPa}$ and -150 MPa respectively [Forquin, 2003; Grange et al., 2008].

Concerning glass, the Hugoniot Elastic Limit (HEL) was deduced from plate impact experiments by Cagnoux [1985]. The material behaves first elastically and then non-linearly beyond the HEL. The yield stress $\sigma_{y}$ may be deduced from the HEL using a Tresca or von Mises criterion

$$
\sigma_{y}=\frac{1-2 v}{1-v} \sigma_{H E L}
$$


where $v$ is the Poisson's ratio of the undamaged material. With $v=0.22$, the yield stress of soda-lime glass is approximately $2.9 \mathrm{GPa}$.

Last, the compressive strength of the five reference materials is much higher than their mean tensile failure stress (Table 1). However the compressive strengths vary a lot. In particular those of Ductal ${ }^{\circledR}$ and limestone are much lower than those of SiC ceramics and glass. This is why a dynamic confinement system will be used during Edge-On Impact (EOI) tests performed with the concrete and rock materials; this system aims at preventing as much as possible any compressive damage close to the impact point. The EOI tests will be detailed in the next part.

\section{Dynamic fragmentation in brittle materials}

Tensile cracking, one of the major degradation mechanisms during impact, can be observed by using so-called Edge-On Impact (EOI) configurations instead of a real configuration for which the degradation is 'hidden' in the bulk of the material. Several configurations were developed by the Ernst-Mach-Institute (EMI) in Germany [Hornemann et al. 1984; Strassburger et al., 1994] and by the Centre Technique d'Arcueil (CTA) in France [Riou et al., 1998; Denoual et al., 1998; Forquin and Hild, 2008]. It is shown that the same damage mechanism (i.e., damage in tension) is observed in EOI and in real impact configurations [Denoual et al., 1996]. During an EOI test, a cylindrical projectile hits the edge of a tile to be fragmented. In the same way as for real impact, a compressive wave propagates within the target that induces a radial motion of the material (along the axis centred on the impact point). This radial motion creates tensile hoop stresses that may induce intense damage of the target made of oriented microcracks. An ultra-high speed camera may be used to visualize the development of the fragmentation process in 'real time' (open configuration). The damage 
pattern may be also observed after impact if a so-called sarcophagus configuration is used [Denoual et al., 1998; Forquin, 2003]. It corresponds to a metallic casing that surrounds the target to maintain the fragments in place and to observe the macroscopic and microscopic post-mortem cracking pattern. Various results of EOI tests obtained with the five reference materials (Table 1) are detailed below.

\section{IV.1. Edge-On Impact tests performed with SiC-100 ceramic}

Several EOI tests were performed on tiles of SiC-100 [Strassburger et al., 1994; Riou et al., 1998]. Among those of Riou et al. [1998], Figure 7a shows the damage pattern observed in a 15-mm large target (horizontal axis of Figure 7a) and a 10-mm thick target (axis perpendicular to the pictures of Figure 7a). Damage is composed of a large number of millimetre-long cracks oriented in the radial direction from the impact point. This damage is not generated from the release wave coming from the rear face since the first part of the target is damaged less than $2 \mu$ s after impact (the longitudinal wave velocity being $11800 \mathrm{~m} / \mathrm{s}$, the covered distance during $1.9 \mu \mathrm{s}$ is $22 \mathrm{~mm}$ ). One may also note that the characteristic time of damage is very short (about few tens of microseconds) since the final damage pattern is almost observed at time $2.9 \mu \mathrm{s}$.

\section{IV.2. Edge-On Impact tests performed on R-SiC ceramic}

The $\left(60 \times 30 \times 8 \mathrm{~mm}^{3}\right) \mathrm{R}-\mathrm{SiC}$ tiles, which are obtained by sintering SiC powder (commercial name: Crystars, Saint-Gobain industrial ceramics), are porous (Figure 7b). The open porosity is regular and continuous from one side to the other, in such a way that it can be infiltrated by an aluminium alloy, which fills most of the open porosities during squeeze casting [Forquin et 
al., 2003a]. A porosity of the order of $17 \%$ was measured for R-SiC (Table 1). Edge-on impact tests were performed with high-strength steel projectiles (diameter: $11 \mathrm{~mm}$, height: $15 \mathrm{~mm}$ ) travelling with two different velocities. The results of EOI tests obtained with a sarcophagus configuration, after infiltration by a hyper-fluid resin and fine diamondpolishing, are given in Figure $7 \mathrm{~b}$. The damage pattern shows two distinct zones. A first one, made of numerous oriented micro-cracks, spreads over half the tile. This highly damaged area is followed by numerous radial and longer cracks that reach the rear face. The gradient of crack density highlights the influence of stress rate on the crack density.

\section{IV.3. Edge-On Impact test performed on a limestone rock}

Edge-On impact tests were carried out on Ductal ${ }^{\circledR}$ concrete with and without fibres [Forquin, 2003; Forquin and Hild, 2008] and on crinoidal limestone [Grange et al., 2008]. A special sarcophagus configuration drawn in Figure 8 was developed for this type of materials [Forquin and Hild, 2008]. It is composed of the standard aluminium casing that surrounds the target (Figure 8). Moreover, two half-cylinders made of tungsten and two half-crowns made of steel are put in contact with the lateral faces of the concrete tile near the impact point. This confinement system ensures a plane strain compression loading in front of the projectile. Consequently, the hydrostatic pressure in this area increases and it allows one to benefit from the large increase of strength of rock and concrete materials with the level of confinement pressure. Therefore the extent of compressive damage is reduced and the modelling of the test is easier. As no additional static loading is used to ensure a good confinement, the confinement system is really effective during the back and forth time of waves in the confinement (about a dozen of microseconds). This is why this system is called dynamic confinement. 
Edge-On Impact tests were also performed on crinoidal limestone. A slab of size $300 \times 150 \times 15 \mathrm{~mm}^{3}$ is impacted on the edge by an aluminium alloy projectile (diameter: 20 $\mathrm{mm}$, length: $50 \mathrm{~mm}$ ) travelling at $100 \mathrm{~m} / \mathrm{s}$. A typical damage pattern is shown in Figure 8 . It is composed of a network of radial and hoop cracks. No compressive damage is observed in the area surrounded by the dynamic confinement system.

\section{IV.4. Edge-On Impact test on an Ultra-High Strength Concrete}

Results of EOI tests carried out on the Ductal ${ }^{\circledR}$ matrix with and without fibres are shown in Figure 9. The size of the target is unchanged wrt. to the previous one and the same projectiles are used (aluminium projectile, diameter: $20 \mathrm{~mm}$, length: $50 \mathrm{~mm}$ ). The projectile velocity is about $90 \mathrm{~m} / \mathrm{s}$. An intense fragmentation is visible beyond the area of confinement. It is composed of numerous cracks oriented in the radial direction (from the impact point). This damage zone spreads over about $80 \mathrm{~mm}$. A crack density in the range of $10^{7}$ to $2 \times 10^{7}$ cracks $/ \mathrm{m}^{3}$ was estimated between radii of 30 and $50 \mathrm{~mm}$. Moreover, spall cracks oriented perpendicularly to the axial direction are also visible at a distance of $60 \mathrm{~mm}$ from the impact point. These cracks are the likely consequence of interactions of reflected waves from the opposite side of the projectile and the rear face of the target. Last, fibres did not prevent crack initiation and propagation even if they provided a substantial residual strength to the fragmented target as observed in bending tests performed with specimens reinforced with steel fibres [Forquin and Hild, 2008]. 


\section{IV.5. Edge-On Impact test on sodalime silicate glass}

An edge-on impact configuration was also developed to study the origin and growth of damage in sodalime silicate glass due to impact. The target of size $100 \times 100 \times 10 \mathrm{~mm}^{3}$ is impacted on the edge by a so-called 'BR4' bullet (i.e., magnum 44 projectile with a lead core) travelling at a speed of $430 \mathrm{~m} / \mathrm{s}$. Two results are shown in Figure 10. The first picture shows for different times after impact the change of cracking visualized by an ultra-high-speed camera. Different types of damage are observed:

- cracks develop from the impact point forming a circular cracking front,

- cracks propagate from the impacted edge due to the Rayleigh wave forming the Rayleigh cone,

- cracks develop within the target from flaws located on the lateral faces of the tile. Tensile hoop stresses that follow the compressive wave induce these cracks,

- cracks propagate from the rear face and the lateral edges when the incident wave is reflected on this free surface. These cracks are oriented mainly in the normal direction of these edges,

- a final cracking pattern is visible on the second picture obtained from a sarcophagus configuration. Distinct families of oriented cracks are again detected. As shown by Brajer et al. [2003], the damage pattern is the consequence of cracks initiated from surface flaws that are activated by the tensile stress fields that develop in the wake of the compressive wave, the shear wave, the Rayleigh wave [Graff, 1975] and of wave reflection on free surfaces.

By analyzing edge-on impact tests, it is concluded that when submitted to high-stressrate and tensile stresses, brittle materials such as ceramics, rocks, concretes or glass give rise 
to a high density of oriented (micro)cracks initiated from volume or surface defects. Moreover, as shown by dynamic tensile tests available in literature, such as spalling tests, a significant increase of failure stress is observed under high loading rates (i.e., strain rates greater than a few tens of $\mathrm{s}^{-1}$ in concrete [Weerheijm, 1992; Klepaczko and Brara, 2001; Wu et al., 2005; Schuler et al., 2006]. Brittle materials behave in a totally different manner under dynamic and quasi-static loadings for which a single crack is usually observed and a very low sensitivity to loading rate is reported. However, one may already underline several common points that exist between the quasi-static failure mode and damage under dynamic conditions, namely, the origin of cracking is a priori identical (i.e., caused by the same population of defects). A second point would be a "local weakest link hypothesis" that assumes that no defect is activated in the vicinity of the existing cracks, an area that depends on the size of the corresponding crack as shown by numerical simulations performed by Denoual and Hild [2000]. This hypothesis will be the fundamental basis for the modelling of the fragmentation process described below.

\section{Modelling of the fragmentation process in brittle materials}

A fragmentation process is discrete by essence. In the theory developed by Mott [1947], the fragmentation of a rapidly expanding ring was studied. It contains some key ingredients (i.e., the randomness of the process is clearly stated and accounted for) to analyze the distribution of fragments in 2D experiments [Grady and Kipp, 1985]. Inertia effects were also to have an influence on the fragment size [Grady, 1982; Glenn and Chudnovsky, 1986]. From a numerical point of view, different approaches are developed [Ravi-Chandar, 1998]. Discrete models are proposed [Kusano et al., 1992; Xu and Needleman, 1994; Camacho and Ortiz, 1996; Mastilovic and Krajcinovic, 1999; Zavattieri and Espinosa, 2001; Zhou and Molinari, 
2004] when the fragment size is greater than or equal to the size of a representative element. An alternative route to the previous approaches would be to resort to eXtended Finite Element simulations. However, up to now, most, if not all, reported simulations account for single fragmentation under dynamic loading conditions [Belytschko et al., 2003; Réthoré et al., 2005; de Borst et al., 2006; Menouillard et al., 2006]. Models based upon Smoothed Particle Hydrodynamics [Monaghan, 1990; Libersky and Petscheck, 1993] are also used to simulate the fragmentation of brittle materials under shock loading [Hiermaier and Riedel, 1997].

The aim of the present study is to describe and model in a unified way a fragmentation process in a brittle material for any loading rate, and accounting for various defect distributions. As shown by the previous experimental results, under low stress rates, single fragmentation (a unique crack) occurs whereas multiple fragmentation (numerous cracks) is observed under high stress rates. The modelling is expected to show how the number of cracks depends on strain rate and how the loading rate influences ultimate stress and stressstrain curves. To answer these questions, the phenomenology of a fragmentation process is detailed first. Next, a general expression of the non-obscuration probability is given and an analytical solution is expressed showing the role of volume (or surface) size. Last, the changes of number of cracks, ultimate stress, and time to failure are discussed as functions of stress-rate, volume size and material parameters.

\section{V.1. The "local-weakest-link hypothesis"}

\section{V.1.a - Phenomenology of a fragmentation process in a brittle material}

Dynamic fragmentation corresponds to the initiation and propagation of a large number of cracks from volume or surface defects that exist in a structure $\Omega$, of size $Z, Z$ being a length, 
surface area or volume. The defects are assumed to be randomly distributed and activated for a random level of stress (for example a function of the size of each defect considered [Jayatilaka and Trustrum, 1977]). The number of critical defects in Z (i.e., whose activation stress is exceeded) is described by a density of critical defects related to the applied stress level $\lambda_{t}(\sigma)$, see Equation (9). Figure 11 shows a schematic of a fragmentation process. Defects are randomly distributed along the spatial scale (horizontal axis) and along the stress level scale (vertical axis) assuming that the stress level varies linearly with time (second vertical axis). As the stress level is increasing $(\dot{\sigma}>0)$, the number of critical defects is increasing. However, the cracks that propagate from the first critical defects relax stresses in their vicinity $(\dot{\sigma}<0)$ and prevent the activation of critical defects in an "obscured domain" of size $Z_{o}(T-t)$ centred on this crack, where $T$ - $t$ corresponds to the time interval between crack inception $t$ and the current time $T$ (Figure 11). The growth of obscuration domains (i.e., zones in which $\dot{\sigma}<0$ ) from activated defects is depicted by triangles (obscuration hyper-cones) in Figure 11, corresponding to a constant propagation velocity. The fragmentation process ends when the whole domain is obscured. Therefore, dynamic fragmentation corresponds to a competition between, on the one hand, new critical defects that progressively initiate cracks with the increase of the stress level, and on the other hand, the obscuration of areas of potential critical defects by cracks created before.

The interaction law between cracks already created and critical defects of the material is given by the concept of probability of non-obscuration or "local weakest-link hypothesis." The density and number of cracks are then derived. Thereafter, basic ingredients of a fragmentation process, i.e., laws for the density of critical defects $\lambda_{t}(\sigma)$ and the size of obscured zone $Z_{o}(T-t)$ are proposed. 


\section{V.1.b - General form for the probability of non-obscuration $P_{n o}$}

One wishes to describe any fragmentation phenomenon corresponding to the random inception of one or several cracks in a given domain $\Omega$ of size $Z$. It is necessary to write the condition (in terms of probability) for a point $M$ at a time $T$ not to be obscured, i.e., able to initiate a new crack, if a critical defect exits at that point and if it may be activated at time $T$.

This condition corresponds to the absence of any critical defects in the horizon of $(M, T)$, i.e., "local weakest-link hypothesis." This horizon corresponds to the space-time zone in which one crack might release the stress level at point $M$ and time $T$ (see Figure 11). According to the "local weakest-link hypothesis," the probability of non-obscuration is equal to the product of the elementary probabilities of no-inception of new cracks in each elementary space-time zones of $\Omega$ belonging to the horizon of the point $M$ at time $T$

$$
P_{n o}(M, T)=\prod_{[\text {horizon of }(M, T) \in \Omega]} P_{\notin}^{i}
$$

where $P_{\notin}^{i}$ is the elementary probability of no-inception of new crack in the space-time area $d Z \mathrm{x} d t$ located at $(\underline{x}, t)$ belonging to the horizon of $(M, T)$ and to the considered domain $\Omega$. If one assumes that the material contains point defects of density $\lambda_{t}$ (hypothesis of a Poisson point process of intensity $\lambda_{t}$, see Section III), the elementary probability $P_{\sharp}^{i}$ is expressed according to Equation (14) if the density $\lambda_{t}(\underline{x}, t)$ is a continuous function between $t$ and $t+d t$

$$
P_{\notin}^{i}(\underline{x}, t)=\exp \left(-\frac{\partial \lambda_{t}(\underline{x}, t)}{\partial t} d Z d t\right)
$$


If the density $\lambda_{t}(\underline{x}, t)$ is discontinuous between $t_{i}$ and $t_{i}+d t$, i.e., $\lambda_{t}\left(\underline{x}, t_{i}+d t\right)-\lambda_{t}\left(\underline{x}, t_{i}\right)=\left[\lambda_{t}\right]_{x, t}$, the elementary probability of no-inception of new crack in the space-time area $d Z \mathrm{x} d t$ located at $\left(\underline{x}, t_{i}\right)$ is expressed as

$$
P_{\notin}^{i}\left(\underline{x}, t_{i}\right)=\exp \left(-\left[\lambda_{t}\right]_{\left(\underline{x}, t_{i}\right)} d Z\right)
$$

Therefore, the general form of the non-obscuration probability at $(M, T)$ takes the following expression

$$
P_{n o}(M, T)=\exp \left(-\int_{(\underline{x}, t) \in[\text { horizon of }(M, T) \in \Omega]} \frac{\partial \lambda_{t}(\underline{x}, t)}{\partial t} d Z d t-\sum_{i} \int_{\left(\underline{x}, t_{i}\right) \in[\text { horizon of }(M, T) \in \Omega]}\left[\lambda_{t}\right]_{\left(\underline{x}, t_{i}\right)} d Z\right) .
$$

This expression will be analyzed thereafter in a number of particular cases. First, the crack density is derived.

\section{V.1.c - Number of cracks and crack density}

The number of cracks generated in $\Omega$ at a time $T$ is computed as a function of the crack density

$$
N_{\text {cracks }}(T)=\int_{\Omega} \lambda_{\text {cracks }}(M, T) d Z
$$

The crack density is obtained by integrating its derivate and assuming a zero density at time $T=0$. Therefore, the history of loading is taken into account

$$
\lambda_{\text {cracks }}(M, T)=\int_{0}^{T}\left[\frac{\partial \lambda_{\text {cracks }}}{\partial t}(M, t)\right] d t+\sum_{i}\left[\lambda_{\text {cracks }}\right]_{M, t_{i}} .
$$


However, new cracks are formed only in the partial area that is not obscured. Therefore, the increment of new cracks is assumed to be proportional to the increment of critical defects and weighted by the fraction of non-obscured zones. In a location that is not obscured, any new critical defect is converted into a new crack. The fraction of non-obscured zones is comparable to the probability of non-obscuration. The increment of crack density reads

$$
\frac{\partial \lambda_{\text {cracks }}}{\partial t}(M, t)=P_{n o}(M, t) \frac{\partial \lambda_{t}}{\partial t}(M, t),\left[\lambda_{\text {cracks }}\right]_{M, t_{i}}=P_{n o}\left(M, t_{i}\right)\left[\lambda_{t}\right]_{M, t_{i}} .
$$

The probability of non-obscuration is essential for analyzing and modelling fragmentation processes in brittle materials. The basic ingredients are now detailed. Next, an analytical expression of the non-obscuration probability is developed from few basic hypotheses.

\section{V.2. Modelling of dynamic-fragmentation processes}

According to Equation (16), the obscuration probability depends on the density of critical defects $\lambda_{\mathrm{t}}$ and on the size of obscured zone $Z_{o}$ due to a single crack. Typical expressions are detailed below if an analytical solution of the obscuration probability is needed.

\section{V.2.a - Density of critical defects $\lambda_{t}$}

If one assumes that the same population of defects is activated as under quasi-static tests, the density of critical flaws is again given in the form of a power law of the positive (tension) principal stress

$$
\lambda_{t}\left(\sigma_{1}\right)=\lambda_{0}\left(\frac{\left\langle\sigma_{1}\right\rangle}{S_{0}}\right)^{m}
$$


and the Weibull parameters $m$ and $\lambda_{0}\left(S_{0}\right)^{-m}$ are assumed identical to those identified from the quasi-static experiments.

\section{V.2.b - Size of obscured domain due to a single crack}

The cracks are assumed to propagate with a constant velocity equal to $k C$, where $k$ is a constant parameter and $C$ is the one-dimensional wave speed $(C=\sqrt{E / \rho})$. Based upon the concept of conservation of energy, an analytical solution for $k$ was proposed [Broek 1982; Kanninen and Popelar 1985]. It was demonstrated that when the crack length becomes significantly larger than the initial crack size, the cracking velocity tends to a limit close to 0.38C. However, according to Freund $[1972 ; 1990]$, cracks in brittle materials may accelerate up to the Rayleigh wave speed $C_{R}$, e.g., $C_{R}=0.59 C$ with $v=0.2$. Moreover, the parameter $k$ was investigated in several brittle materials, in particular when transparent. For example, experimental studies showed a limiting velocity about $0.5 C_{R}$ in glass, about $0.6 C_{R}$ in Plexiglas and about $0.4 C_{R}$ in Homalite-100 [Ravi-Chandar and Knauss 1982; 1984a; 1984b; 1984c; 1984d; Knauss and Ravi-Chandar 1985; 1986; Sharon et al. 1995]. Strassburger and Senf [1995] also investigated the terminal crack velocity in a silicon carbide and in glass materials and observed a crack velocity of approximately one half of $C_{R}$ in both cases. Therefore, it is reasonable to assume a crack velocity in brittle materials within the range $0.4 C_{R}$ to $0.6 C_{R}$ (or $0.23 C$ to $0.35 C$ with $v=0.2$ )

One further assumes that the zone of stress release is centred on the point of crack initiation and grows in a self-similar way with a diameter proportional to the size of the crack. Therefore the size of the zone of obscuration at a time $T$ corresponding to a single crack created at time $t$ is given by 


$$
Z_{o}[(T-t)]=S[k C(T-t)]^{n}
$$

where $S$ is a shape parameter of the obscuration volume (equal to $4 \pi / 3$ when assuming that obscuration volumes are similar to spheres in a $3 \mathrm{D}$ medium $(n=3), S=\pi$ for a disc in a $2 \mathrm{D}$ medium $(n=2)$ or $S=2$ in a $1 \mathrm{D}$ medium $(n=1))$.

\section{V.3. Heterogeneous stress field}

Let us focus on the fragmentation process in a domain $\Omega$ submitted to a heterogeneous tensile stress field satisfying the following condition

$$
\langle\sigma(\underline{x}, t)\rangle=h_{\sigma}(\underline{x}) \sigma_{\max }(t) \text { with } h_{\sigma}(\underline{x})=\frac{\left\langle\sigma\left(\underline{x}, t_{0}\right)\right\rangle}{\sigma_{\max }\left(t_{0}\right)}, \sigma_{\max }(t)=\max _{\underline{x} \in Z}\langle\sigma(\underline{x}, t)\rangle
$$

where $t_{0}$ is a given time for which the maximum principal stress is greater than zero. This would be a typical stress field encountered in a volume in equilibrium and loaded by a force $\mathrm{F}(t)$ located on a unique point (for example a quasi-static three-point flexural test, or a Brazilian test). Moreover, if the density of critical defects depends on the stress level according to Equation (20), then the elementary probability of no-inception of new cracks in the space-time area $d Z \times d t$ located at $(\underline{x}, t)$ reads

$$
P_{\notin}^{i}(\underline{x}, t)=\exp \left(-\frac{d \lambda_{t}\left(\sigma_{\max }(t)\right)}{d t}\left(h_{\sigma}(\underline{x})\right)^{m} d Z d t\right)
$$

Therefore, the probability of non-obscuration becomes

$$
P_{\text {no }}(M, T)=\exp \left(-\int_{(\underline{x}, t) \in[\text { horizon of }(M, T) \in \Omega]} \frac{d \lambda_{t}\left(\sigma_{\max }(t)\right)}{d t}\left(h_{\sigma}(\underline{x})\right)^{m} d Z d t\right)
$$


The space-time domain of integration is delimited by the cone-shaped horizon of vertex $(M$, $T)$ and the boundaries of $\Omega$. The points $(\underline{x}, t)$ concerned are

$$
(\underline{x}, t) \in[\text { horizon of }(M, T)] \Leftrightarrow\left\{\begin{array}{c}
(\underline{x}) \in \Omega \\
\text { and } \\
\underline{x} \text { as }\left\{S\left|\underline{x}-\underline{x}_{M}\right|^{n}<Z_{o}(T-t)\right\}
\end{array}\right.
$$

where $\underline{x}_{M}$ corresponds to the space coordinate of point $M$. The probability of non-obscuration is then expressed as

$$
P_{n o}(M, T)=\exp \left(-\int_{0}^{T} \frac{d \lambda_{t}\left(\sigma_{\max }(t)\right)}{d t} Z_{o}^{e f f}\left(\underline{x}_{M}, T-t\right) d t\right)
$$

where $Z_{o}^{\text {eff }}\left(\underline{x}_{M}, T-t\right)$ is the effective volume of obscuration centred on $(M, T)$ due to defects generated between $t$ and $t+d t$

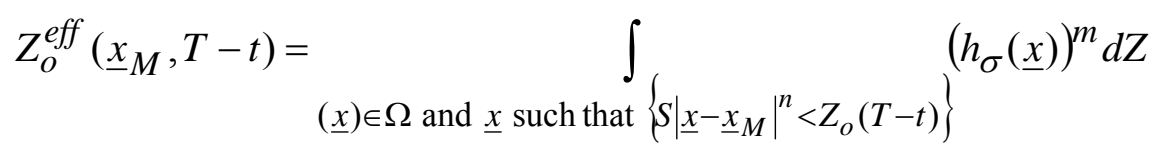

The integration bounds are, on the one hand, the boundaries of the domain $\Omega$ (Equation (25a)) and, on the other hand, the inverted cone in a space-time diagram corresponding to Equation (25b). One may note that the probability of non-obscuration simplifies by mainly using one of the integration limits.

In the particular case of a horizon mainly delimited by the whole domain $\Omega$ (Equation (25a)), the effective obscuration domain corresponds to the expression of the effective domain under quasi-static loading conditions (see Section III, Equation (3))

$$
Z_{o}^{e f f}\left(\underline{x}_{M}, T-t\right) \approx Z_{e f f}\left[\text { Davies, 1973] }=\int_{\Omega}\left(h_{\sigma}(\underline{x})\right)^{m} d Z\right.
$$


Therefore, the probability of obscuration (Equation (26)) corresponds to the failure probability expressed by Weibull (Equation (1)) and depends on the effective domain and on the density of critical defect associated with the maximum stress in $\Omega\left(\lambda_{t}\left(\sigma_{\max }(T)\right)\right)$

$$
P_{o}(M, T)=1-P_{n o}(M, T) \equiv P_{F}=1-\exp \left(-Z_{\text {eff }} \lambda_{t}\left(\sigma_{\max }(T)\right)\right)
$$

When the horizon is strictly included inside the domain $\Omega$ (horizon given by Equation (25b)), and if a uniform stress field is assumed, the obscuration probability (Equation (26)) corresponds to [Denoual and Hild, 2000]

$$
P_{o}(M, T)=1-P_{n o}(M, T)=1-\exp \left(-\int_{0}^{T} \frac{d \lambda_{t}}{d t}[\sigma(t)] Z_{o}(T-t) d t\right)
$$

where $Z_{o}(T-t)$ is the obscured domain at time $T$ due to a crack initiated at time $t$. In such cases, the obscuration probability is comparable to a damage variable $D$ [Denoual et al., 1997]. It is interesting to note that the first order approximation of Equation (30) leads to the differential equation proposed by Grady and Kipp [1980] to describe the growth law of a damage variable. Moreover, an analytical solution may be obtained by assuming a constant stress rate $(\sigma=\dot{\sigma} t)$ in addition to the density of critical defects given in Equation (20) and the shape of obscuration zone given by Equation (21)

$$
D(T) \equiv P_{o}=1-\exp \left(-\frac{m ! n !}{(m+n) !}\left(\frac{T}{t_{c}}\right)^{m+n}\right)
$$

The obscuration probability (or equivalently the damage variable $D$ ) is expressed as a function of three parameters, namely, $n$ the space dimension, $m$ the Weibull modulus, and $T / t_{c}$ the dimensionless time. The characteristic time $t_{c}$ reads 


$$
t_{c}=\underbrace{\left(\sigma_{0} \lambda_{0}^{-\frac{1}{m}}\right)^{\frac{m}{m+n}}}_{\text {Crack inception }} \underbrace{(\dot{\sigma})^{-\frac{m}{m+n}}}_{\text {Loading }} \underbrace{\left(S_{\text {propagation }}^{\frac{1}{n}} k C\right)^{-\frac{n}{m+n}}}_{\text {Crack }}
$$

For any value $m>3$ and considering $n=3$, the probability of obscuration is less than $5 \%$ at $t_{c}$ and it is greater than $95 \%$ for $2 t_{c}$. Therefore, the characteristic time represents the time during which most of the obscuration phenomenon occurs. Equation (32) shows that $t_{c}$ depends on three types of parameters. The first term corresponds to parameters related to crack initiation (i.e., the Weibull parameters); the second term highlights the influence of loading rate whereas the third term corresponds to parameters related to the crack growth (i.e., $k C$ being the propagation velocity of cracks).

Equation (32) shows the tendency and sensitivity of the characteristic time to each parameters of the problem. For example, the higher the loading rate or the crack velocity, the shorter the time to damage the material. Moreover, by assuming $m$ much larger than $n$ $(m \gg n)$, the exponents of each term of Equation (32) are close to respectively $1,-1$ and 0 . This means, for example, that the sensitivity of $t_{c}$ to the crack speed is small compared to the parameters related to crack initiation and loading rate.

A characteristic stress $\left(\sigma_{c}=\dot{\sigma} t_{c}\right)$ may be also defined as

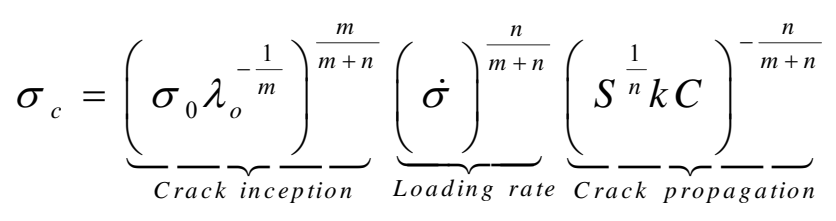

This equation again highlights how each parameter of the problem influences the ultimate level of stress. For example, the higher the strain rate, the higher the characteristic stress. Two other characteristic parameters are also defined. The characteristic density $\left(\lambda_{c}=\lambda_{t}\left(t_{c}\right)\right)$ reads 


$$
\lambda_{c}=\underbrace{\left(\sigma_{0} \lambda_{o}^{-\frac{1}{m}}\right)^{-\frac{m n}{m+n}}}_{\text {Crack inception }} \underbrace{(\dot{\sigma})^{\frac{m n}{m+n}}}_{\text {Loading rate }} \underbrace{\left(S_{\text {propagation }}^{\frac{1}{n}} k C\right)^{-\frac{m n}{m+n}}}_{\text {Crack }}
$$

Last, a characteristic zone size $\left(Z_{c}=Z_{o}\left(t_{c}\right)\right)$ is expressed as

$$
Z_{c}=\underbrace{\left(\sigma_{0} \lambda_{0}^{-\frac{1}{m}}\right)^{\frac{m n}{m+n}}}_{\text {Crack inception }} \underbrace{(\dot{\sigma})^{-\frac{m n}{m+n}}}_{\text {Loading }} \underbrace{\left(S^{\frac{1}{n}} k C\right)^{\frac{m n}{m+n}}}_{\text {Crack propagation }}
$$

Let us note that $Z_{c}$ is equal to $1 / \lambda_{c}$ in accordance with the condition $Z_{c} \lambda_{c}=1$.

In the next part, an analytical solution to Equation (24) is developed. In particular, it is shown how the probability of non-obscuration of Equations (16) and (26) is changed into Equations (30) and (31) when the loading rate increases.

\section{V.4. Non-obscuration probability of a point $M$ centred in $\Omega$}

\section{V.4.a - Influence of 5 key parameters on the fragmentation process}

The obscuration probability being known, one may wonder when does single fragmentation (i.e., a single crack) or multiple fragmentation (i.e., numerous cracks) occur knowing the loading rate, the material properties and the size of the domain $\Omega$. Figure 12 allows one to understand how each parameter namely, the stress rate, the crack velocity, the Weibull parameters and the size of $\Omega$ influence the number of cones that contribute to obscure the whole domain $\Omega$. For example, the faster the cracks propagate, the larger the opening angle of obscuration cones, thus the faster the complete obscuration of $\Omega$. Consequently, the ultimate tensile strength and the number of cracks decrease. Conversely, the higher the stress 
rate, the lower the opening angle of obscuration cones (when keeping the same scale of stress level and dilating the time scale); thus, the higher the ultimate tensile strength and the corresponding number of cracks.

\section{V.4.b - Influence of the domain size (Z) on the obscuration probability}

Figure $12 \mathrm{~b}$ allows one to understand the influence of the size of the considered domain on the nature of fragmentation (i.e., single or multiple). When the size of $\Omega$ is sufficiently small, a single crack will be created in $\Omega$ and will obscure the whole domain giving rise to a single fragmentation process. Therefore, the mean failure stress is random and weakly influenced by the loading rate.

An analytical solution of the probability of obscuration of point $M$ at time $T$ may be deduced by considering the following hypotheses. The size of the obscuration domain is given by Equation (21) and a point $M$ is located at the centre of the domain (as illustrated in Figure $12 \mathrm{~b}$, all points of the boundary of $\Omega$ are assumed to be equidistant from $M$ ). In such cases, the inverted horizon-cone will cut the boundary of $\Omega$ whenever the size $Z$ is less than a critical size $Z_{c r i t i c a l}=S(k C T)^{n}$

$$
\left\{\begin{array}{l}
Z<S(k C . T)^{n} \Rightarrow \text { Horizon of }(M, T): \text { inverted cone of top }(M, T) \text { cut by } \Omega \\
Z>S(k C . T)^{n} \Rightarrow \text { Horizon of }(M, T): \text { full inverted cone of top }(M, T)
\end{array}\right.
$$

In the first case (Equation (36a)), one may define a time $t_{Z}>0$ such that $S\left(k C\left(T-t_{Z}\right)\right)^{n}=$ $Z$ (see Figure 12b), the shape of the horizon of $(M, T)$ corresponds to the inverted cone if $t>t_{Z}$ and the size of horizon is equal to $Z$ when $t<t_{Z}$. Therefore, the non-obscuration probability given by Equation (13) is composed of two parts: 
- the first one corresponds to the product of elementary probabilities of no crack inception for $t \leq t_{Z}$

- whereas the second one corresponds to the product of elementary probabilities of no crack inception for $t>t_{Z}$

$$
P_{n o}(M, T)=\left(\prod_{\text {Horizon }\left(t>t_{Z}\right)} P_{\notin}^{i}\right) \times\left(\prod_{\text {Horizon }\left(t \leq t_{Z}\right)} P_{\notin}^{i}\right)
$$

If Equation (14) is used in the previous expression and if one assumes a stress field given by Equation (22), the probability of non-obscuration becomes

$$
P_{n o}(M, T)=\underbrace{\exp \left(-\int_{t=t_{Z}}^{T} \frac{d \lambda_{t}\left(\sigma_{\max }(t)\right)}{d t} Z_{o}^{\text {eff }}(T-t) d t\right)}_{\text {Multiple fragmentation }} \times \underbrace{\exp \left(-Z_{\text {eff }} \int_{t=0}^{t_{Z}} \frac{d \lambda_{t}\left(\sigma_{\max }(t)\right)}{d t} d t\right)}_{\text {Single fragmentation }}
$$

where $Z_{\text {eff }}$ is the size of the effective domain [Davies, 1973] (Equation (28)) and $Z_{o}^{\text {eff }}(T-t)$ the size of the effective domain of obscuration

$$
Z_{o}^{\text {eff }}(T-t)=\int_{\underline{x} \text { as }} \int_{\left\{S\left|\underline{x}-\underline{x}_{M}\right|^{n}<Z_{o}(T-t)\right\}}\left(h_{\sigma}(\underline{x})\right)^{m} d Z
$$

In the particular case of a uniform stress field, the non-obscuration probability reads

$$
P_{\text {no }}(M, T)=\underbrace{\exp \left(-\int_{t=t_{Z}}^{T} \frac{d \lambda_{t}(t)}{d t}\left[Z_{o}(T-t)\right] d t\right)}_{\text {Multiple fragmentation }} \times \underbrace{\exp \left(-Z \int_{t=0}^{t_{Z}} \frac{d \lambda_{t}(t)}{d t} d t\right)}_{\text {Single fragmentation }}
$$

$$
\text { V.4.c - Analytical solution for } P_{\text {no }} \text { considering a constant stress rate } \dot{\sigma}
$$


Equation (40) was obtained by considering a centred point $M$ in $\Omega$ and a uniform stress field. It may be simplified if one uses the density of critical defect given in Equation (20), the expression of the size of the obscured domain given by Equation (21), and if a constant stress rate is assumed. In that case, Equation (40) becomes

$$
P_{n o}(T)=\exp \left(-\int_{t_{z}}^{T} m \frac{t^{m-1}(T-t)^{n}}{t_{c}^{m+n}} d t\right) \times \exp \left(-Z \lambda_{0}\left(\frac{\dot{\sigma} t_{Z}}{\sigma_{0}}\right)^{m}\right)
$$

where $t_{c}$ is the characteristic time defined previously (Equation (32)). It is worth noting that time $t_{Z}$ is not constant but depends upon time $T$

$$
Z=S\left[k C\left(T-t_{Z}\right)\right]^{n} \Leftrightarrow t_{Z}=T-\frac{1}{k C}\left[\frac{Z}{S}\right]^{\frac{1}{n}}
$$

To use a new variable that is time independent, a constant stress $\sigma_{Z}$ is defined as

$$
\sigma_{Z}=\dot{\sigma}\left(T-t_{Z}\right)=\frac{\dot{\sigma}}{k C}\left[\frac{Z}{S}\right]^{\frac{1}{n}}
$$

Last, the non-obscuration probability becomes

$$
P_{n o}(\sigma)=\exp \left(-\frac{m ! n !}{(m+n) !}\left(\frac{\sigma_{Z}}{\sigma_{c}}\right)^{m+n} g\left(\frac{\sigma}{\sigma_{Z}}\right)\right)
$$

where $\sigma_{c}$ is the characteristic stress defined by Equation (33), and the function $g$ reads

$$
\left\{\begin{array}{l}
\forall n, g(x \leq 1)=x^{m+n} \\
n=1, g(x>1)=x^{m+n}-(x-1)^{m+n} \\
n=2, g(x>1)=x^{m+n}-(x-1)^{m+n}-(m+n)(x-1)^{m+1} \\
n=3, g(x>1)=x^{m+n}-(x-1)^{m+n}-(m+n)(x-1)^{m+2}-\frac{(m+n)(m+n-1)}{2}(x-1)^{m+1}
\end{array}\right.
$$


The non-obscuration probability depends upon four parameters, namely, $n$ the space dimension, $m$ the Weibull modulus, the ratio $\sigma_{Z} / \sigma_{c}$, and the normalized stress $\sigma / \sigma_{Z}$. The ratio $\sigma_{Z} / \sigma_{c}$ is the key parameter that controls the fragmentation regime. This parameter is expressed as a function of the ratio $Z / Z_{c}$

$$
\frac{\sigma_{Z}}{\sigma_{c}}=\left(\frac{Z}{Z_{c}}\right)^{\frac{1}{n}} \text { and } P_{n o}(\sigma)=\exp \left(-\frac{m ! n !}{(m+n) !}\left(\frac{Z}{Z_{c}}\right)^{\frac{m+n}{n}} g\left(\frac{\sigma}{\sigma_{Z}}\right)\right)
$$

\section{V.4.d - Obscuration probability as function of $Z / Z_{c}$}

Equation (46) gives the change of the obscuration probability with time $t$ or microscopic stress $(\sigma=\dot{\sigma} t)$. According to Equation (45), $g$ is a function that is monotonically increasing and the obscuration probability vanishes when $t=0$ and tends to one when $t \rightarrow+\infty$. One may $\log -\log$ plot the change of $x=\sigma / \sigma_{Z}$ as a function of $Z / Z_{c}$ for different values of the obscuration probability $P_{o}$ (namely $0.1,0.5$ and 0.9 , see Figure 13 ). During a fragmentation process, $Z / Z_{c}$ is given and $x$ is increasing from 0 to $+\infty$ (if a continuous increase of stress is assumed). Therefore, a fragmentation process corresponds to horizontal lines in Figure 13 and areas corresponding to obscuration probabilities less than 0.1 or greater than 0.9 are depicted.

Figure 13 shows that the obscuration probability is a function of $x$, which is dependent upon the ratio $Z / Z_{c}$. For large domains (i.e., $Z \gg Z_{c}$ ), the obscuration probability evolves (from 0.1 to 0.9 ) for low values of $x\left(x \ll 1\right.$ i.e. $\left.\sigma \ll \sigma_{Z}\right)$. This is the case when no intersection occurs between the horizon-cone and the domain boundary (Figure 12a). Numerous cracks are expected to obscure $\Omega$. By using $g(x)=x^{m+n}$, the probability of non- 
obscuration tends to the solution given in Equation (30). This case corresponds to multiple fragmentation not influenced by boundaries of $\Omega$

$$
\left(t_{Z} \leq 0 \Leftrightarrow x \leq 1\right) \Rightarrow P_{n o}(\sigma) \rightarrow \exp \left(-\frac{m ! n !}{(m+n) !}\left(\frac{\sigma_{Z}}{\sigma_{c}}\right)^{m+n}\left(\frac{\sigma}{\sigma_{Z}}\right)^{m+n}\right)
$$

If a small domain $\Omega$ is considered $\left(Z \ll Z_{C}\right.$ ), the probability of obscuration changes for high values of $x\left(x \gg 1\right.$ i.e. $\sigma \gg \sigma_{Z}$, see Figure 13). In such situations, $\sigma \gg \sigma_{Z}$ and the domain is obscured at time $T \approx t_{Z}$. In this case the horizon-cone intersects the domain $\Omega$ (Figure $12 \mathrm{~b}$ ). For large values of $x(x \gg 1)$, Equation (45) becomes

$$
\left(t_{Z} \rightarrow T \Leftrightarrow x \rightarrow \infty\right) \Rightarrow g(x) \rightarrow \frac{(m+n) !}{m ! n !}(x)^{m}
$$

In that case, the obscuration probability tends to the failure probability given by a Weibull model

$$
\left(t_{Z} \rightarrow T \Leftrightarrow x \rightarrow \infty\right) \Rightarrow P_{n o} \rightarrow \exp \left(-\left(\frac{\sigma_{Z}}{\sigma_{c}}\right)^{m+n}\left(\frac{\sigma}{\sigma_{Z}}\right)^{m}\right)=\exp \left(-Z \lambda_{0}\left(\frac{\sigma}{\sigma_{0}}\right)^{m}\right)
$$

As shown in Figure 12 and Equation (40), the nature of the fragmentation process is strongly related to the size $Z$ of the domain $\Omega$ to be compared with $Z_{c}$. Large volumes are more favourable for multiple fragmentation, and the obscuration probability may be compared to a damage variable. On the other hand, small domains lead to single fragmentation, and the obscuration probability is equivalent to a failure probability. 
The analytical solution for the crack density is deduced from Equation (46) and using Equations (18) and (19)

$$
\lambda_{\text {cracks }}(\sigma)=\int_{0}^{\sigma} P_{n o}(\sigma) \frac{d \lambda_{t}}{d \sigma} d \sigma=\frac{1}{Z}\left(\frac{Z}{Z_{c}}\right)^{\frac{m+n}{n}} \int_{0}^{x} P_{n o}(x)\left(m \cdot x^{m-1}\right) d x
$$

This expression is computed in cases of single and multiple fragmentation processes using Equations (47) and (49).

$$
\text { V.5.b - Crack density for a single fragmentation process }\left(Z \ll Z_{C}\right)
$$

In the first case $(x \gg 1$ and $g$ given by Equation (48)), the non-obscuration probability is described by Equation (49). The average number of cracks in $\Omega$ is given by

$$
Z \lambda_{\text {cracks }}\left(x=\frac{\sigma}{\sigma_{Z}}\right)=1-\exp \left(-x^{m}\left(\frac{Z}{Z_{c}}\right)^{\frac{m+n}{n}}\right)=1-\exp \left(-Z \lambda_{0}\left(\frac{\sigma}{\sigma_{0}}\right)^{m}\right)
$$

Therefore, according to Equation (51), the average number of cracks in $\Omega$ tends to 1 when the stress level exceeds the average failure stress $\left(\sigma_{w}\right)$

$$
Z \lambda_{\text {cracks }}(\sigma)=P_{r}(\sigma)=1-\exp \left(-\left(\Gamma\left(1+\frac{1}{m}\right) \frac{\sigma}{\sigma_{w}}\right)^{m}\right)
$$


where $\Gamma$ is the Euler function of the second kind (Equation (7))

$$
\text { V.5.c - Crack density for a multiple fragmentation process }\left(Z \gg Z_{C}\right)
$$

For multiple fragmentation (i.e., $x \ll 1$ ), the non-obscuration probability is expressed by Equation (47). The normalized crack density reads

$$
\frac{\lambda_{\text {cracks }}}{\lambda_{c}}(\sigma)=\frac{m}{m+n}\left[\frac{(m+n) !}{m ! n !}\right]^{\frac{m}{m+n}} \gamma\left(\frac{m}{m+n}, \frac{m ! n !}{(m+n) !}\left(\frac{\sigma}{\sigma_{c}}\right)^{m+n}\right)
$$

where $\gamma$ is the incomplete gamma function

$$
\gamma(\alpha, T)=\int_{0}^{T} \exp (-t) t^{\alpha-1} d t
$$

According to Equation (53), at the beginning of loading $\left(\sigma \ll \sigma_{C}\right)$, the crack density is expressed as

$$
\frac{\lambda_{\text {cracks }}}{\lambda_{c}}\left(\sigma<<\sigma_{c}\right)=\left(\frac{\sigma}{\sigma_{c}}\right)^{m}
$$

At the end of loading, the crack density saturates

$$
\frac{\lambda_{\text {cracks }}}{\lambda_{c}}\left(\sigma>>\sigma_{c}\right)=\left(\frac{(m+n) !}{m ! n !}\right)^{\frac{m}{m+n}} \Gamma\left(1+\frac{m}{m+n}\right)
$$

The time $t_{\text {cracks }}$ satisfying Equations (55) and (56) characterizes the characteristic time associated with saturation for a multiple fragmentation process. This time is scaled by the characteristic time $t_{c}$ 


$$
\frac{t_{\text {cracks }}}{t_{c}}=\left(\frac{(m+n) !}{m ! n !}\right)^{\frac{1}{m+n}}\left(\Gamma\left(1+\frac{m}{m+n}\right)\right)^{\frac{1}{m}}
$$

The ratio $t_{\text {cracks }} / t_{c}$ is plotted in Figure 14 when $n=3$. It is bounded between 1.2 and 1.62 for a Weibull modulus varying within the range 1 to 30 , a confirmation that multiple fragmentation mainly evolves during $t_{c}$ and $2 t_{c}$.

\section{V.5.d - Transition between single and multiple fragmentation regimes}

Figure 15 shows the change of the average number of cracks $\left(Z \lambda_{\text {cracks }}\right)$ in $\Omega$ when saturation is reached by using Equation (50). For small domains $\left(Z \ll Z_{C}\right)$, a single crack is expected in $\Omega$ (see Equation (51)). For domain sizes greater than $Z_{c}$, the crack density tends rapidly to the solution given in Equation (56). Therefore, one may define as transition criterion between single and multiple fragmentation, the condition for which the number of cracks in $\Omega$ given by Equation (56) equals one

$$
\frac{Z_{\text {transition }}}{Z_{c}}=\left(\frac{m ! n !}{(m+n) !}\right)^{\frac{m}{m+n}}\left[\Gamma\left(1+\frac{m}{m+n}\right)\right]^{-1}
$$

This ratio is plotted as a function of $m$ for $n=3$ in Figure 16. Considering a given stress rate (i.e., $Z_{c}$ constant), the higher the Weibull modulus, the smaller the volume size needed to have multiple fragmentation. With a high Weibull modulus, as numerous defects are activated "quasi-simultaneously," the obscuration phenomenon is prevented and, consequently, multiple fragmentation occurs more easily. 
V.6. Ultimate macroscopic strength and mean microscopic obscuration stress

\section{V.6.a - Ultimate macroscopic strength}

A first method for calculating the tensile strength is to determine the maximum value of the "macroscopic non-obscured stress." In the same way as Rabotnov [1963], a macroscopic stress $\Sigma$ is defined as the microscopic (or effective) stress $\sigma$ multiplied by $d=1-D$, where $D$ is a damage variable defined as the fraction of domain that is obscured. This simplification, which allows us to derive closed-form solutions, consists in assuming not only that the stresses are decreasing in the obscuration zones $(\dot{\sigma}<0)$, but also that the cohesion is neglected in the obscured zones. The "macroscopic non-obscured stress" $\Sigma_{n o}$ is defined as

$$
\sum_{n o}=\left(1-P_{o}\right) \sigma=\exp \left(-\frac{m ! n !}{(m+n) !}\left(\frac{\sigma_{Z}}{\sigma_{c}}\right)^{m+n} g\left(\frac{\sigma}{\sigma_{Z}}\right)\right) \sigma,
$$

The ultimate macroscopic strength is defined for any fragmentation process as the maximum "macroscopic non-obscured stress"

$$
\Sigma^{u}=\max _{t} \Sigma_{n o}(t)=\Sigma_{n o}\left(t^{u}\right)
$$

with $t^{u}$ such that

$$
\frac{d \Sigma_{n o}}{d t}\left(t^{u}\right)=0
$$


For a single fragmentation process, the non-obscuration probability is given by Equation (49).

Therefore the "macroscopic non-obscured stress" reads

$$
\Sigma_{n o}=\left(1-P_{F}\right) \sigma=\exp \left(-\left(\frac{\sigma_{Z}}{\sigma_{c}}\right)^{m+n}\left(\frac{\sigma}{\sigma_{Z}}\right)^{m}\right) \sigma,
$$

The maximum value becomes

$$
\sum_{\text {single }}^{u}=\sigma_{c}\left[\left(\frac{1}{m \cdot e}\right)^{\frac{1}{m}}\left(\frac{\sigma_{c}}{\sigma_{Z}}\right)^{\frac{n}{m}}\right]=\left(\frac{1}{m \cdot e}\right)^{\frac{1}{m}} \sigma_{0}\left(Z \lambda_{0}\right)^{-\frac{1}{m}},
$$

Thus, similarly to the quasi-static average failure stress (Equation (5)), the ultimate macroscopic strength is stress rate independent and is proportional to the size of the domain $\Omega$ raised to the power $-1 / m$. The meaning of $\Sigma_{\text {single }}^{u}$ with respect to $\sigma_{w}$ will be discussed in the sequel. The time $t_{\text {single }}^{u}$ for which the ultimate macroscopic strength is reached is given by

$$
t_{\text {single }}^{u}=t_{c}\left[\left(\frac{1}{m}\right)^{\frac{1}{m}}\left(\frac{\sigma_{c}}{\sigma_{Z}}\right)^{\frac{n}{m}}\right]=e^{\frac{1}{m}} \frac{\sum_{\text {single }}^{u}}{\dot{\sigma}},
$$

It is worth noting that for high Weibull modulus $(\mathrm{m}>>1)$, since $\Sigma_{\text {single }}^{u}$ tends to $\sigma_{w}$, the time $t_{\text {single }}^{u}$ tends to the average failure time of the Weibull model $\left(\sigma_{w} / \dot{\sigma}\right)$.

\section{V.6.c - Ultimate macroscopic strength in multiple fragmentation}

For a multiple fragmentation regime, the function $g$ is equal to $x^{m+n}$, and the non-obscuration probability is given by Equation (47). Therefore, the "macroscopic non-obscured stress" corresponds to the macroscopic stress of a damage model [Denoual et al., 1997] 


$$
\Sigma_{n o}=(1-D) \sigma
$$

The ultimate strength $\left(\Sigma_{\text {multiple }}^{u}\right)$ and the corresponding time $\left(t_{\text {multiple }}^{u}\right)$ are proportional to the characteristic stress and time with a correction coefficient that depends on the Weibull modulus only

$$
\Sigma_{\text {multiple }}^{u}=\sigma_{c}\left(\frac{1}{e} \frac{(m+n-1) !}{m ! n !}\right)^{\frac{1}{m+n}} \text { and } t_{\text {multiple }}^{u}=t_{c}\left(\frac{(m+n-1) !}{m ! n !}\right)^{\frac{1}{m+n}}
$$

The ratio $\left(t_{\text {multiple }}^{u} / t_{c}\right)$ is plotted in Figure 14. It varies between 1 and 1.3 for a Weibull modulus in the range of 1 to 30 . This shows again that multiple fragmentation mainly evolves during $t_{c}$ and $2 t_{c}$.

\section{V.6.d - Transition criterion between a single and a multiple fragmentation}

One may define a new criterion to describe the transition between single fragmentation and multiple fragmentation processes based on the ultimate macroscopic strength level computed above. If the ultimate macroscopic strength defined by Equations (63) and (66) are equal $\left(\sum_{\text {single }}^{u}=\sum_{\text {multiple }}^{u}\right)$, a transition domain size is obtained

$$
\frac{Z_{\text {transition }}}{Z_{c}}=\left(\frac{\sigma_{Z}}{\sigma_{c}}\right)_{\text {transition }}^{n}=\left[\frac{(m-1) ! n !}{(m+n-1) !}\right]^{\frac{m}{m+n}}\left[\frac{1}{m e}\right]^{\frac{n}{m+n}}
$$

This new transition in terms of $Z_{\text {transition }} / Z_{c}$ is plotted as function of the Weibull modulus $m$ for $n=3$ (Figure 16). It is very close to the first criterion (Equation (58)).

The "macroscopic non-obscured stress" $\Sigma_{n o}$ defined previously represents the fraction of microscopic stress in the material that is not obscured by the propagating cracks. 
Therefore, the maximum macroscopic stress corresponds, in a pure deterministic vision, to the maximum load that the material may carry, for any domain size or applied stress-rate. Under quasi-static loading conditions, the failure of brittle materials is sudden and the failure stress is random. Therefore, the macroscopic non-obscured stress would correspond to the average failure stress if a large number of specimens were loaded at the same time and if the average of all stress-strain curves was recorded.

Last, the macroscopic non-obscured stress gives a possible representation of the mechanical behaviour of a fibres bundle loaded under quasi-static or dynamic loading. Another definition of stress and strength may be obtained by considering each specimen separately. This second approach is detailed next.

\section{V.6.e - The mean microscopic obscuration stress}

Another way of defining the tensile strength of the material is to compute the average of the random microscopic stresses when obscuration occurs. This corresponds to a statistical treatment of the data considering different increments of obscuration probability. The mean microscopic obscuration stress is defined by

$$
\bar{\sigma}_{o}=\int_{0}^{1} \sigma\left(P_{o}\right) d P_{o}=\int_{0}^{1} \sigma\left(P_{n o}\right) d P_{n o}
$$

It is computed by considering the change of the obscuration probability with the microscopic stress $\sigma$. If one uses the analytical solution of the obscuration probability (Equation (46)), the mean microscopic obscuration stress reads 


$$
\bar{\sigma}_{o}=-\int_{0}^{\infty} \sigma \frac{d P_{n o}(\sigma)}{d \sigma} d \sigma=\sigma_{Z} \frac{m ! n !}{(m+n) !}\left(\frac{Z}{Z_{c}}\right)^{\frac{m+n}{n}} \int_{0}^{\infty} x \cdot g^{\prime}(x) \cdot P_{n o}(x) d x \text {. }
$$

The corresponding standard deviation becomes

$$
\sigma_{o}^{s d}=\sqrt{\int_{0}^{1} \sigma^{2}\left(P_{o}\right)-\left(\bar{\sigma}_{o}\right)^{2} d P_{o}} .
$$

V.6.f - Mean microscopic failure stress in single fragmentation

The non-obscuration probability is given by Equation (49). Therefore, the mean microscopic failure stress is expressed as

$$
\bar{\sigma}_{\text {single }}=\sigma_{w}=\int_{0}^{1} \sigma\left(P_{r}\right) d P_{r}=S_{0}\left(\lambda_{0} Z H_{m}\right)^{-1 / m} \Gamma\left(1+\frac{1}{m}\right),
$$

It corresponds to the classical average failure stress obtained by considering a Weibull model (Equation (5)). The standard deviation is identical to Equation (6).

\section{V.6.g - Mean microscopic damage stress in multiple fragmentation}

For multiple fragmentation, the mean microscopic damage stress is defined as

$$
\bar{\sigma}_{\text {multiple }}=\int_{0}^{1} \sigma(D) d D
$$

Considering the growth law of the damage variable for a multiple fragmentation [see Equation (31)], the mean microscopic damage stress is proportional to the characteristic stress 


$$
\bar{\sigma}_{\text {multiple }}=\sigma_{c}\left(\frac{(m+n) !}{m ! n !}\right)^{\frac{1}{m+n}} \Gamma\left(1+\frac{1}{m+n}\right),
$$

A corresponding time $t_{\text {multiple }}^{\text {obs }}$ may be defined as

$$
t_{\text {multiple }}^{\text {obs }}=\frac{\bar{\sigma}_{\text {multiple }}}{\dot{\sigma}}=t_{c}\left(\frac{(m+n) !}{m ! n !}\right)^{\frac{1}{m+n}} \Gamma\left(1+\frac{1}{m+n}\right),
$$

and represents the mean time duration for which the damage variable evolves between 0 and 1 . The ratio $\left(t_{\text {multiple }}^{\text {obs }} / t_{c}\right)$ is plotted in Figure 14 and varies between 1.2 and 1.6, and it shows again that the duration of the multiple fragmentation process is of the order of $t_{c}$.

$$
\sigma_{\text {multiple }}^{\text {sd }}=\sigma_{c}\left(\frac{(m+n) !}{m ! n !}\right)^{\frac{1}{m+n}} \sqrt{\Gamma\left(1+\frac{2}{m+n}\right)-\Gamma^{2}\left(1+\frac{1}{m+n}\right)},
$$

This standard deviation is proportional to $\bar{\sigma}_{\text {multiple }}$ with a correction coefficient given by the plot of Figure 5 in which the Weibull modulus $m$ is replaced by $m+n$. One may note that even if $\sigma_{\text {multiple }}^{\text {sd }}$ is related to a multiple fragmentation process, it does not tend to zero when $\dot{\sigma}$ increases. Thus, $\sigma_{\text {multiple }}^{\text {sd }}$ is not representative of the scatter of ultimate stress but it characterises the distribution of microscopic stress when damage evolves from 0 to 1.

\section{V.6.h - Transition criterion between single and multiple fragmentation}

It is also possible to define a criterion to describe the transition between single fragmentation and multiple fragmentation processes based on the mean microscopic obscuration stress level. A new transition size $Z_{\text {transition }}$ is obtained by assuming that the two mean microscopic obscuration stresses are equal $\left(\bar{\sigma}_{\text {single }}=\bar{\sigma}_{\text {multiple }}\right)$ 


$$
\frac{Z_{\text {transition }}}{Z_{c}}=\left(\frac{\sigma_{Z}}{\sigma_{c}}\right)_{\text {transition }}^{n}=\left[\frac{m ! n !}{(m+n) !}\right]^{\frac{m+n}{m}}\left[\frac{\Gamma(1+1 / m)}{\Gamma(1+1 /(m+n))}\right]^{m}
$$

This new transition criterion $Z_{\text {transition }} / Z_{c}$ is plotted as a function of the Weibull modulus in Figure 16 for $n=3$; it is very close to the two previous ones (Equations (58) and (68)).

V.6.i - Changes of the ultimate macroscopic strength and the mean microscopic obscuration stress with stress rate

Figures 17 and 18 show the changes of stress level as function of respectively the stress rate $\dot{\sigma}$ and the ratio $Z / Z_{c}$ (considering the parameters of a SiC-100 ceramic, see Table 1). Six curves are plotted in each graph. The first three correspond to the mean microscopic obscuration stresses given by Equations (69), (72), (74) that are respectively the general solution, the particular solution for single fragmentation, and the particular solution for a multiple fragmentation. The last three correspond to the ultimate macroscopic strengths given by Equations (60), (63), (66), respectively the general solution, the particular solution for single fragmentation, and the particular solution for multiple fragmentation. The two transition criteria corresponding to Equations (68) and (77) are also shown in the plot of Figure 18. The ultimate macroscopic strength level is below that of the mean microscopic obscuration stress for any considered volume size or stress rate.

In this part, two definitions of the tensile strength of a brittle material were proposed for any stress-rate and volume size. The "ultimate macroscopic strength" was defined as the maximum level of macroscopic stress. The "mean obscuration stress" was built as an average value of microscopic stresses when the obscuration probability evolves from 0 to 1 . Both criteria are stress-rate independent and volume size dependant at low stress-rates. At high stress-rates, in both cases, the strength increases with the stress-rate raised to the power 
$n /(m+n)$. The transition criteria derived from both definitions are almost identical, whatever the considered Weibull modulus. Next, both curves of tensile strength vs. stress-rate are compared to data obtained by Monte-Carlo simulations.

\section{V.6.j - Comparison with results obtained by Monte-Carlo simulations}

Denoual and Hild [2000] carried out Monte-Carlo simulations of a fragmentation process in a cube of SiC-100 (Table 1) of volume size equal to $1.25 \mathrm{~mm}^{3}(n=3)$. The volume was subjected to remote tension when $\dot{\sigma}$ was constant. When a crack is activated, a zone of stress relaxation is produced following Equation (21). The macroscopic stress is therefore equal to $\dot{\sigma} T$ times the fraction of non-relaxed volumes. 500 realizations were performed for each stress rate. The dots in Figure 19 correspond to the average values of the maximum macroscopic stress whereas the standard deviation is represented by error bars. For a stress rate within $[0,500 \mathrm{MPa} / \mu \mathrm{s}]$, the ultimate strength is not modified by the loading rate and is equal to the average failure stress $\left(\sigma_{w}\right)$ of a Weibull model (Equations (5) and (72)). When $\dot{\sigma}$ increases by approximately one order of magnitude, the ultimate strength follows the dynamic solution of Equation (60), i.e. the ultimate macroscopic strength for a multiple fragmentation ( $\Sigma_{\text {multiple }}^{u}$, Equation (66)). During the transition, the standard deviation of Monte-Carlo simulations significantly decreases when the stress rate increases. Thus, Denoual and Hild [2000] proposed a transition size $Z_{\text {transition }}$ assuming that the quasi-static mean failure stress and the dynamic ultimate strength are equal $\left(\bar{\sigma}_{\text {single }}=\Sigma_{\text {multiple }}^{u}\right)$

$$
\frac{Z_{\text {transition }}}{Z_{c}}=\left[\frac{e . m ! n !}{(m+n-1) !}\right]^{\frac{m}{m+n}} \Gamma\left(\frac{m+1}{m}\right)^{m}
$$


This transition criterion $Z_{\text {transition }} / Z_{c}$ is plotted as function of the Weibull modulus in Figure 16 for $n=3$; it appears slightly different than the three criteria proposed above (Equations (58), (68) and (77)) especially for high Weibull moduli.

Last, one may ask why the average values of Monte-Carlo simulations fit the curve of the mean microscopic obscuration stress at low stress rate, whereas these data follow the curve of the macroscopic ultimate strength at high stress rate. Since cracks are initiated independently from each other under quasi-static loading (single fragmentation, one crack in each domain $\Omega$ ) the tensile strength is defined as the average value of independent failure stresses and the mean microscopic obscuration stress applies $\left(\bar{\sigma}_{\text {single }}=\sigma_{w}\right)$. Conversely, under high loading rate, multiple fragmentation occurs corresponding to a high quantity of cracks that evolves simultaneously in the domain $\Omega$. This is why the ultimate macroscopic strength applies $\left(\Sigma_{\text {multiple }}^{u}\right)$.

The mean microscopic obscuration stress would apply under high stress rates for example to characterise the average microscopic stress of independent micro-domains each one obscured by a single crack. In the other-hand, the ultimate macroscopic strength would be of interest under quasi-static loading to characterise the global strength of a macro-domain made of micro-domains as in a composite material made of fibres bundles. In such case, although random events (fibres breakage) take place at a microscopic scale, the macroscopic behaviour is deterministic.

V.7. Anisotropic damage model for multiple fragmentation and first validations

To account for microcracking under dynamic loading conditions, the early models are based upon the analysis of cracked systems [Budiansky and O'Connell, 1976; Margolin, 1983] on a continuum level at which constitutive equations are written. The models developed by Taylor 
et al. [1986] and Rajendran [1994] use the previous framework. This approach usually leads to an isotropic description of damage. More heuristic models have also been proposed [Johnson and Holmquist, 1992]. Cracking is essentially anisotropic and the model needs to account for it to be realistic in terms of actual damage predictions [Denoual et al., 1996; Dragon and Halm, 1996; Espinosa et al., 1998].

According to the Monte-Carlo simulations (Figure 19), under low stress rate, the behaviour is probabilistic (random failure stresses), stress-rate-independent but domain size dependent. Under high loading rate, the behaviour of brittle materials becomes deterministic with an ultimate strength stress-rate-dependent but volume-size-independent. An anisotropic damage model was proposed by Denoual and Hild [2000] to describe the deterministic behaviour of brittle materials at high stress rate. The bases of the modelling are the following. Three damage variables are used associated to each cracking directions $\left(\mathbf{d}_{\mathrm{i}}\right)$ assumed to be orthogonal. The strain tensor $\varepsilon$ is related to the stress tensor $\Sigma$ by

$$
\boldsymbol{\varepsilon}=\mathbf{K}\left(D_{1}, D_{2}, D_{3}\right) \mathbf{\Sigma}
$$

In the principal frame, the compliance tensor $\mathbf{K}$ is defined by

$$
\mathbf{K}\left(D_{1}, D_{2}, D_{3}\right)=\frac{1}{E}\left(\begin{array}{ccc}
\frac{1}{1-D_{1}} & -v & -v \\
-v & \frac{1}{1-D_{2}} & -v \\
-v & -v & \frac{1}{1-D_{3}}
\end{array}\right)_{\left(\mathbf{d}_{1}, \mathbf{d}_{2}, \mathbf{d}_{3}\right)}
$$

where $E$ is the Young's modulus and $v$ the Poisson's ratio of the undamaged material. The growth of each damage variable $D_{\mathrm{i}}$ is based upon the defect density $\lambda_{t}$ and derived by using the obscuration probability for multiple fragmentation in a domain loaded uniformly (Equation (30)) 


$$
\frac{d^{n-1}}{d t^{n-1}}\left(\frac{1}{1-D_{i}} \frac{d D_{i}}{d t}\right)=n ! S\left(k C_{0}\right)^{n} \lambda_{t}\left[\sigma_{i}(t)\right] \text { when } \frac{d \sigma_{i}}{d t}>0 \text { and } \sigma_{i}>0
$$

where no index summation is used. For a constant stress rate $\left(\sigma_{i}(t)=\dot{\sigma}_{i} t\right)$, the damage variable follows the analytical solution of Equation (31) and the maximum value of the macroscopic stress $\Sigma_{i}=\left(1-D_{i}\right) \sigma_{i}$ corresponds to the ultimate macroscopic strength $\left(\Sigma_{\text {multiple }}^{u}\right)$ of Equation (66).

\section{V.7.a - Multiple fragmentation in R-SiC ceramic target}

This type of (local) model was used to simulate the dynamic fragmentation during edge-on impact tests on SiC ceramics [Denoual and Hild, 2000], on aluminium infiltrated ceramics [Forquin et al., 2003], on microconcrete [Forquin and Erzar, 2009], on glass [Grujicic, 2009]. It is used herein to analyze the experimental results of Figure $7 \mathrm{~b}$ by resorting to finite element analyses. The material parameters used in the simulations are given in Table 1. It should be remembered that no parameter is tuned by using the EOI experiments. The following results are therefore validations of the proposed approach. Figure 20 shows the numerical simulation of two edge-on impact tests with R-SiC tiles. The maps of crack densities are given for three different times and two different impact velocities. The dashed boxes correspond to those found experimentally (Figure $7 \mathrm{~b}$ ). When $t=3 \mu \mathrm{s}$, the crack density is greater than $10^{2.5}$ cracks $/ \mathrm{mm}^{3}$ in the rectangles. Figures $20-\mathrm{b}, \mathrm{c}$ show that a damage front gradually invades about one half to two thirds of the tile in less than $4 \mu \mathrm{s}$. It can be noted that after $t=4 \mu \mathrm{s}$, the density in the rectangles does not change significantly. It can therefore be compared with post-mortem analyses shown in Figure $7 \mathrm{~b}$.

A fragmentation analysis is carried out in the vicinity of a $1-\mathrm{mm}^{3}$ volume $13 \mathrm{~mm}$ ahead of the impact point. The crack density is evaluated in the following way. The mean 
distance $(d)$ between two neighbouring cracks is estimated. For example, six circles centred about the impact point have been drawn in the pictures shown in Figure $7 \mathrm{~b}$. It was observed that, on average, each circle is intercepted by a crack every $0.2 \mathrm{~mm}$ in the first case (impact velocity of $100 \mathrm{~m} / \mathrm{s}$ ) and every $0.1 \mathrm{~mm}$ in the second case (impact velocity of $200 \mathrm{~m} / \mathrm{s}$ ). Thus, the crack density is estimated in both cases as $(1 / d)^{3}$, which corresponds to a value of the order of $10^{2}$ and $10^{3}$ cracks $/ \mathrm{mm}^{3}$ to be compared to the predictions of Figure 20. According to numerical simulations, the final crack density in a zone located $13 \mathrm{~mm}$ from the impact point is about $10^{3}$ cracks $/ \mathrm{mm}^{3}$ (i.e. $10^{12} \mathrm{cracks} / \mathrm{m}^{3}$ ) and $10^{3.5}$ cracks $/ \mathrm{mm}^{3}$ (i.e. $10^{12.5}$ cracks $/ \mathrm{m}^{3}$ ) respectively for projectile velocities of 100 and $200 \mathrm{~m} / \mathrm{s}$.

In the present case, the benefit of a damage model in comparison with other numerical methods in which each crack is described is clearly shown since the total number of cracks in the target exceeds few millions and the computation took less than a few minutes on a conventional PC.

\section{V.7.b - Modelling of the dynamic strength of a micro-concrete}

The dynamic tensile strength of a dry micro-concrete (MB50) was experimentally investigated by means of spalling tests and computations [Erzar and Forquin, 2009]. The striker is designed to get a uniform tensile stress field within the specimen. A laser device, acting like a VISAR, is directed towards the free end of the specimen to record the particle velocity. The spall strength of MB50 concrete is deduced from a linear acoustic approximation introduced by Novikov [1966]

$$
\sigma_{\text {spall }}=\frac{1}{2} \rho C_{0} \Delta V_{p b}
$$


where $\Delta V_{p b}$, which is referred to as the pullback velocity, is the difference of velocity between the maximum value and that at rebound. Moreover, strain gauges are used to evaluate the level of strain-rate within the damaged part of the specimen. The results obtained with dried samples are shown in Figure 21. Moreover, direct tensile tests performed on identical specimens (cylinders $45.7 \mathrm{~mm}$ in diameter, $120 \mathrm{~mm}$ in length) at low strain-rate (about $10^{-5} \mathrm{~s}^{-1}$ ) showed a much lower quasi-static strength (3.9 MPa). In parallel, 20 bend tests were performed to identify the Weibull parameters for small effective volume $\left(39.9 \mathrm{~mm}^{3}\right.$ instead of $200000 \mathrm{~mm}^{3}$ for direct tensile tests; see Table 1). Predictions of the model, i.e. the average failure stress $\left(\sigma_{w}\left(Z_{\text {eff }}\right)\right)$ given by Weibull law and the ultimate macroscopic strength $\left(\sum_{\text {multiple }}^{u}(\dot{\varepsilon})\right.$, Equation (66)), are compared with the quasi-static and dynamic (experimental) results in Figure 21. Both effects, namely, the increase of strength with loading rate at high strain rate, and volume effect described by the Weibull law at low strain-rates, are well predicted.

V.8. Multi-scale modelling of any fragmentation processes

The previous model does not allow one to describe the probabilistic behaviour of brittle materials under low stress rates. To simulate in a finite element code any fragmentation process (single or multiple) with a unique model, a modified growth of the density of defect is proposed [Denoual and Hild, 2002; Hild et al., 2003]

$$
\hat{\lambda}_{t}\left[\sigma_{i}(t)\right]=\left\{\begin{array}{lc}
0 & \text { if } \sigma_{i}(t) \leq \sigma_{k} \\
\lambda_{0}\left(\frac{\sigma_{i}(t)}{\sigma_{0}}\right)^{m} & \text { otherwise }
\end{array}\right.
$$


where $\sigma_{k}$ is stress generated randomly for each finite element $k$ according to the Weibull law of Equation (1) and considering $Z_{\text {eff }}=Z_{F E}$

$$
\sigma_{k}=S_{0}\left(\lambda_{0} Z_{F E} \ln \left(\frac{1}{1-P_{k}}\right)\right)^{\frac{1}{m}}
$$

$P_{k}$ being obtained by random number varying between 0 and 1 . An example of distribution of random failure stresses is given in Figure 22 for a "very coarse mesh" used later on $\left(Z_{F E}=93.8 \mathrm{~mm}^{3}\right)$.

For a constant applied stress rate, an analytical solution of Equations (81) and (83) was proposed [Forquin, 2003; Hild et al., 2003]

$$
\begin{aligned}
& D(t)=1-\exp \left\{-\left(\frac{t_{k}}{t_{c}}\right)^{m+n} \frac{m ! n !}{(m+n) !} h(\tau, m, n)\right\} \text { with } t_{k}=\frac{\sigma_{k}}{\dot{\sigma}}, \tau=\frac{t-t_{k}}{t_{k}} \text { and } \\
& h(\tau, m, n)=(1+\tau)^{m+n}-\left(1+(m+n) \tau+\frac{(m+n)(m+n-1)}{2} \tau^{2}\right)
\end{aligned}
$$

The analytical solution of Equation (85) is compared with the previous Monte-Carlo simulations in Figure 23 considering three values of stress $\sigma_{k}\left(\sigma_{w}, \sigma_{w}-\sigma_{s d}\right.$ and $\left.\sigma_{w}+\sigma_{s d}\right)$. The multi-scale model of Equations (81) and (83) allows one to obtain the probabilistic behaviour of Weibull at low stress rates as well as the deterministic ultimate macroscopic strength (Equation (66)) at high stress rates. Moreover, the reduction of scatter of failure stresses when the stress rate is increasing describes quite well what is predicted by Monte-Carlo simulations.

\section{V.8.a - Multi-scale modelling of the fragmentation in SiC-100 ceramic target}


The multi-scale model is used to analyze an EOI test on a SiC-100 ceramic [Denoual and Hild, 2002]. Strain measurements are performed over a field of $32 \times 32 \mathrm{~mm}^{2}$ during impact. Details on the moiré photography set-up are reported in [Bertin-Mourot et al., 1997]. The advantage of the moiré measurement is that quantitative rather than qualitative analyses can be performed between experiments and simulations. Figure 24-a shows the fringe pattern approximately $2 \mu$ s after impact. The comparison of numerical and experimental strains is given in Figure 24-b. The strain diagram is plotted for a point $\mathrm{M}$ at a distance of $13 \mathrm{~mm}$ from the surface hit by the projectile (circular mark in Figure 24-a). It can be noted that the radial strain level reaches an important value (of the order of $0.8 \%$ ) before any significant change of the hoop strain. This is consistent with a cylindrical stress wave in which the tensile strain is induced by the radial motion of the material.

The multi-scale model requires probabilistic numerical simulations instead of the deterministic simulations proposed with a classical (i.e., local) description. That is, numerous simulations have to be carried out when the average behaviour is analyzed. Five hundred realizations of the simulation are performed with the multi-scale model (a CPU time of 4 minutes per realization is needed on a conventional PC). The average and standard deviation of the hoop and radial strains are plotted in Figure 24-b. The multi-scale model yields good predictions of the strain levels. All the experimental measurements fall in the grey shaded zone, i.e., the experiment may be compared to one realization of the 500 numerical simulations. The use of an anisotropic damage model is necessary if one wants to accurately predict the strain levels. An elastic computation underestimates both radial and hoop strains. An isotropic damage model would have given even lower strain levels [Denoual et al., 1996].

This type of model was also used to analyze the dynamic fragmentation in compression tests on SiC ceramics [Forquin et al., 2003b], in EOI tests on glass [Brajer et al., 
2003; 2009], and on limestone rocks [Grange et al., 2008]. Next, it is used to simulate dynamic fragmentation that occurs during EOI tests performed on Ductal ${ }^{\circledR}$ concrete.

\section{V.8.b - Multi-scale modelling of the fragmentation in Ductal ${ }^{\circledR}$ concrete target}

As underlined above, the transition between single and multiple fragmentation depends on the stress rate for a given domain size Z. Multiple fragmentation is obtained at high stress rates whereas single fragmentation is observed at low stress rates. However, the transition criterion depends on $Z$ as well. Thus, for a given stress rate, multiple fragmentation will occur in sufficiently large domains (i.e. $Z>>Z_{\text {transition }}(\dot{\sigma})$ ) whereas single fragmentation is expected in small domains (i.e. $Z<<Z_{\text {transition }}(\dot{\sigma})$ ). Several numerical simulations of edge-on impact configurations (Ductal ${ }^{\circledR}$ concrete targets) were performed with different sizes of finite elements to observe how the transition between single and multiple fragmentation occurs in the computation. First, numerical simulations were performed with a plasticity-like model without damage to characterise the tensile loading rate as a function of the distance from impact point. The plasticity model referred to as KST [Krieg, 1978; Swenson and Taylor, 1983] model gives a description of geomaterials behaviour under low and high confinements. The equivalent (von Mises) stress is related to the pressure $P$ by a pressure-dependent yield stress $\sigma_{y}(P)$

$$
\sigma_{e q}=\sigma_{y}(P)=\left\{\begin{array}{lll}
\max \left(\sigma_{e q}^{\min }, \sqrt{a_{0}+a_{1} P+a_{2} P^{2}}\right) & \text { when } \sqrt{a_{0}+a_{1} P+a_{2} P^{2}}<\sigma_{e q}^{\max } \\
\min \left(\sigma_{e q}^{\max }, \sqrt{a_{0}+a_{1} P+a_{2} P^{2}}\right) & \text { when } \sqrt{a_{0}+a_{1} P+a_{2} P^{2}}>\sigma_{e q}^{\min }
\end{array}\right.
$$

where $\sigma_{e q}^{\min }$ is the minimum yield stress assumed to be equal to the ultimate strength under uniaxial compression. Simple compression tests performed with hourglass samples of 
$\operatorname{Ductal}^{\circledR}$ concrete without fibres showed a mean ultimate strength of about $222 \mathrm{MPa}$ [Forquin, 2003]. Triaxial compression tests performed on the same material under hydrostatic pressures as high as $600 \mathrm{MPa}$ [Buzaud, 2003] allowed us to tune the coefficients $a_{0}, a_{1}, a_{2}$ and the maximum equivalent stress $\sigma_{e q}^{\max }$. All these coefficients are reported in Table 2. Similar tests performed by Buzaud [2003] also provide points of the compaction curve (i.e., change of the volumetric strain with pressure) that is described in KST model by a piece-wise linear relationship $\left(\varepsilon_{v}^{(i)}, P^{(i)}\right)$

$$
P= \begin{cases}-K_{i} \varepsilon_{v} & \text { when } \varepsilon_{v} \geq \varepsilon_{v}^{(1)} \\ P^{(i-1)} \frac{\varepsilon_{v}-\varepsilon_{v}^{(i)}}{\varepsilon_{v}^{(i-1)}-\varepsilon_{v}^{(i)}}+P^{(i)} \frac{\varepsilon_{v}-\varepsilon_{v}^{(i-1)}}{\varepsilon_{v}^{(i)}-\varepsilon_{v}^{(i-1)}} & \text { when } \varepsilon_{v}^{(i-1)} \geq \varepsilon_{v} \geq \varepsilon_{v}^{(i)} \\ -K_{f} \varepsilon_{v} & \text { when } \varepsilon_{v} \leq \varepsilon_{v}^{(n)}\end{cases}
$$

where $K_{i}$ and $K_{f}$ denote the initial and final bulk moduli, and (n) the last point used to define the overall volumetric behaviour ( $n=3$ in Table 2). Edge-on impact tests of Figure 9 were simulated with the commercial explicit code Abaqus [Hibbitt et al., 2001]. An aluminium alloy projectile (diameter: $20 \mathrm{~mm}$, length: $50 \mathrm{~mm}$ ) impacts a 10-mm thick concrete target with a velocity of $88 \mathrm{~m} / \mathrm{s}$. In the numerical simulations, the dynamic confinement system is composed of a steel half-cylinder (diameter: $24 \mathrm{~mm}$ ) put in contact against the concrete tile (Figure 22). Few microseconds after impact, a high-pressure field develops within the confined area in the range of $150 \mathrm{MPa}-250 \mathrm{MPa}$, which justifies the use of the KST model. In the wake of the compressive wave, tensile hoop stresses develop within the target, a consequence of the radial motion due to the compressive wave. The stress-rate level is plotted in Figure 25 (left) as function of the distance from the impact point. It is in the range of $24 \mathrm{MPa} / \mu \mathrm{s}$ to $2.4 \mathrm{MPa} / \mu \mathrm{s}$ at a distance of respectively $20 \mathrm{~mm}$ and $70 \mathrm{~mm}$ from the impacted edge of the target. To know whether single or multiple fragmentation should be expected, the transition sizes $Z_{\text {transition }}(\dot{\sigma})$ of Equations (78) and (58) (criteria $\bar{\sigma}_{\text {single }}=\Sigma_{\text {multiple }}^{u}$ 
and $\left.Z \lambda_{\text {cracks }}=1\right)$ are plotted versus the distance from the impact point in Figure 25-right considering the stress rate level of Figure 25-left. Close to the impact point $(20 \mathrm{~mm})$, as the stress rate is high $(24 \mathrm{MPa} / \mu \mathrm{s})$, the transition occurs for a small volume (about $2.7 \mathrm{~mm}^{3}$ with criterion $\bar{\sigma}_{\text {single }}=\Sigma_{\text {multiple }}^{u}$ and $0.28 \mathrm{~mm}^{3}$ with criterion $Z \lambda_{\text {cracks }}=1$ ). On the other hand, far away from impact point $(>70 \mathrm{~mm})$, the stress rate is ten times lower and a larger volume $\left(Z>600 \mathrm{~mm}^{3}\right.$ with criterion $\bar{\sigma}_{\text {single }}=\sum_{\text {multiple }}^{u}$ and $Z>61 \mathrm{~mm}^{3}$ with criterion $\left.Z \lambda_{\text {cracks }}=1\right)$ is needed to have multiple fragmentation. Next, the result of numerical simulations performed with the local and multiscale fragmentation models are shown with four mesh sizes to observe whether the radius of transition between single and multiple fragmentation is correctly predicted by one of the two criteria shown in Figure 25-right.

The KST model was coupled to the anisotropic damage model presented above to simulate fragmentation processes by taking account the behaviour of confined geomaterials under high pressure levels. It is worth noting that other coupling strategies were proposed (see, e.g., [Gailly and Espinosa, 2002]). The present model is implemented as a VUMAT routine made of two parts. First, the microscopic stress tensor $\sigma$ is computed from volumetric and deviatoric strain components taking into account the compaction law (Equation (87)) and the pressure-dependent yield stress (Equation (86)) of the KST model. Second, the three damage variables associated to each principal microscopic stress is computed according to the growth law (81). Last, the macroscopic stress tensor is computed from Equations (79) and (80)

$$
\boldsymbol{\Sigma}=\mathbf{K}^{-1}\left(D_{1}, D_{2}, D_{3}\right) \mathbf{K}(0,0,0) \boldsymbol{\sigma}
$$

The edge-on impact tests of Figure 9 (aluminium projectile impacting at $88 \mathrm{~m} / \mathrm{s}$ a Ductal ${ }^{\circledR}$ concrete target) is now simulated with the fragmentation model coupled to the KST model. Figure 26 shows the fields of damage $\left(D_{1}\right)$ and crack density $\left(\lambda_{\text {cracks }}^{(1)}, \log\right.$-scale $)$ associated 
with the major principal stress at times $\mathrm{t}=20 \mu$ sand $35 \mu$ s and considering different finite element sizes $\left(Z_{F E}=93.8 \mathrm{~mm}^{3}, 23.4 \mathrm{~mm}^{3}, 5.86 \mathrm{~mm}^{3}, 1.67 \mathrm{~mm}^{3}\right)$ labelled respectively "very coarse mesh," "coarse mesh," "fine mesh" and "very fine mesh".

First, the so-called "local model" or "multiple fragmentation model" is used with the fine mesh. Each damage variable is computed from Equation (81) considering the defect density given in Equations (1) and (20). In that case, the influence of boundaries of each finite element is not considered (see Figure 12). Thus, according to Figure 19, the ultimate strength is underestimated each time $Z_{F E}<Z_{\text {transition, }}$, i.e. each time the number of cracks $\left(Z_{F E}\right.$ $\lambda_{\text {cracks }}^{(1)}$ ) in each finite element predicted by the modelling is less than one or each time $\lambda_{\text {cracks }}^{(1)}<1 / Z_{F E}$ (see Figure 26a-right considering that for $Z_{F E}=5.86 \mathrm{~mm}^{3}$, $\left.1 / Z_{F E}=10^{8.23} \mathrm{~m}^{-3}\right)$. This is why the crack density predicted at the scale of the finite element is unrealistic (since a fraction of one crack does not make sense) even if the crack density field may be deemed correct at the scale of the whole structure. In other words, Figure 26a gives the purely continuum vision of the fragmentation process in the target even when the fragmentation process is discrete at the scale of each finite element.

The multi-scale model was used for the numerical simulations of Figures 26b, $c, d$ and e. The damage growth law (81) combined to that of the crack density (83) gives a deterministic ultimate strength at high stress rates and a random failure stress at low stress rates (Figure 23). On each picture of Figures 26b, c, $d$ and e, two zones are observed. In the first part of the target (area inside the mid-circles centred on the impact point), all elements are damaged and a continuous crack density field is observed. The level of crack density appears to be always greater than $1 / Z_{F E}\left(1 / Z_{F E}=10^{7.02}, 10^{7.63}, 10^{8.23}, 10^{8.77} \mathrm{~m}^{3}\right.$ respectively for the very coarse, coarse, fine and very fine meshes) i.e., multiple fragmentation is observed in each finite element included in this area. Moreover, the level of crack density in this area is similar to that of Figure 26a (local model). Outside this area, the damage field is discrete and 
is composed of corridors that develop following radial lines that emanate from the impact point. In this area, the "strongest elements" (i.e. those characterized by a high random failure stress $\sigma_{k}$ (Equation (84))) did not break and a probabilistic behaviour is observed. The size of the area that delimits the continuous field of damage $\left(D_{1}=1\right)$ decreases with decreasing element sizes. For example, this area spreads over a radius of $80 \mathrm{~mm}, 58 \mathrm{~mm}, 43 \mathrm{~mm}$ and less than $30 \mathrm{~mm}$ respectively for the very coarse, coarse, fine and very fine meshes. These radii correspond to those predicted by the second transition criterion of Figure 25-right $\left(Z \lambda_{\text {cracks }}{ }^{(1)}=1\right)$. Therefore, this criterion is able to predict the transition between a discrete and a continuous damage field and to predict the minimum finite element size for which the local model may be used.

The influence of the mesh size on the crack density is shown in Figure 27. A $93.8-\mathrm{mm}^{3}$ volume located $60 \mathrm{~mm}$ ahead from the impact point is considered in each numerical simulation. This volume corresponds to a single element for the very coarse mesh, four elements for the coarse mesh, 16 and 64 elements of the fine and very fine meshes, respectively. In each case, the crack density of one element belonging to this volume is plotted as a function of the microscopic stress. With the local model, the change of crack density corresponds to the analytical solution given by Equation (53). In the other cases (multiscale model) the crack density is equal to zero until the random failure stress of the element is reached (Equation (83)). Later on, the response of the four computations differ, namely, for the very coarse and coarse meshes the crack density tends rapidly to the same level as with the local model (see white rectangles of Figure 26a, 26b and 26c). In agreement with the transition criterion (58), see Figure 25b, a single fragmentation process develops at the scale of the fine and very fine meshes at the considered location (Figure 26d and 26e). In both cases, the final crack density of damaged elements may reach higher values than that 
obtained with the local model (Figure 27). However, a small amount (fine mesh) or a large number (very fine mesh) of elements remain undamaged (Figure 26d and 26e).

Last, the mean crack density averaged over the considered volume (16 and 64 elements respectively for the fine and very fine meshes) tends to a similar level as in the other cases (Figure 27). In other words, the smaller the mesh size, the higher the mean level of random failure stresses, the lower the fraction of damaged elements. For instance, in the case of the very fine mesh, the number of damaged elements in the considered volume $Z=93.8 \mathrm{~mm}^{3}$ is equal to 23 out of 64 , and this is quite close to the final number of cracks predicted by the local model for the same volume, namely, $Z \lambda_{\text {cracks }}=35$. These results show that, by construction, the local crack details differ from one mesh to the next. However, the general features remain essentially the same.

\section{V.9. Comparison of the fragmentation properties of six brittle materials}

As shown in Part IV, two configurations of edge-on impact test were developed to characterize fragmentation properties. On the one hand, an open configuration allows one to visualize in real time the change of cracking by means of a high speed camera (Figures 7 and 10). On the other hand, a sarcophagus configuration is used to analyze the damage pattern of targets (post-mortem observations, Figures 7, 8, 9 and 10). Both configurations were used for example with SiC ceramics [Denoual and Hild, 2000; Forquin et al., 2003], with Ductal ${ }^{\circledR}$ concrete [Forquin and Hild, 2008], with limestone rocks [Grange et al., 2008] and with sodalime glass [Brajer et al., 2003]. With both configurations, the cracks are observed on the lateral surface of the target and are due to tensile stresses oriented orthogonally to the normal of the surface. Thus, the analytical solution of the obscuration probability in the neighbourhood of an outer surface is developed next. 
V.9.a - Probability of non obscuration in the neighbourhood of an outer surface considering volume and surface defects

To derive an analytical solution, let us consider a point $M$ located at a distance $x$ from the outer surface $\partial \Omega$ of a $3 \mathrm{D}$ domain $\Omega$ loaded by a uniform microscopic stress field $\sigma$ (Figure 28-right). At the beginning (time $t_{1}$ ), the horizon (assumed spherical in Figure 28) does not intersect the outer surface and the point $\mathrm{M}$ at time $t_{1}$ may only be obscured by volume defects in $\Omega$. Next (times $t_{2}$ and $t_{3}$ ), the horizon of $M$ is composed of a part of spherical horizonvolumes and of a part of the outer surface (circular shape). Therefore, point $M$ at times $t_{2}$ or $t_{3}$ may be obscured by volume defects as well as surface defects and both population of defects have to be taken into account to express the condition of non-obscuration.

Considering $\lambda_{t}^{V}$ and $\lambda_{t}^{S}$ the density of critical defects respectively in the bulk of the domain $\Omega$ and on the surface of the domain $\partial \Omega$, the non-obscuration probability is expressed as

$$
P_{n o}(M, T)=\exp \left(-\int_{(\underline{x}, t) \in[\text { horizon of }(M, T) \in \Omega]} \frac{\partial \lambda_{t}^{V}(\underline{x}, t)}{\partial t} d V d t-\underset{(\underline{x}, t) \in[\text { horizon of }(M, T) \in \partial \Omega]}{\int} \frac{\partial \lambda_{t}^{S}(\underline{x}, t)}{\partial t} d S d t\right)
$$

\section{V.9.b - Non obscuration probability considering surface defects only}

For soda-lime glass, one may consider surface defects only [Brajer et al., 2003]. Let us consider $S_{o}(T-t)$ the area of $\partial \Omega$ in which surface defects initiated at time $t$ might obscure the point $M$ at time T. As long as the radius $r$ of the spherical horizon-volume is less than $x$ (the distance between $\mathrm{M}$ and the outer surface $\partial \Omega$ ) the area $S_{o}(T-t)$ is zero (Figure 28). When the obscuration volume intersects the outer surface, the area $S_{o}(T-t)$ is a disc of radius $\sqrt{r^{2}-x^{2}}$ 


$$
\left\{\begin{array}{l}
r \leq x \Rightarrow S_{o}^{(1)}(T-t)=0 \\
r>x \Rightarrow S_{o}^{(2)}(T-t)=\pi\left[r^{2}-x^{2}\right]
\end{array} \text { with } r=k C(T-t)\right.
$$

Thus, the non-obscuration probability of $M$ at time $T$ reads

$$
\left\{\begin{array}{l}
T>\frac{x}{k C} \Rightarrow P_{n o}(M, T)=\exp \left(-\int_{0}^{T-\frac{x}{k C}} \frac{d \lambda_{t}^{S}}{d t}[\sigma(t)] S_{o}^{(2)}(T-t) d t\right. \\
T \leq \frac{x}{k C} \Rightarrow P_{n o}(M, T)=1
\end{array}\right.
$$

Considering a point $M$ on the surface $(x=0)$ and assuming a constant stress rate $\dot{\sigma}$, the non obscuration probability reads

$$
P_{o}(M \in \partial \Omega, T)=1-\exp \left(-\frac{2 m !}{(m+2) !}\left(\frac{T}{t_{c}^{S}}\right)^{m+2}\right)
$$

where $t_{c}^{S}$ is the characteristic time (see Equation (32)) expressed as a function of the Weibull parameters of surface defects $\left(m, \lambda_{0}^{S}\left(\sigma_{0}^{S}\right)^{-m}\right)$. Thus, considering a solid in which only surface defects are activated, the obscuration probability of a point $M$ located on its surface corresponds to the standard expression of the obscuration probability for a $2 \mathrm{D}$ domain (Equation (31) with $n=2$ ).

\section{V.9.c - Non obscuration probability considering volume defects only}

For the SiC ceramics mentioned above, crinoidal limestone and Ductal ${ }^{\circledR}$, volume defects have to be taken into account (Part III). The size of the obscuration volume $V_{o}(T-t)$ in which volume defects initiated at time $t$ might obscure the point $M$ at time $T$ is expressed as 


$$
\left\{\begin{array}{l}
r \leq x \Rightarrow V_{o}^{(1)}(T-t)=\frac{4 \pi}{3} r^{3} \\
r>x \Rightarrow V_{o}^{(2)}(T-t)=\frac{4 \pi}{3} r^{3}\left[1-\frac{3}{4}\left(\frac{r-x}{r}\right)^{2}+\frac{1}{4}\left(\frac{r-x}{r}\right)^{3}\right] \text { with } r=k C(T-t)
\end{array}\right.
$$

where $r$ is the radius of spheres centred on $M$ (Figure 28). Thus, the non-obscuration probability of $M$ at time $T$ reads

$$
\left\{\begin{array}{l}
T>\frac{x}{k C} \Rightarrow P_{n o}(M, T)=\exp \left(-\int_{0}^{T-\frac{x}{k C}} \frac{d \lambda_{t}^{V}}{d t}[\sigma(t)] V_{o}^{(2)}(T-t) d t-\int_{T-\frac{x}{k C}}^{T} \frac{d \lambda_{t}^{V}}{d t}[\sigma(t)] V_{o}^{(1)}(T-t) d t\right) \\
T \leq \frac{x}{k C} \Rightarrow P_{n o}(M, T)=\exp \left(-\int_{0}^{T} \frac{d \lambda_{t}^{V}}{d t}[\sigma(t)] V_{o}^{(1)}(T-t) d t\right)
\end{array}\right.
$$

In the particular case of a point $M$ on the surface $(x=0)$ and assuming a constant stress rate $\dot{\sigma}$, the non obscuration probability becomes

$$
P_{o}(M \in \partial \Omega, T)=1-\exp \left(-\frac{6 m !}{(m+3) !}\left(\frac{T}{t_{c}^{V}}\right)^{m+3}\right)
$$

where $t_{c}^{V}$ is the characteristic time expressed as a function of the Weibull parameters associated with volume defects $\left(m, \lambda_{0}^{V}\left(\sigma_{0}^{V}\right)^{-m}\right)$, and considering a shape parameter divided by $2(S / 2$ instead of $S$ in Equation (32)). Thus, in the case of volume defects only, the obscuration probability of a point $M$ located on the surface of a solid is almost unchanged in comparison with that of a point located in the bulk of this medium. 

the outer surface of the domain $\partial \Omega$

The analytical solutions for the non-obscuration probabilities (Equations (92) and (95)) are used to predict the characteristic time of cracking saturation $\left(t_{\text {cracks }}\right.$, Equation (57)), the ultimate strength (i.e. the maximum macroscopic stress $\Sigma_{\text {multiple }}^{u}$, Equation (66)), the transition

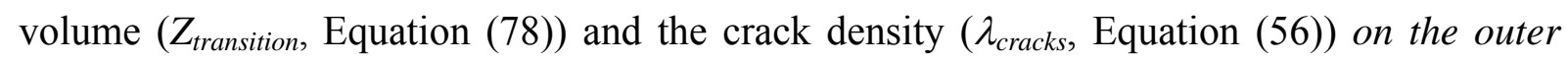
surface of the six reference materials for a stress rate in the range of 1 to $1000 \mathrm{MPa} / \mu \mathrm{s}$ (Figures 29a, b, c, d). It is worth remembering that the range of stress-rate usually differs in impact problems that involve ceramics, glass or geomaterials. For instance, in the edge-on impact tests performed on rocks and concretes, the typical range of stress-rate is one $\mathrm{MPa} / \mu \mathrm{s}$ to a few tens of $\mathrm{MPa} / \mu$ s. Conversely, typical stress-rates of about a few hundreds to a few thousands of $\mathrm{MPa} / \mu$ s are reached with $\mathrm{SiC}$ ceramics and glass.

First, one may note that the characteristic cracking time $t_{\text {cracks }}$ and the ultimate strength $\Sigma_{\text {multiple }}^{u}$ of the two ceramic materials and of glass (on the surface) are quite similar. In the same way, the levels of $t_{\text {cracks }}$ and $\Sigma_{\text {multiple }}^{u}$ for Ductal ${ }^{\circledR}$ and MB50 concretes, and limestone are close. This is likely the consequence of the difference of quasi-static strength between ceramics and glass on the one hand (few hundreds of MPa considering $Z=1 \mathrm{~mm}^{3}$ and $1 \mathrm{~mm}^{2}$ respectively) and that of concrete and rocks (few tens of MPa for the same volume size $\left.\left(1 \mathrm{~mm}^{3}\right)\right)$. As already shown by Equations (32) and (33), the parameters related to crack initiations (i.e., the Weibull parameters) play a major role on the characteristic stress and time associated with fragmentation. Moreover, one may note that the relative increase of strength (Figure 29b) is higher with glass, SiC-100, MB50 concrete and Ductal ${ }^{\circledR}$ than with limestone and R-SiC ceramics, a consequence of the lower Weibull moduli of the three first materials. 
Comparison of Figures 29c and d gives another illustration of the correspondence between the volume of transition (Equation (78)) and the final crack density (Equation (56)), namely, the higher the crack density, the lower the transition volume between single and multiple fragmentations. For a given stress rate, the crack density appears to be higher in geomaterials (limestone, MB50 and Ductal ${ }^{\circledR}$ ) than in ceramic materials and glass. This result is not surprising when considering the characteristic crack density $\lambda_{c}(34)$ that shows that the higher the quasi-static strength, the lower the crack density. Again, this conclusion may be inverted comparing edge-on impact tests mentioned above since loading rates completely differ in ceramic targets in comparison with concrete or limestone targets. Moreover, $\lambda_{c}$ is seen as proportional to the stress rate raised to the power $m n /(m+n)$. This explains the lower increase of crack density observed for glass $(n=2)$ than for the other five brittle materials $(n=3)$, see Figure 29d.

To conclude, the fragmentation properties of geomaterials on the one hand (rocks and concrete), and of glass and ceramics on the other hand, appear quite distinct. This comparison illustrates the major influence played by parameters related to crack initiation in comparison with those related to crack propagation on the fragmentation process in brittle materials.

\section{Summary}

Dynamic fragmentation made of numerous oriented cracks is one of the major damage mechanisms observed in brittle materials such as ceramics, concrete, rocks or glass when submitted to extreme loadings such as blast or impact. Cracks initiate from volume or surface defects such as sintering flaws, porosities, inclusions, scratches and propagate in the considered domain generating a relaxation wave in their vicinity. Thus, the fragmentation process is a competition between new cracks initiated as the stress level increases and obscuration of critical defects as cracks propagate in the domain. Based on two concepts, 
namely, the "local weakest link hypothesis" and the "elementary probability of no-inception of new cracks in each elementary space-time zones belonging to the horizon of a considered point $\mathrm{M}$ at time T," several points were discussed.

First, a general formulation of the non-obscuration probability is proposed for any form of the critical defect densities (continuous or discontinuous), shape of obscuration zones and space dimension. The number of cracks and the crack density were then derived. Assuming a heterogeneous but proportional tensile stress fields, an effective obscuration domain is proposed. It recovers the expression given by Davies [1973] under quasi-static loading conditions.

Moreover, the influence of the domain size and stress-rate on the nature of fragmentation (single or multiple) is explored by means of the non-obscuration probability when considering a point $M$ located in the centre of an examination domain. The obscuration probability corresponds to the failure probability given by Weibull [1951] under low stress rates, and to the damage law developed by Denoual and Hild [2000] to model multiple fragmentation at high stress rates. From this expression, an analytical solution is obtained assuming a constant stress-rate. It is used to express the crack density for any stress-rate. A single crack is obtained at low stress rates (or considering a small domain size). The crack density proposed by Denoual and Hild [2000] is obtained for high stress rates. Thus, this analytical solution shows how single fragmentation turns into multiple fragmentation with the increase of domain size or stress rate. New transition criteria are also proposed.

Two ways are proposed to define tensile strengths of brittle materials. First, the concept of "macroscopic non-obscured stress" is defined as the microscopic stress level considering only the non-obscured part of the domain. Under high loading rates, as the obscuration probability tends to a damage variable, the maximum "macroscopic non-obscured stress" corresponds to the deterministic ultimate strength proposed by Denoual and Hild 
[2000] of a domain that experiences multiple fragmentation. On the other hand, the concept of "microscopic obscuration stress" is built as an average value of the microscopic stress as the obscuration probability varies from 0 to 1 . Under quasi-static loadings, as the obscuration probability tends to the failure probability, the "microscopic obscuration stress" corresponds to the mean failure stress of a Weibull model. For any stress concept, the strength of brittle materials is seen as stress-rate independent but domain-size dependent for low stress rates and stress-rate dependent but domain-size independent at high stress rates. The first concept of strength characterises the maximum stress level in a domain with numerous cracks (as a brittle material under dynamic loading or a fibres bundle under quasi-static loading) whereas the second one is the average stress level considering a superposition of states with single cracking. When compared with Monte-Carlo simulations [Denoual and Hild, 2000] of the fragmentation process of a cube containing point-defects, the ultimate macroscopic strength regime applies at high loading rates whereas the mean microscopic obscuration stress applies at low loading rates. Moreover, from these two concepts of strength, two transition criteria between single and multiple fragmentations were proposed and compared with the previous one. The three criteria are very similar for any value of the Weibull modulus.

Next, a series of validations is proposed. The local model allows for the prediction of the crack density and the damage pattern in ceramic targets as well as the enhancement of strength of a micro-concrete. Moreover, to simulate the fragmentation process in a finite element code for any stress rate, a multiscale model is constructed by generating failure stresses randomly selected for each finite element. This multiscale model allows one to reproduce, at the scale of finite elements, the scatter of failure stresses at low stress rates and the deterministic strength of brittle materials at high stress rates. An anisotropic damage model is built considering one damage variable for each principal stress. It is coupled to the Krieg, Swenson and Taylor (KST) model and used to simulate the fragmentation process 
during edge-on impact tests performed with an ultra-high strength concrete. The numerical simulations performed with four sizes of mesh show that the larger the mesh size, the larger the area of continuous damage field in which a multiple fragmentation occurs at the scale of the volume of finite elements. Conversely, for small or very small elements, a large zone of discontinuous damage field develops. In each damaged element single fragmentation occurs even if the fragmentation remains multiple at the scale of the whole target. Thus, at the scale of the whole target, the nature of fragmentation (i.e. multiple) is unchanged. A main advantage of this type of modelling in comparison with other numerical methods in which each crack is described is that it allows for the description of intense damage made of a large number of micro-cracks (close to the impact point for instance) and a random fragmentation process farther into the target with computation times that do not exceed few minutes on a conventional PC.

An analytical solution for the obscuration probability is proposed for a point located in the neighbourhood of the domain boundary (as for edge-on impact tests). The main fragmentation properties (characteristic cracking time, ultimate strength, crack density and transition volume between single and multiple fragmentation) of the five reference materials presented herein are compared. The comparison underlines the major influence of parameters related to crack initiation on the fragmentation properties.

The main concept developed herein is the obscuration of zones around propagating cracks inhibiting the initiation of new cracks as the dynamic fragmentation process builds up in brittle materials. It leads to a space-time domain, i.e., the horizon, in which no defect should lie to initiate a new crack. In that sense, it is a non-local process in space and time. The same concept was recently used to describe spallation of ductile materials [Trumel et al., 2009]. There are other areas in which the obscuration concept can be applied to predict the formation of crack networks. The main difference is related to the propagation law describing 
the obscuration zone. For instance, when analyzing $\mathrm{CO}_{2}$ sequestration in deep reservoirs, crack networks may appear if the pressure becomes too high [Guy et al., 2008]. Thermal fatigue usually induces multiple surface cracks (striping), for instance in pipes [Seyedi et al., 2006]. It can be described as the competition between microcrack initiations and mesocrack propagations [Malésys et al., 2006; 2009]. In fibre-reinforced composites, multiple cracking is also observed and modelled with similar concepts [Curtin, 1991; Neumeister, 1993; Hui et al., 1995; Hild and Feillard, 1997], and the single to multiple fragmentation transition is also possible [Hild et al., 1994; da Silva et al., 2004].

\section{Acknowledgements}

The developments presented herein are the result of numerous and fruitful discussions with

Drs. Xavier Brajer, Charles Cottenot, Christophe Denoual, Sébastien Grange, René Gy, Laurent Rota, Stéphane Roux, and Mr. Stéphane Menccaci. Funding from Délégation Générale de l'Armement, Nitrochimie and Saint-Gobain is also gratefully acknowledged.

\section{References}

Arioz, O. (2007). "Effects of elevated temperatures on properties of concrete." Fire Safety J. $42,516-522$.

Barr, P. (1990). "Guidelines for the design and assessment of concrete structures subjected to impact." Atomic Energy Authority, London.

Bayard, O. (2003). "Approche multi-échelles du comportement mécanique des bétons à ultra hautes performances renforcés par des fibres courtes." Ph.D. dissertation, Ecole Normale Supérieure de Cachan (in French). 
Bischoff, P.H., Perry, S.H. (1991). "Compressive behaviour of concrete at high strain rates." Materials and Structures 24, 425-450.

Belytschko, T., Chen, H., Jingxiao, X., Goangseup, Z. (2003). "Dynamic crack propagation based on loss of hyperbolicity and a new discontinuous enrichment." Int. J. Num. Meth. Eng. 58, 1873-1905.

Bertin-Mourot, T., Denoual, C., Dehors, G., Louvigné, P.-F., Thomas, T. (1997). "High Speed Photography of Moiré Fringes - Application to Ceramics under Impact." J. Phys. IV, Coll. C3, Suppl. III, 311-316.

de Borst, R., Remmers, J.J.C., Needleman, A. (2006). "Mesh-independent numerical representations of cohesive-zone models." Eng. Fract. Mech. 173, 160-177.

Brajer, X., Forquin, P., Gy, R., Hild, F. (2003). "The role of surface and volume defects in the fracture of glass under quasi-static and dynamic loadings." J. Non-Cryst. Solids. $316,42-53$.

Brajer, X., Hild, F., Roux, S., Gy R. (2003). "A numerical model to describe damage in glass under impact loading." J. Phys. IV 110, 299-304.

Brajer, X., Hild, F., Roux, S., 2009. "On the dynamic fragmentation of glass: A mesodamage model." Int. J. Fract., submitted.

Bridgman P.W. Studies in Large Plastic Flow and Fracture, McGraw-Hill, New York 1952.

Broek, D. (1982). Elementary Engineering Fracture Mechanics. Martinus Nijhoff, The Hague, the Netherlands.

Budiansky, B., O'Connell R.J. (1976). "Elastic Moduli of a Cracked System." Int. J. Solids Struct. 12, 81-97.

Buzaud, E. (2003). Personal communication. DGA/Centre d'Etudes de Gramat. 
Cagnoux, J. (1985). "Déformation et ruine d'un verre Pyrex soumis à un choc intense : étude expérimentale et modélisation du comportement." Ph.D. dissertation, Université de Poitiers, France (in French).

Cagnoux, J., Don, D. (1994). "Compression uniaxiale, hydrostatique et triaxiale du quartzite de Villejust et du calcaire de Montmoyen." report T94-38, DGA/Centre d'Etudes de Gramat, France (in French).

Camacho, G.T., Ortiz, M. (1996). "Computational Modelling of Impact Damage in Brittle Materials." Int. J. Solids Struct., 33, 2899-2938.

Cheyrezy, M., Maret, V., Frouin, L. (1995). "Microstructural analysis of RPC." Cem. Concr. Res. 25 (7), 1491-1500.

Curtin, W.A. (1991). "Exact Theory of Fiber Fragmentation in Single-Filament Composite." J. Mater. Sci. 26, 5239-5253.

Darrigade, A., Buzaud, E. (1999). "High performance concrete: a numerical and experimental study." In: 9th Int. Symposium on the Interactions of the Effects of Munitions with Structures, Berlin.

Davies, D.G.S. (1973). "The Statistical Approach to Engineering Design in Ceramics." Proc. Brit. Ceram. Soc., 22, 429-452.

Denoual, C., Barbier, G., Hild, F. (1997). "A Probabilistic Approach for Fragmentation of Ceramics under Impact Loading." C. R. Acad. Sci. Paris IIb 325, 685-691.

Denoual, C., Cottenot, C.E., Hild, F. (1996). "On the Identification of Damage during Impact of a Ceramic by a Hard Projectile." Proceedings 16th International Conference on BALLISTICS, APDS, Arlington (USA), 541-550.

Denoual, C., Cottenot, C.E., Hild, F. (1998). "Analysis of the Degradation Mechanisms in an Impacted Ceramic." Proceedings Shock Compression of Condensed Matter, AIP Press, New York (USA), 427-430. 
Denoual, C., Hild, F. (2000). "A Damage Model for the Dynamic Fragmentation of Brittle Solids." Comp. Meth. Appl. Mech. Eng. 183, 247-258.

Denoual, C., Hild, F. (2002). "Dynamic Fragmentation of Brittle Solids: A Multi-Scale Model." Eur. J. Mech. A/Solids 21 (1), 105-120.

Dragon, A., Halm, D. (1996). "A Model of Damage by Mesocrack Growth - Unilateral Behavior and Induced Anisotropy." C. R. Acad. Sci. Paris IIb 322, 275-282.

Erzar B., Forquin P. (2009). "Dynamic tensile experiments for concrete by spalling technique." Exp. Mech., submitted.

Espinosa, H.D., Zavattieri, P.D., Dwivedi, S.K. (1998). "A Finite Deformation Continuum/Discrete Model for the Description of Fragmentation and Damage in Brittle Materials." J. Mech. Phys. Solids 46, 1909-1942.

Forquin, P. (2003). "Endommagement et fissuration de matériaux fragiles sous impact balistique, rôle de la microstructure." Ph.D. dissertation, Ecole Normale Supérieure de Cachan, France (in French).

Forquin, P., Arias, A., Zaera, R. (2007). "An experimental method of measuring the confined compression strength of geomaterials." Int. J. Solids Struct. 44, 4291-317.

Forquin, P., Arias, A., Zaera, R. (2008b). "Role of porosity in controlling the mechanical and impact behaviours of cement-based materials" Int. J. Impact Eng., 35 (3), 133-146.

Forquin, P., Denoual, C., Cottenot, C.E., Hild, F. (2003b). "Experiments and Modelling of the Compressive Behaviour of two SiC Ceramics." Mechanics of Materials 35, $987-$ 1002.

Forquin P., Erzar B. (2009). "Dynamic fragmentation process in concrete under impact and spalling tests." Int. J. Fract., submitted.

Forquin, P., Gary, G., Gatuingt, F. (2008a). "A testing technique for concrete under confinement at high rates of strain." Int. J. Impact Eng. 35 (6) 425-446. 
Forquin, P., Hild, F. (2008). "Dynamic Fragmentation of an Ultra-High Strength Concrete during Edge-On Impact Tests." J. Engrg. Mech. 134 (4), 302-315.

Forquin P., Safa K., Gary G. (2009). "Influence of free water on the quasi-static and dynamic strength of concrete in confined compression tests." Cement Conc. Res., submitted.

Forquin, P., Tran, L., Louvigné, P-F., Rota, L., Hild., F. (2003a). "Effect of Aluminum Reinforcement on the Dynamic Fragmentation of SiC Ceramics." Int. J. Impact Eng. 28, 1061-1076.

Forrestal, M.J., Altman, B.S., Cargile, J.D., Hanchak, S.J. (1994). "An empirical equation for penetration depth of ogive-nose projectiles into concrete targets." Int. J. Impact Eng. $15,395-405$.

Forrestal M.J., Frew D.J., Hanchak S.J., Brar N.S. (1996). "Penetration of grout and concrete targets with ogive-nose steel projectiles." Int. J. Impact Eng. 18, 465-476.

Freund, L.B. (1972). "Crack Propagation in an Elastic Solid Subjected to General Loading Constant Rate of Extension." J. Mech. Phys. Solids 20, 129-140.

Freund, L.B. (1990). Dynamic Fracture Mechanics. Cambridge University Press, Cambridge (UK).

Freudenthal, A.M. (1968). "Statistical Approach to Brittle Fracture." In: Fracture, H. Liebowitz, Edt. Academic Press, New York (USA), vol. II. 591-619.

Frew, D.J., Hanchak, S.J., Green, M.L., Forrestal, M.J. (1998). "Penetration of concrete targets with ogive-nose steel rods." Int. J. Impact. Eng. 21, 489-497.

Gailly, B.A. Espinosa, H.D. (2002). "Modeling of Failure Mode Transition in Ballistic Penetration with a Continuum Model Describing Microcracking and Flow of Pulverized Media." Int. J. Num. Meth. Eng. 54, 365-398, 2002. 
Gary G., Klepaczko J.R. (1992). "Résumé des résultats expérimentaux sur mini-béton 1992, essais de compression." GRECO Géomatériaux. Rapport scientifique, projet 1.3, "dynamique des bétons et des roches", 105-118 (in French).

Gary G., Klepaczko J.R., Hamelin P., Rossi P. (1991). "Résultats concernant le comportement dynamique en compression du microbéton." GRECO Géomatériaux. Rapport Scientifique, groupe 1, projet 1.3, "dynamique des bétons et des roches", 134138 (in French).

Ghan, Y.N., Peng, G.F., Anson M. (1999). "Residual strength and pore structure of highstrength concrete and normal strength concrete after exposure to high temperatures." Cement and Concrete Comp. 21, 23-27.

Glenn, L.A., Chudnovsky A. (1986). "Strain-energy effects on dynamic fragmentation." J. Appl. Phys. 59, 1379-1380.

Gomez, J.T., Shukla, A. (2001). "Multiple impact penetration of semi-infinite concrete." Int. J. Impact Eng. 25, 965-979.

Gorham, D.A. (1989). "Specimen inertia in high strain-rate compression." J. Phys D Appl. Phys. 22, 1888-1893.

Grady, D.E. (1982). "Local Inertia Effects in Dynamic Fragmentation." J. Appl. Phys. 53, $322-325$.

Grady, D.E., Kipp, M.E. (1980). "Continuum Modeling of Explosive Fracture in Oil Shale." Int. J. Rock Min. Sci. \& Geomech. Abstr. 17, 147-157.

Grady, D.E., Kipp, M.E. (1985). "Geometric Statistics and Dynamic Fragmentation." J. Appl. Phys. 58, 1210-1222.

Graff, K.F. (1975). Wave Motion in Elastic Solids. Clarendon, Oxford, UK.

Grange S., Forquin P., Mencacci S., Hild F. (2008). "On the dynamic fragmentation of two limestones using edge-on impact tests." Int. J. Impact Eng. 35(9), 977-991. 
Grujicic, M., Pandurangan, B., Coutris, N., Cheeseman, B.A., Fountzoulas, C., Patel, P., Templeton, D.W., Bishnoi, K.D. (2009) "A simple ballistic material model for sodalime glass." Int. J. Impact Eng. 36, 386-401.

Gulino, R., Phoenix, S.L. (1991). "Weibull Strength Statistics for Graphite Fibres Measured from the Break Progression in a Model Graphite/Glass/Epoxy Microcomposite." $J$. Mater. Sci. 26 (11), 3107-3118.

Guy, N., Seyedi D.M., Hild, F. (2008) "Hydro-mechanical modelling of underground $\mathrm{CO}_{2}$ storage and risk evaluation through a probabilistic fracturing model. Proc. 12th International Conference of International Association for Computer Methods and Advances in Geomechanics (IACMAG), 7p.

Heard H.A., Cline C.F. (1980). "Mechanical Behaviour of Polycrystalline BeO, $\mathrm{Al}_{2} \mathrm{O}_{3}$ and AlN at High Pressure." J. Mater. Sci. 15, 1889-1897.

Hibbitt, H.D., Karlsson, B.I., Sorensen, P. (2001). "Abaqus User's manual, ABAQUS/EXPLICIT 6.1." Version 5.8, volumes I and II.

Hiermaier, S., Riedel, W. (1997). "Numerical Simulation of Failure in Brittle Materials using Smooth Particle Hydrodynamics." New Models and Numerical codes for Schock Wave Processes in Condensed Media, St Catherine's College, Oxford (UK).

Hild F., Billardon R., Marquis D. (1992). "Hétérogénéité des contraintes et rupture des matériaux fragiles." C. R. Acad. Sci. Paris II 315, 1293-1298.

Hild, F., Domergue, J.-M., Evans, A.G., Leckie, F.A. (1994) "Tensile and Flexural Ultimate Strength of Fiber-Reinforced Ceramic-Matrix Composites." Int. J. Solids Struct. 31, 1035-1045.

Hild, F., Forquin, P., Silva, A.R.C. (2003). "Single and Multiple Fragmentation of Brittle Geomaterials." Rev. Franç. Gén. Civil 7 (7-8), 973-1003. 
Hild, F., Feillard, P. (1997) "Ultimate Strength Properties of Fiber-Reinforced Composites." Rel. Eng. Sys. Saf., 56, 225-235.

Hoek, E., Franklin, J.A. (1968). "A simple triaxial cell for field and laboratory testing of rock." Trans. Instn Min. Metall. 77, A22-26.

Hornemann, U., Kalthoff, J.F., Rothenhäusler, H., Senf, H., Winkler, S. (1984). "Experimental Investigation of Wave and Fracture Propagation in Glass - Slabs Loaded by Steel Cylinders at High Impact Velocities." EMI report E 4/84, Weil am Rhein (Germany).

Hui, C.Y., Phoenix, S.L., Ibnabdeljalil, M., Smith, R.L. (1995) "An Exact Closed Form Solution for Fragmentation of Weibull Fibers in a Single Filament Composite with Applications to Fiber-Reinforced Ceramics" J. Mech. Phys. Solids 43, 1551-1585.

Ibrahimbegovic, A., Delaplace, A. (2003). "Microscale and mesoscale discrete models for dynamic fracture of structures built of brittle material." Comput. Struct. 81 (12), 12551266.

Jayatilaka, A. de S., Trustrum, K. (1977). "Statistical Approach to Brittle Fracture." J. Mater. Sci., 12, 1426-1430.

Jeulin, D. (1991). "Modèles morphologiques de structures aléatoires et changement d'échelle." thèse d'État, Université de Caen (in French).

Johnson, G.R., Holmquist, T.J. (1992). "An Improved Computational Constitutive Model for Brittle Materials." High Pres. Sci. Tech. 2, 981-984.

Kanninen, M.F., Popelar, C.H. (1985). Advanced Fracture Mechanics. Oxford University Press, Oxford (UK).

Kennedy R.P. (1976). "A Review of procedures for the analysis and design of concrete structures to resist missile impact effects." Nuclear Engineering and Design 37, 183 203. 
Kingery, W.D., Bowen, H.K., Uhlmann, D.R. (1976). Introduction to Ceramics. John Wiley and Sons, Inc., New York (USA).

Klepaczko, J.R., Brara, A. (2001). "An experimental method for dynamic tensile testing of concrete by spalling." Int. J. Impact Eng. 25, 387-409.

Knauss, W.G., Ravi-Chandar, K. (1985). "Some basic problems in stress wave dominated fracture." Int. J. Fract. 27 (3-4), 127-143.

Knauss, W.G., Ravi-Chandar, K. (1986). "Fundamental considerations in dynamic fracture." Eng. Fract. Mech. 23 (1), 9-20.

Kotsovos M.D., Newman J.B. (1980). "Mathematical description of deformational behavior of concrete under generalized stress beyond ultimate strength." J. Am. Concr. Inst. ACI $77,340-346$.

Krieg, R.D. (1978). "A simple constitutive description for soils and crushable foams." Report, SC-DR-7260883, Sandia National Laboratory.

Kusano, N., Aoyagi, T., Aizawa, J., Ueno, H., Morikawa, H., Kobayashi, N. (1992). "Impulsive Local Damage Analysis of Concrete Structure by the Distinct Finite Element Method." Nuclear Eng. Design 138, 105-110.

Kutter, H.K., Fairhurst, C. (1971). "On the Fracture Process in Blasting." Int. J. Rock Mech. Min. Sci. 8, 181-202.

Lankford, J. (1981). "Temperature-strain rate dependence of compressive strength and damage mechanisms in aluminium oxide." J. Mater. Sci. 16, 1567-1578.

Lankford, J. (1991). "The compressive strength of strong ceramics: microplasticity versus microfracture." J. Hard Materials 2 (1-2), 55-77.

Li, Q.M., Reid, S.R., Wen, H.M., Telford A.R. (2005). "Local impact effects of hard missiles on concrete targets." Int J. Impact Eng. 32, 224-284. 
Libersky, L.D., Petscheck, A.G. (1993). High Strain Lagrangian Hydrodynamics. J. Comp. Phys., 109, 67-75.

Malésys, N., Seyedi, M., Vincent L., Hild F. (2006) "On the formation of crack networks in high cycle fatigue." C. R. Mécanique 334, 419-424.

Malésys, N., Vincent, L., Hild, F. (2009) "A probabilistic model to predict the formation and propagation of crack networks in thermal fatigue." Int. J. Fat. 31, 565-574.

Malier, Y. (1992). Les bétons à hautes performances. Presses de l'Ecole Nationale des Ponts et Chaussées, France (in French).

Margolin. L.G. (1983). "Elasticity Moduli of a Cracked Body." Int. J. Fract. 22, 65-79.

Mastilovic, S., Krajcinovic D. (1999). "High-Velocity Expansion of a Cavity within a Brittle Material." J. Mech. Phys. Solids 47, 577-600.

Maugis, D. (1988). "Cinétique de la fracture et adhérence." $4^{\text {es }}$ journées d'études sur l'adhérence, Lyon, Société Française du Vide. I ("Adhérence"), 1-51 (in French).

Menouillard, T., Réthoré, J., Combescure, A., Bung, H. (2006). "Efficient explicit time stepping for the eXtended Finite Element Method." Int. J. Num. Meth. Eng. 68, 911939.

Monaghan, J.J. (1992). "Smoothed Particle Hydrodynamics." Annu. Rev. Astron. Astrophys., $30,543-574$

Mott, N.F. (1947). "Fragmentation of Shell Cases." Proc. Roy. Soc. London A189, 300-308.

Neumeister, J.M. (1993) "A Constitutive Law for Continuous Fiber Reinforced Brittle Matrix Composites with Fiber Fragmentation and Stress Recovery." J. Mech. Phys. Solids 41, 1383-1404.

Novikov S.A., Divnov I.I., Ivanov A.G. (1966). "An investigation of the fracture of steel, aluminium and copper under explosive loading." Fiz. Met. Metalloved. 21, 608-615. 
Oakley, D.R. (1996). "An empirical study of the effect of stressed area on the strength of float glass surfaces." J. Non-Cryst. Solids. 196, 134-8.

Palaniswamy, R., Shah, S.P. (1974). "Fracture and stress-strain relationship of concrete under triaxial compression." J. Struct. Div. ASCE. ST5, 901-916.

Ravi-Chandar, K. (1998). "Dynamic fracture of nominally brittle materials." Int. J. Fract. 90, 83-102.

Ravi-Chandar, K., Knauss, W.G. (1982). "Dynamic crack-tip stresses under stress wave loading. A comparison of theory and experiment." Int. J. Fract. 20 (3), 209-222.

Ravi-Chandar, K., Knauss, W.G. (1984a). "An experimental investigation into dynamic fracture: I, Crack initiation and arrest." Int. J. Fract. 25 (4), 247-262.

Ravi-Chandar, K., Knauss, W.G. (1984b). "An experimental investigation into dynamic fracture: II, Microstructural aspects." Int. J. Fract. 26 (1), 65-80.

Ravi-Chandar, K., Knauss, W.G. (1984c). "An experimental investigation into dynamic fracture: III, Steady-state crack propagation and crack branching." Int. J. Fract. 26 (2), $141-154$.

Ravi-Chandar, K., Knauss, W.G. (1984d). "An experimental investigation into dynamic fracture: IV, On the interaction of stress waves with propagating cracks." Int. J. Fract. $26(3), 189-200$.

Ravi-Chandar, K., Yang, B. (1997). "On the role of microcracks in the dynamic fracture of brittle materials." J. Mech. Phys. Solids, 45 (4), 535-563.

Réthoré, J., Gravouil, A., Combescure, A. (2005). "An Energy Conserving Scheme for Dynamic Crack Growth with the eXtended Finite Element Method." Int. J. Num. Meth. Eng. 63, 631-659.

Richard, P., Cheyrezy, M. (1995). "Composition of reactive power concretes." Cement Conc. Res. 25 (7), 1501-1511. 
Riou, P., Denoual, C., Cottenot, C.E. (1998). "Visualization of the Damage Evolution in Impacted Silicon Carbide Ceramics." Int. J. Impact Eng. 21 (4), 225-235.

Rabotnov, Y.N. (1963). "On the equation of state for creep." In: Progress in Applied Mechanics - The Prager Anniversary Volume, The Macmillian Company, New York (USA), 307-315.

Rajendran, A.M. (1994). "Modeling the Impact Behavior of AD85 Ceramic under Multiaxial Loading." Int. J. Impact Eng. 15, 749-768.

den Reijer, P.C. (1991). "Impact on Ceramic Faced Armour." Ph.D. dissertation. Technical University of Delft.

Rossi, P. (1988). "Fissuration du béton: du matériau à la structure. Application de la mécanique linéaire de la rupture." Ph.D. dissertation. Ecole Nationale des Ponts et Chaussées, France (in French).

Rossi, P. (1991). "A physical phenomenon which can explain the material behaviour of concrete under high strain rates." Materials and Structures 24, 422-424.

Saad, M., Abo-El-Eneini, S.A., Hanna, G.B., Kotkatat, M.F. (1996). "Effect of temperature on physical and mechanical properties of concrete containing silica fume." Cement and Concrete Res. 26 (5), 669-675.

Savva, A., Manita, P., Sideris, K.K. (2005). "Influence of elevated temperatures on the mechanical properties of blended cement concretes prepared with limestone and siliceous aggregates." Cement \& Concrete Comp. 27, 239-248.

Schuler, H., Mayrhofer, C., Thoma, K. (2006). "Spall experiments for the measurement of the tensile strength and fracture energy of concrete at high strain rates." Int. J. Impact Eng. 32, 1635-1650.

Seyedi, M., Taheri, S., Hild, F. (2006) "Numerical modeling of crack propagation and shielding effects in a striping network." Nucl. Eng. Design 236, 954-964. 
Sharon, E., Gross, S.P., Fineberg, J. (1995). "Local crack branching as a mechanism for instability in dynamic fracture." Phys. Rev. Lett. 74 (25), 5096-5099.

Shockey, D.A., Curran, D.R., Seaman, L., Rosenberg, J.T., Petersen C.F. (1974). "Fragmentation of Rocks under Dynamic Loads." Int. J. Rock Mech. Min. Sci. 11, 303317.

da Silva, A.R.C., Proença, S.P.B., Billardon, R., Hild, F. (2004) "Probabilistic Approach to Predict Cracking in Lightly Reinforced Microconcrete Pannels." J. Eng. Mech., 130, 931-941.

Spanier, J., Oldham, K.B. (1987). An atlas of functions. Springer, New York (USA).

Strassburger, E., Senf, H. (1995). "Experimental Investigations of Wave and Fracture Phenomena in Impacted Ceramics and Glasses." EMI Report, ARL-CR-214.

Strassburger, E., Senf, H., Rothenhäusler, H. (1994). "Fracture Propagation during Impact in Three Types of Ceramics." J. Physique IV C8, 653-658.

Swenson, D.V., Taylor, L.M. (1983). "A finite element model for the analysis of tailored pulse stimulation of boreholes." Int. J. Num. Analyt. Meth. Geomech. 7, 469-484.

Taylor, L.M., Chen, E.-P., Kuszmaul, J.S. (1986). "Microcrack-Induced Damage Accumulation in brittle Rocks under Dynamic Loading." Comp. Meth. Appl. Mech. Eng. 55, 301-320.

Trumel, H., Hild, F., Roy, G., Pellegrini, Y.-P., Denoual, C. (2009). "On Probabilistic Aspects in the Dynamic Degradation of Ductile Materials." J. Mech. Phys. Solids submitted.

Toutlemonde, F. (1994). "Résistance au choc de structures en béton." Ph.D. dissertation. Ecole Nationale des Ponts et Chaussées (in French).

Weibull, W. (1939). "A Statistical Theory of the Strength of Materials." Report 151, Roy. Swed. Inst. Eng. Res. 
Weibull, W. (1951). "A Statistical Distribution Function of Wide Applicability." ASME J. Appl. Mech. 18 (3), 293-297.

Weerheijm, J. (1992). "Concrete under impact tensile loading and lateral compression." Doctoral thesis, Delft University.

Weerheijm, J., Van Doormaal, J.C.A.M. (2007). "Tensile failure of concrete at high loading rates: New test data on strength and fracture energy from instrumented spalling tests." Int J Impact Eng. 34, 609-626.

Wu, H., Zhang, Q., Huang, F., Jin, Q. (2005). "Experimental and numerical investigation on the dynamic tensile strength of concrete." Int. J. Impact Eng. 32, 605-17.

Xiao, J., König, G. (2004). "Study on concrete at high temperature in China—an overview." Fire Safety J. 39, 89-103.

Xu, X.-P., Needleman, A. (1994). "Numerical simulations of fast crack growth in brittle solids." J. Mech. Phys. Solids, 42, 1397-1434.

Zavattieri P.D., Espinosa, H.D. (2001). "Grain Level Analysis of Crack Initiation and Propagation in Brittle Materials." Acta Mat. 49, 4291-4311.

Zhou, F., Molinari, J.-F. (2004). "Stochastic fracture of ceramics under dynamic tensile loading." Int. J. Solids Struct. 41, 6573-6596.

Zimmerman, R.G. (1972). "Major factors affecting the multiaxial compressive strength of plain concrete. The deformations and the rupture of solids subjected to multiaxial stresses", in: Proc. of RILEM Int Symposium, Cannes, RILEM, Paris. 1, 257-272. 


\section{Figures}

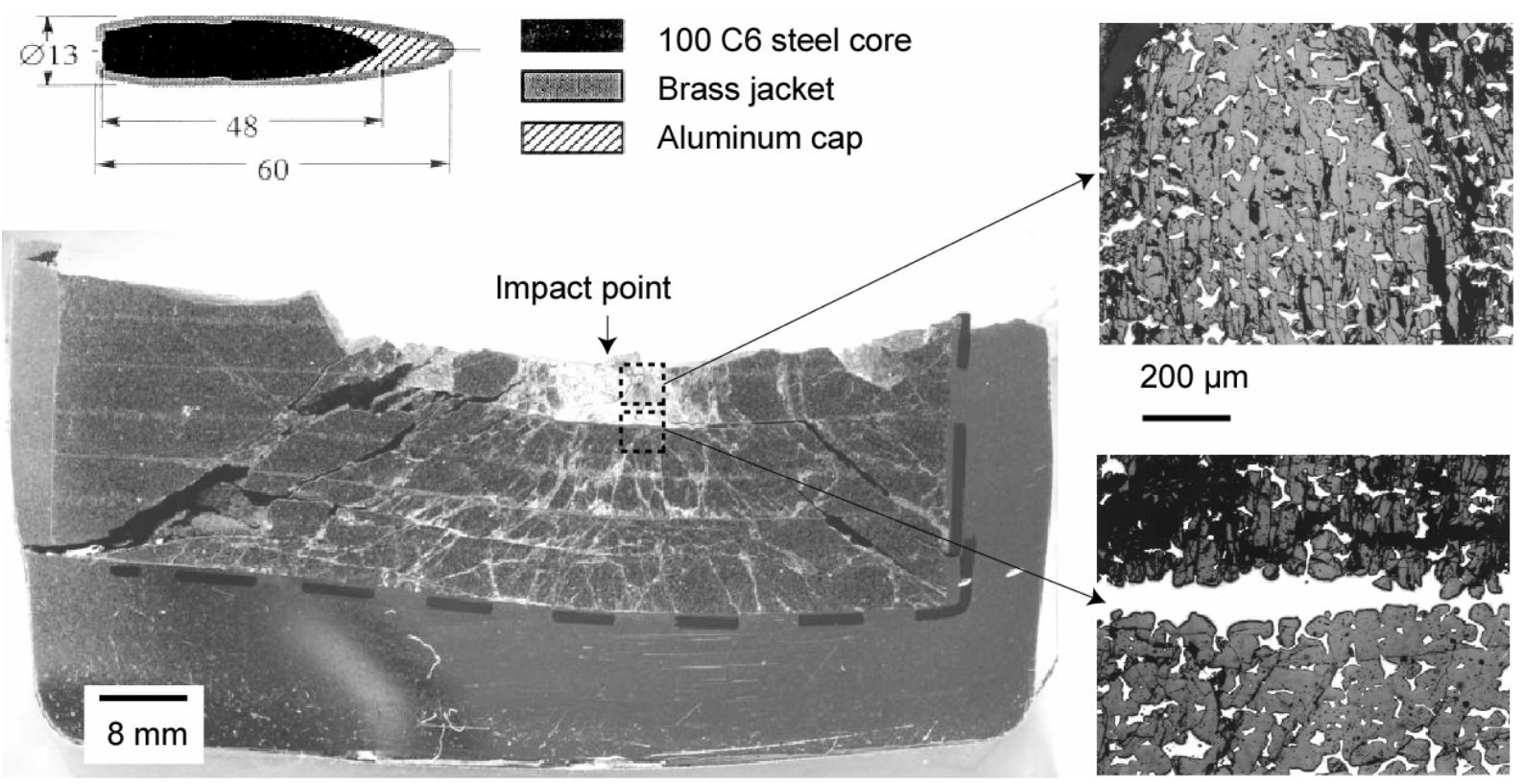

Figure 1. Impact of an armour-piercing projectile AP12.7 mm travelling at $880 \mathrm{~m} / \mathrm{s}$ against a multilayered armour made of three infiltrated ceramic tiles (R-SiC-Al) as front face and aluminium alloy as backing. 


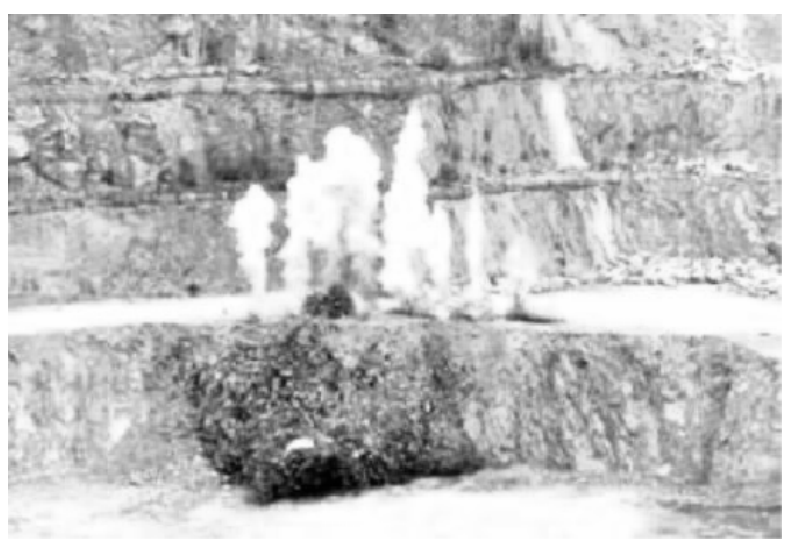

Pyrotechnic test in an open quarry

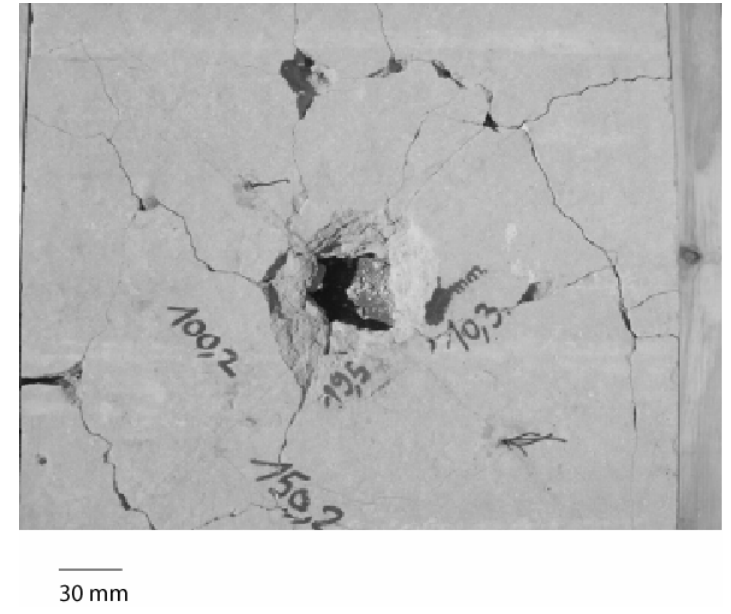

Fragmentation of a Beaucaire limestone by a blast loading [Hild et al., 2003]

-b-

Figure 2. Fragmentation of rock in open quarry (a) and of a slab (b) by blast loading. 


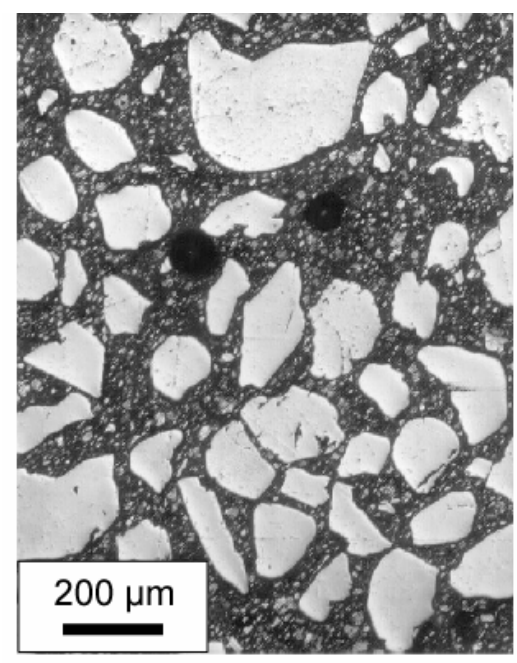

\begin{tabular}{|l|l|}
\hline Fine sand & $885 \mathrm{~kg} / \mathrm{m}^{3}$ \\
Cement & $730 \mathrm{~kg} / \mathrm{m}^{3}$ \\
Crushed quartz & $220 \mathrm{~kg} / \mathrm{m}^{3}$ \\
Silica fume & $235 \mathrm{~kg} / \mathrm{m}^{3}$ \\
Water & $160 \mathrm{I} / \mathrm{m}^{3}$ \\
Super plastifier & $10 \mathrm{~kg} / \mathrm{m}^{3}$ \\
Steel fibres (vol. \%) & $2 \%$ \\
\hline
\end{tabular}

\section{Aluminium backing}

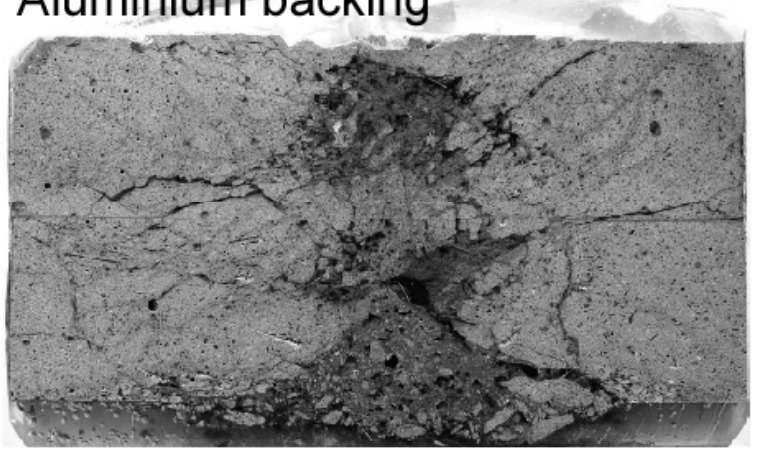

$\uparrow$

Impact point
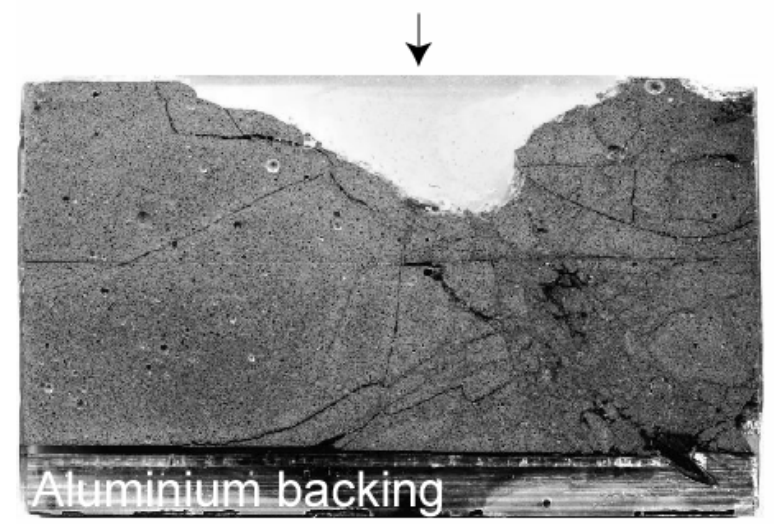

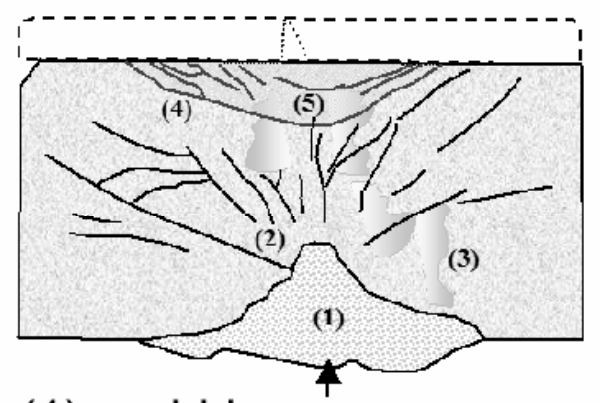

(1) scabbing

(2) radial cracks

(3) likely hoop cracks

(4) spalling on rear face

(5) damaged zone close to tunnel

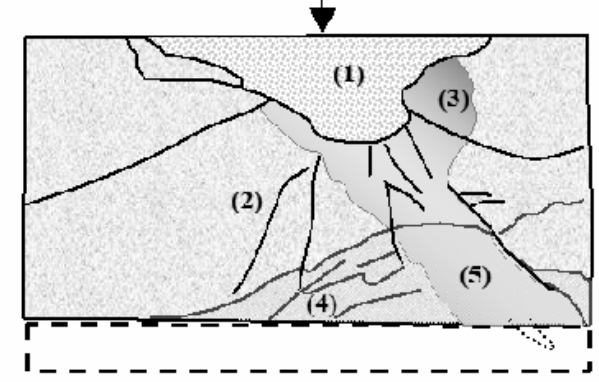

Figure 3. Impact of an Armour-Piercing projectile AP $7.62 \mathrm{~mm}$ (steel core, impact velocity: $840 \mathrm{~m} / \mathrm{s}$ ) against a bilayered target (Ductal® concrete: $60 \mathrm{~mm}+$ aluminium backing: $10 \mathrm{~mm}$ ). 


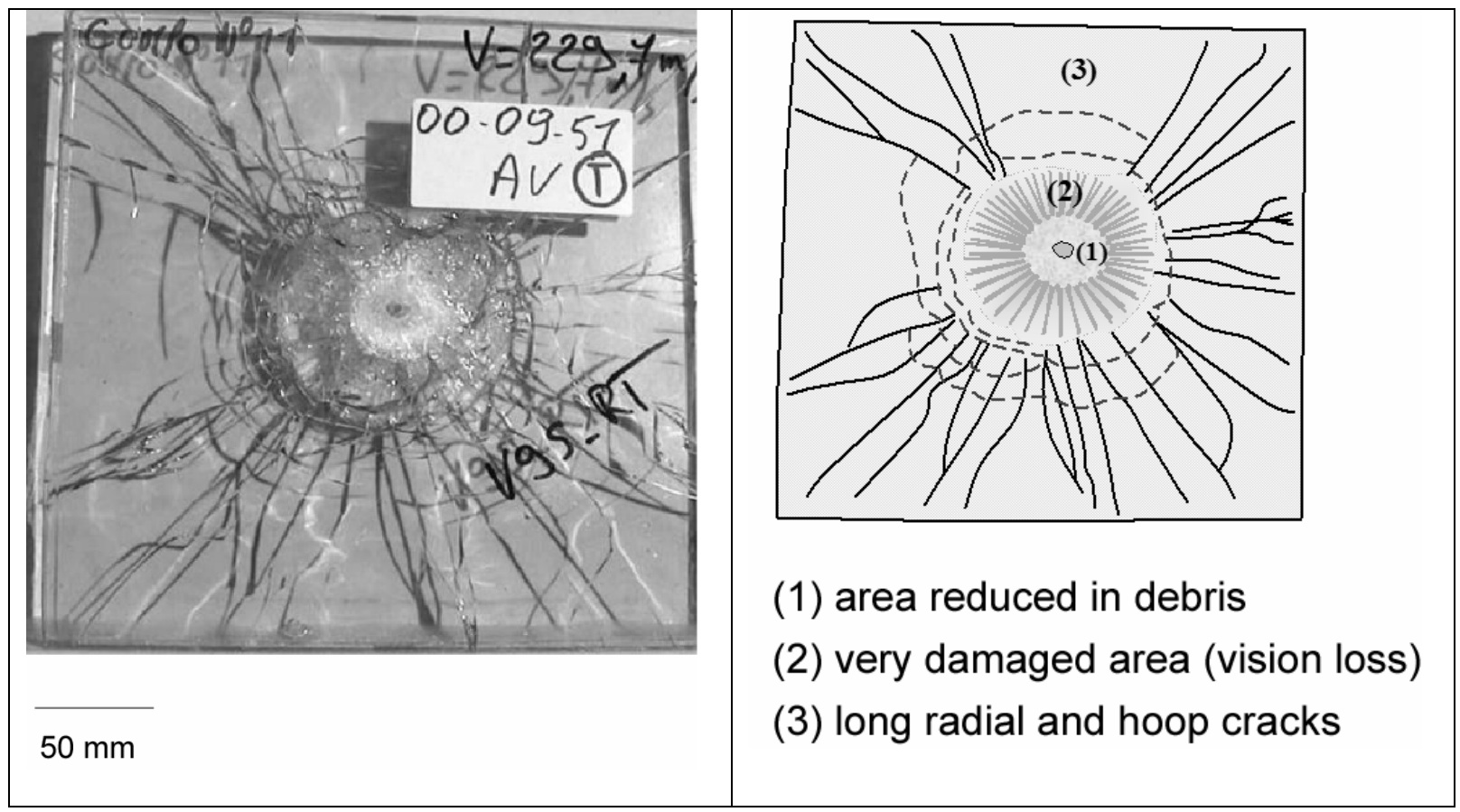

Figure 4. Impact of a 'BR4' projectile (impact velocity: $230 \mathrm{~m} / \mathrm{s}$ ) against a glass armour and sketch of the damage pattern. 


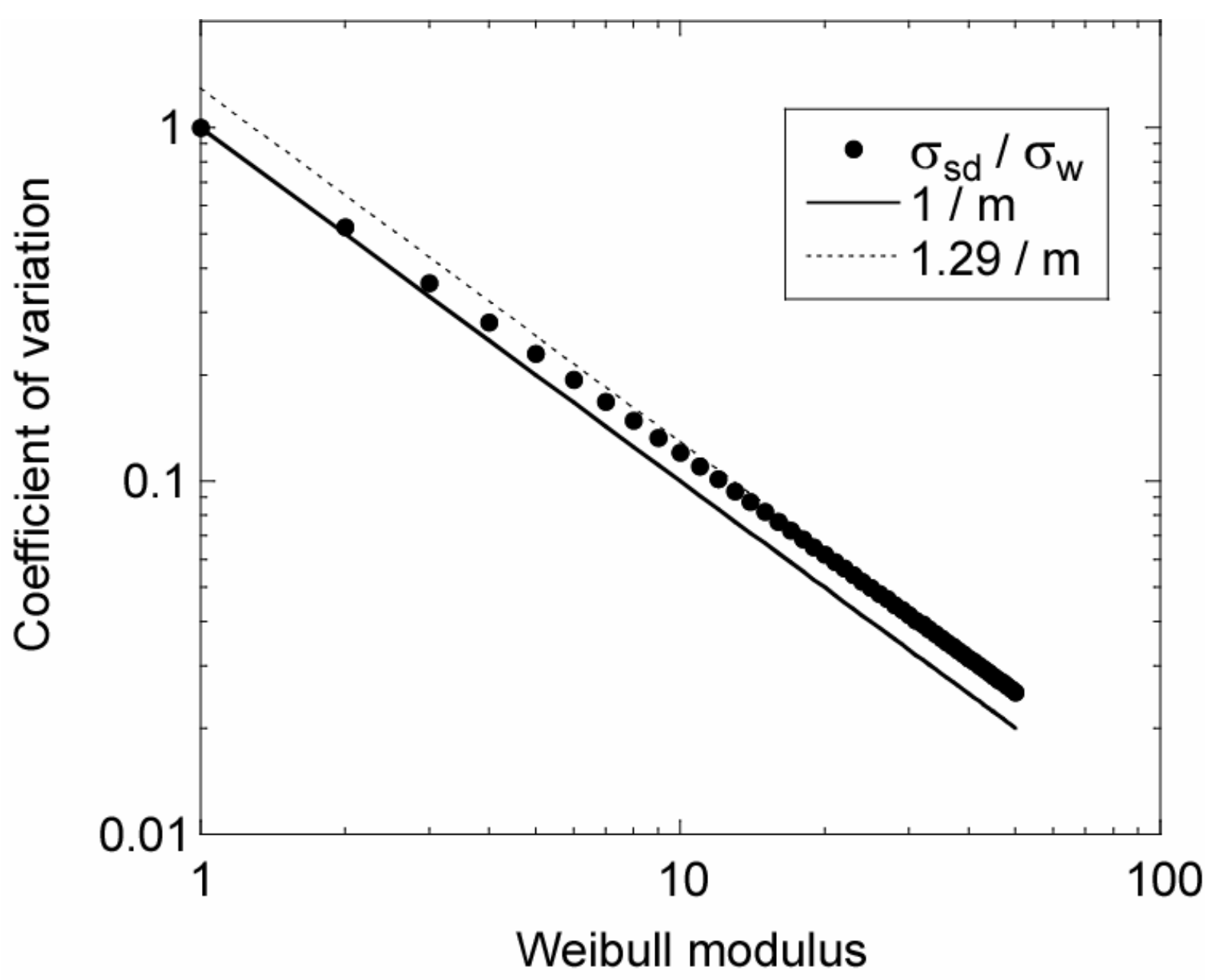

Figure 5. Change of the coefficient of variation $\sigma_{s d} / \sigma_{w}$ as a function of the Weibull modulus $m$. 

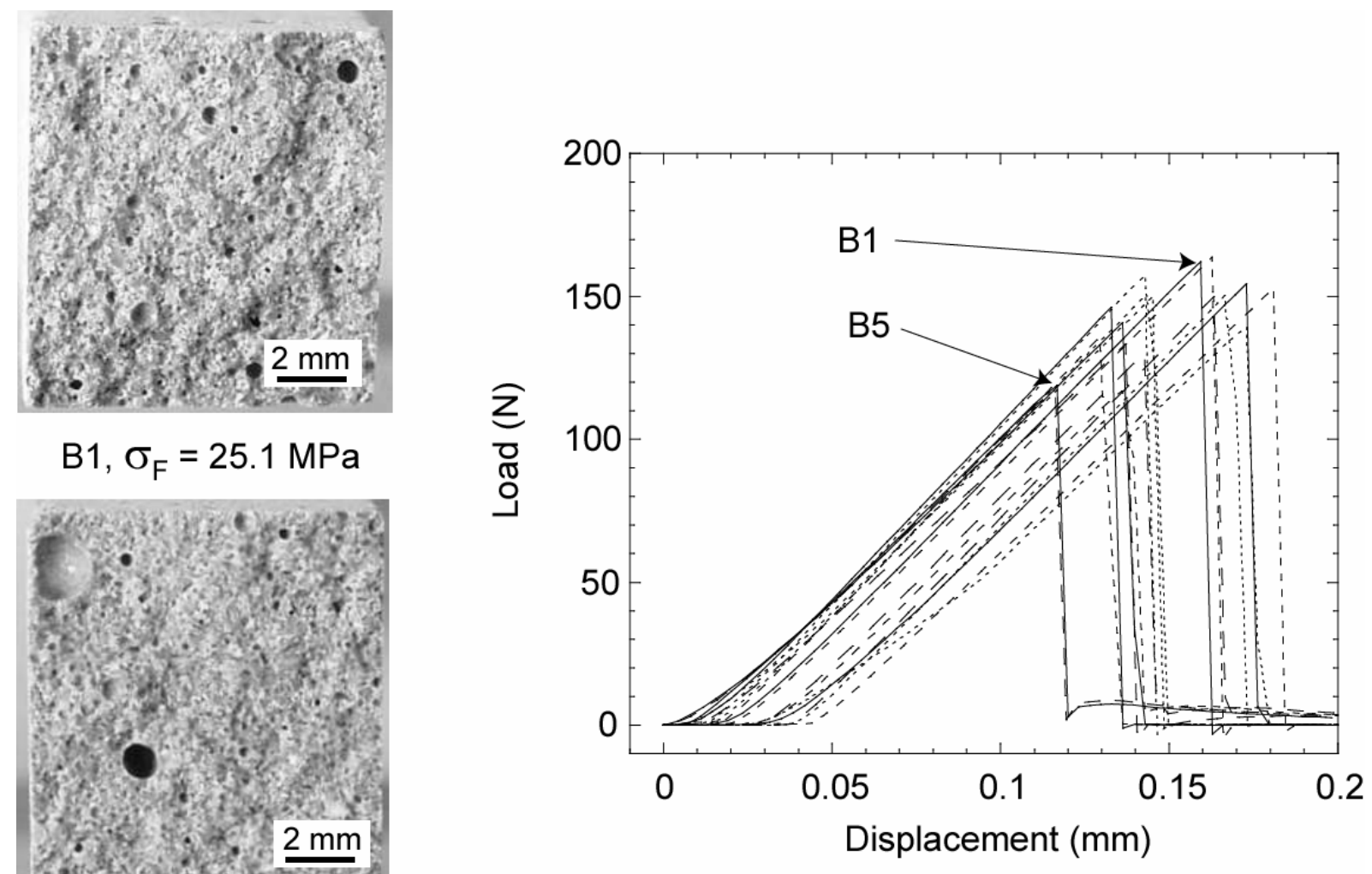

$\mathrm{B} 5, \sigma_{\mathrm{F}}=18.1 \mathrm{MPa}$

Figure 6. Results of 3-point bend tests performed with Ductal ${ }^{\circledR}$ concrete without fibres and two post-mortem observations. 

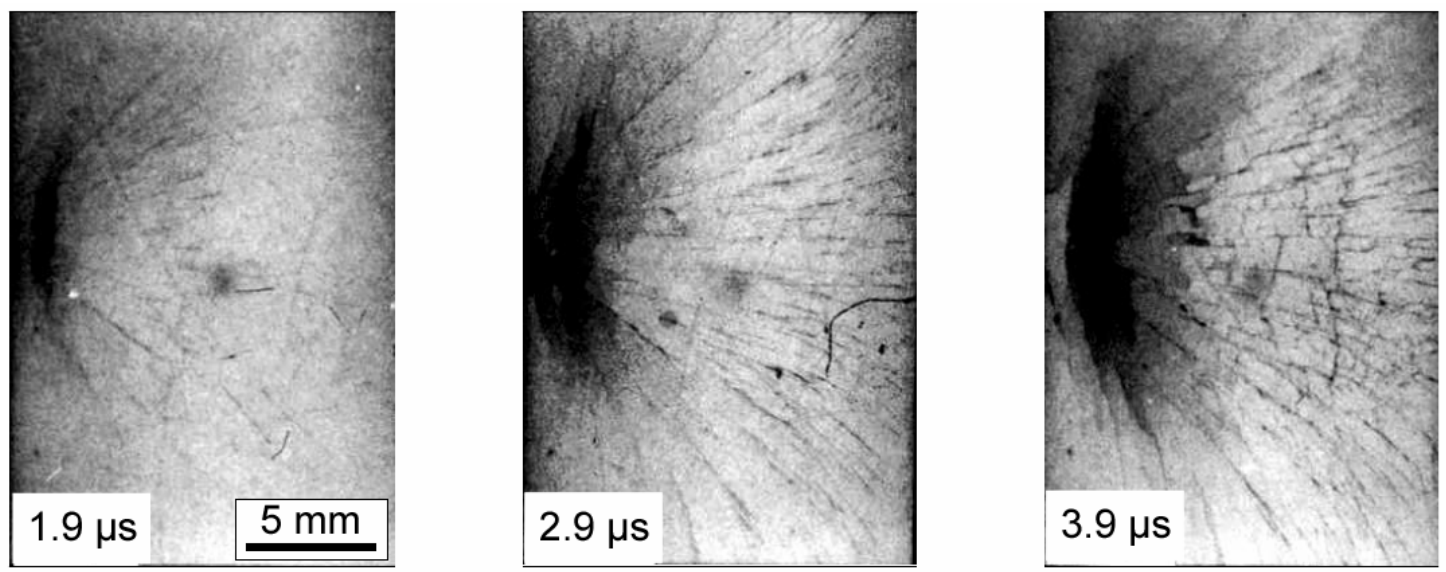

$-a-$
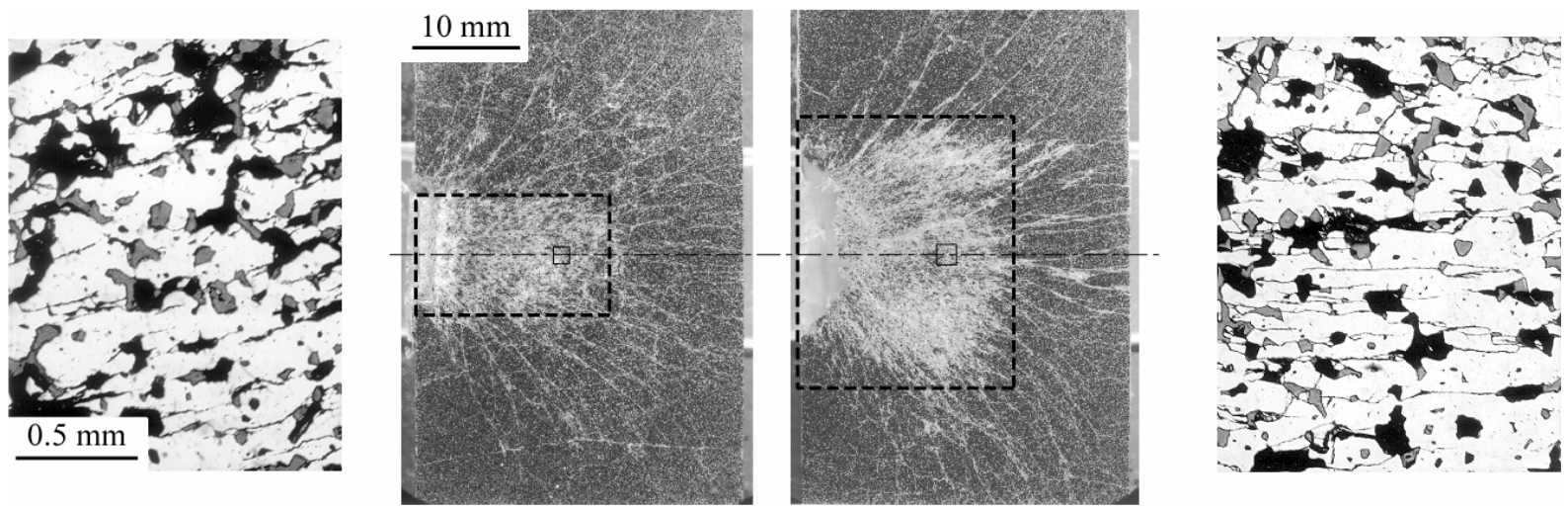

$-b-$

Figure 7. -a-Fragmentation of a $\mathrm{SiC}-100$ ceramic during an EOI test observed with an ultraspeed camera [Riou et al., 1998]. Steel projectile of diameter $11 \mathrm{~mm}$ (AFNOR 100C6, AISI 52 100) impacting at $250 \mathrm{~m} / \mathrm{s}$.

-b-Edge-On Impact against R-SiC ceramic. Post-mortem observations and zoom around a central zone located $13 \mathrm{~mm}$ from the impact point for two impact velocities (left: $100 \mathrm{~m} / \mathrm{s}$, right: $200 \mathrm{~m} / \mathrm{s})$. 

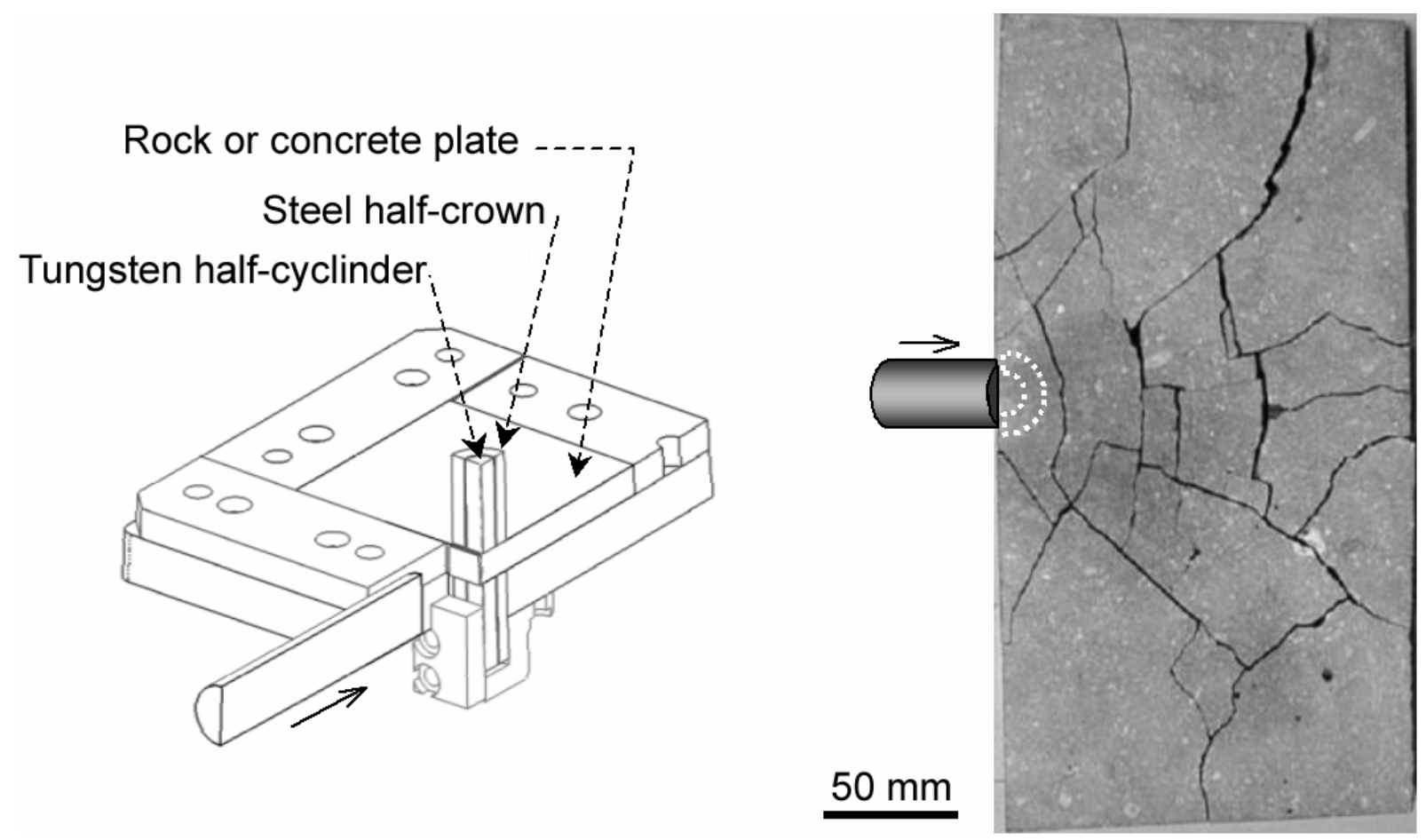

Figure 8. Edge-On Impact against crinoidal limestone (sarcophagus configuration with a “dynamic confinement system"). 

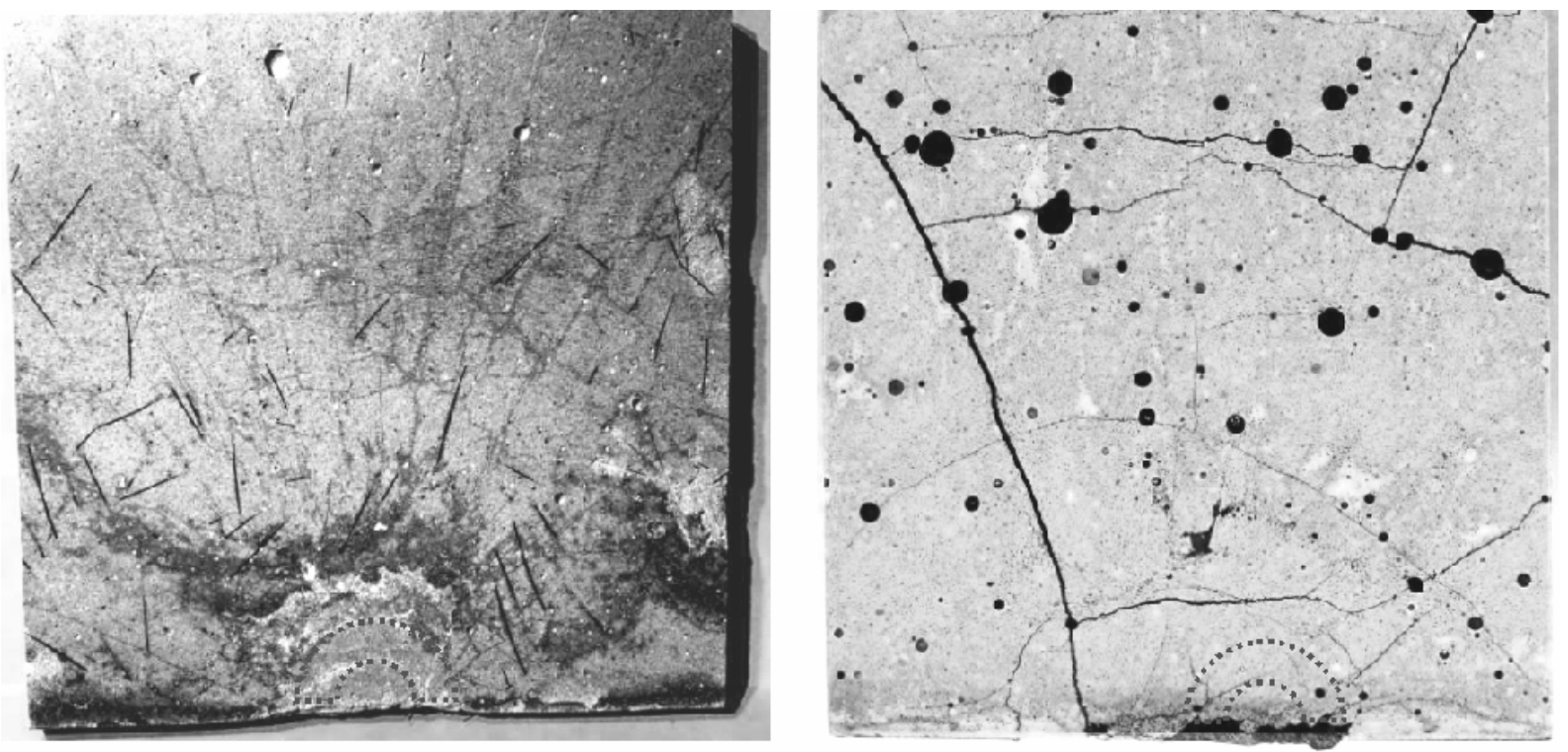

\section{$20 \mathrm{~mm}$}

Figure 9. Edge-On Impact with Ductal ${ }^{\circledR}$ concrete in a sarcophagus configuration (left: Ductal $^{\circledR}$ with fibres, right: Ductal ${ }^{\circledR}$ with no fibre) [Forquin and Hild, 2008]. 


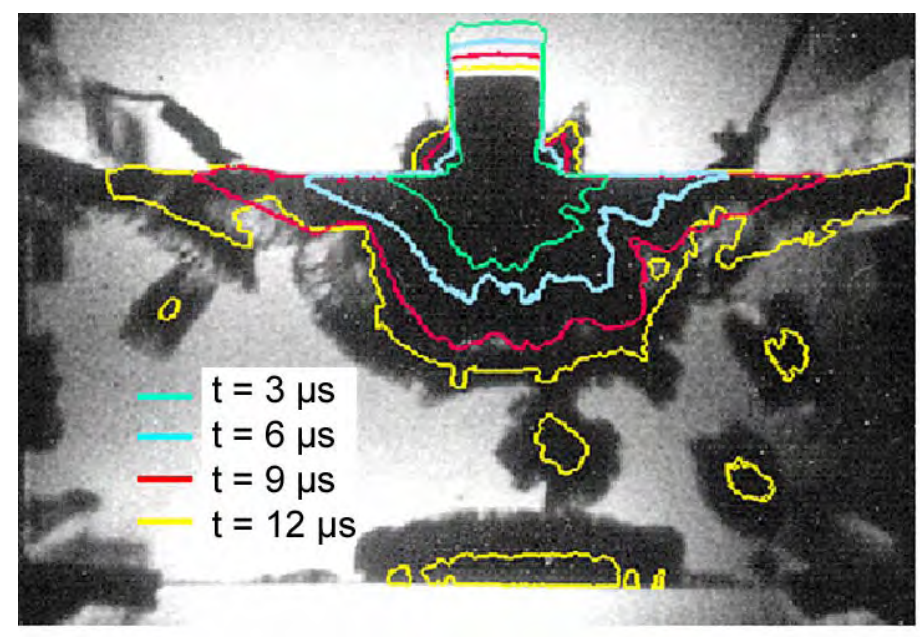

Rayleigh cone Circular crack front

$10 \mathrm{~mm}$

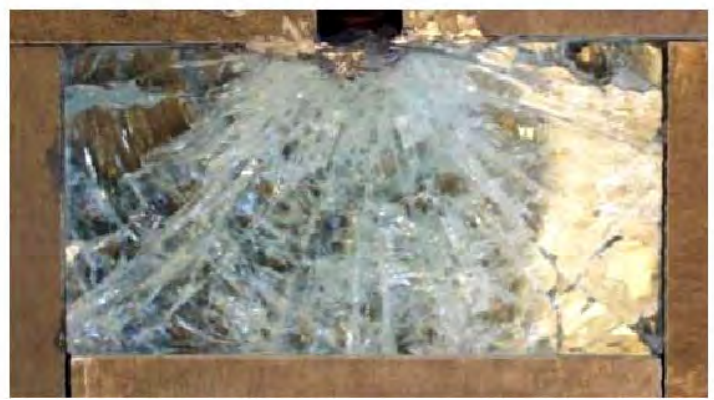

Figure 10. Edge-On Impact against soda-lime glass impacted by a 44-magnum projectile. Top view: visualization of damage with an ultra-high speed camera and sketch of damage pattern, bottom: sarcophagus configuration. 


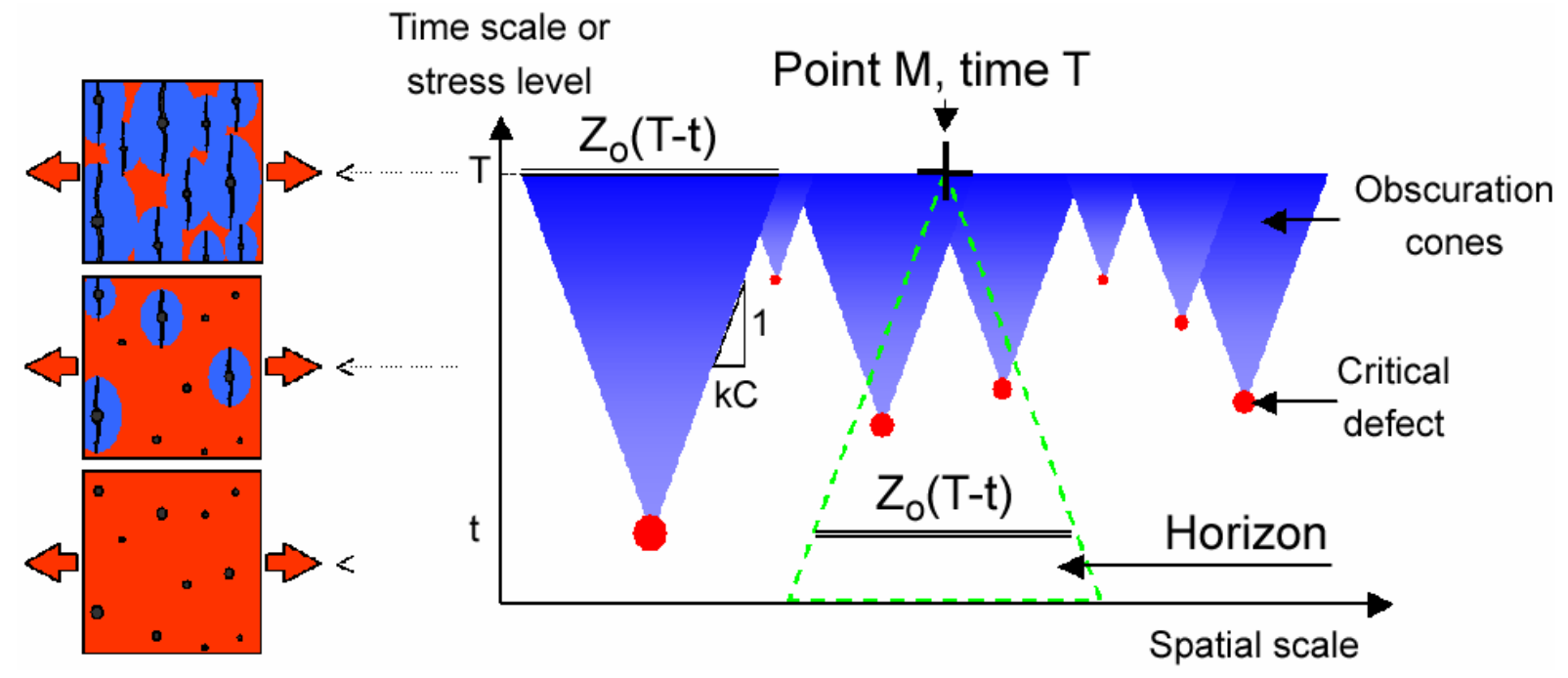

Figure 11. Obscuration phenomenon and horizon of a point $M$ at time $T$. 
Time scale or stress level

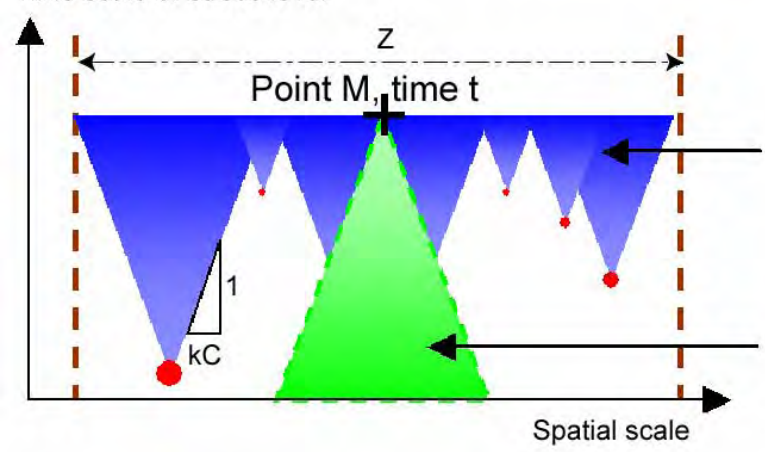

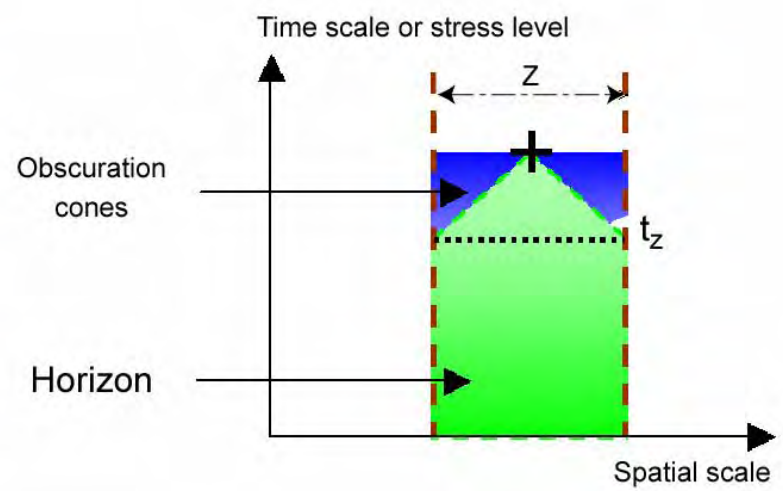

Figure 12. Influence of the size of the considered domain on the fragmentation process and the horizon of a point $M$ at time T. -a-Multiple fragmentation. -b-Single fragmentation. 

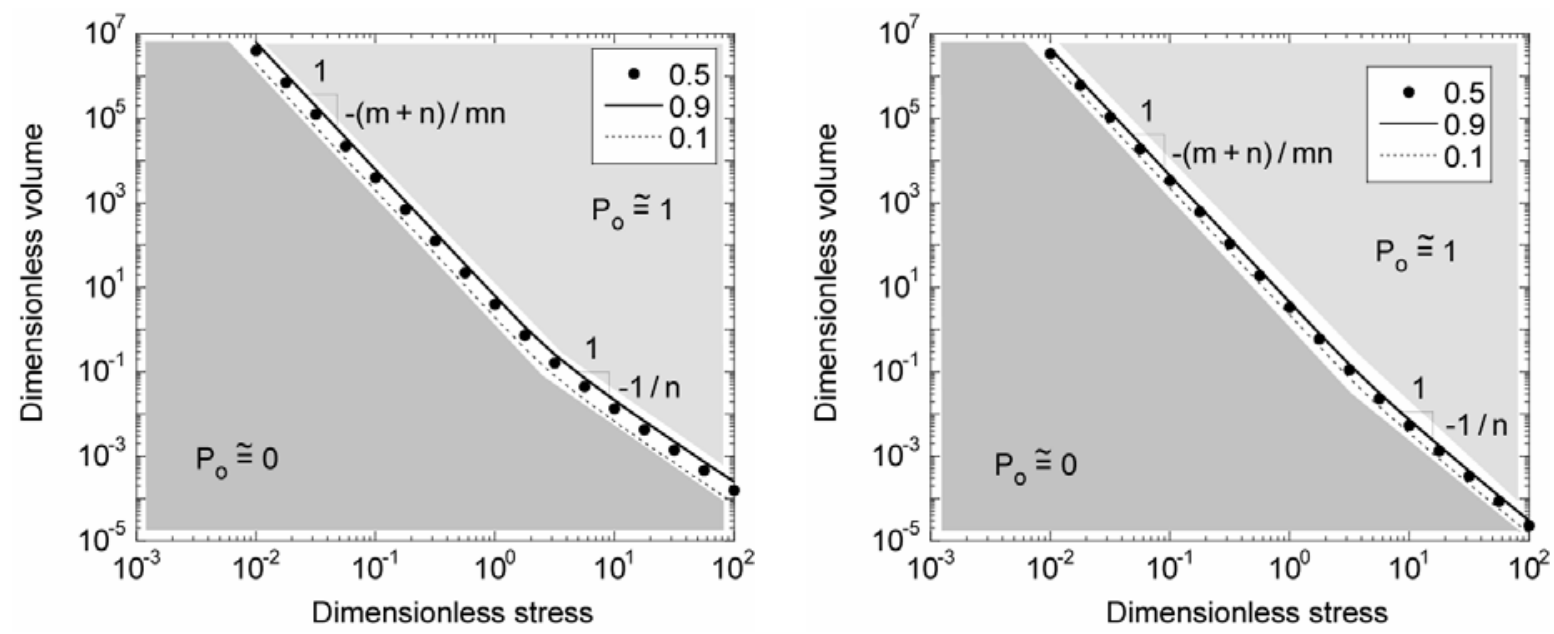

Figure 13. Change of $x$ with $Z / Z_{c}$ for given values of the probability of obscuration $P_{o}(0.1$, 0.5 and 0.9 ) when $m=5$ (left) or $m=10$ (right), and $n=3$. 


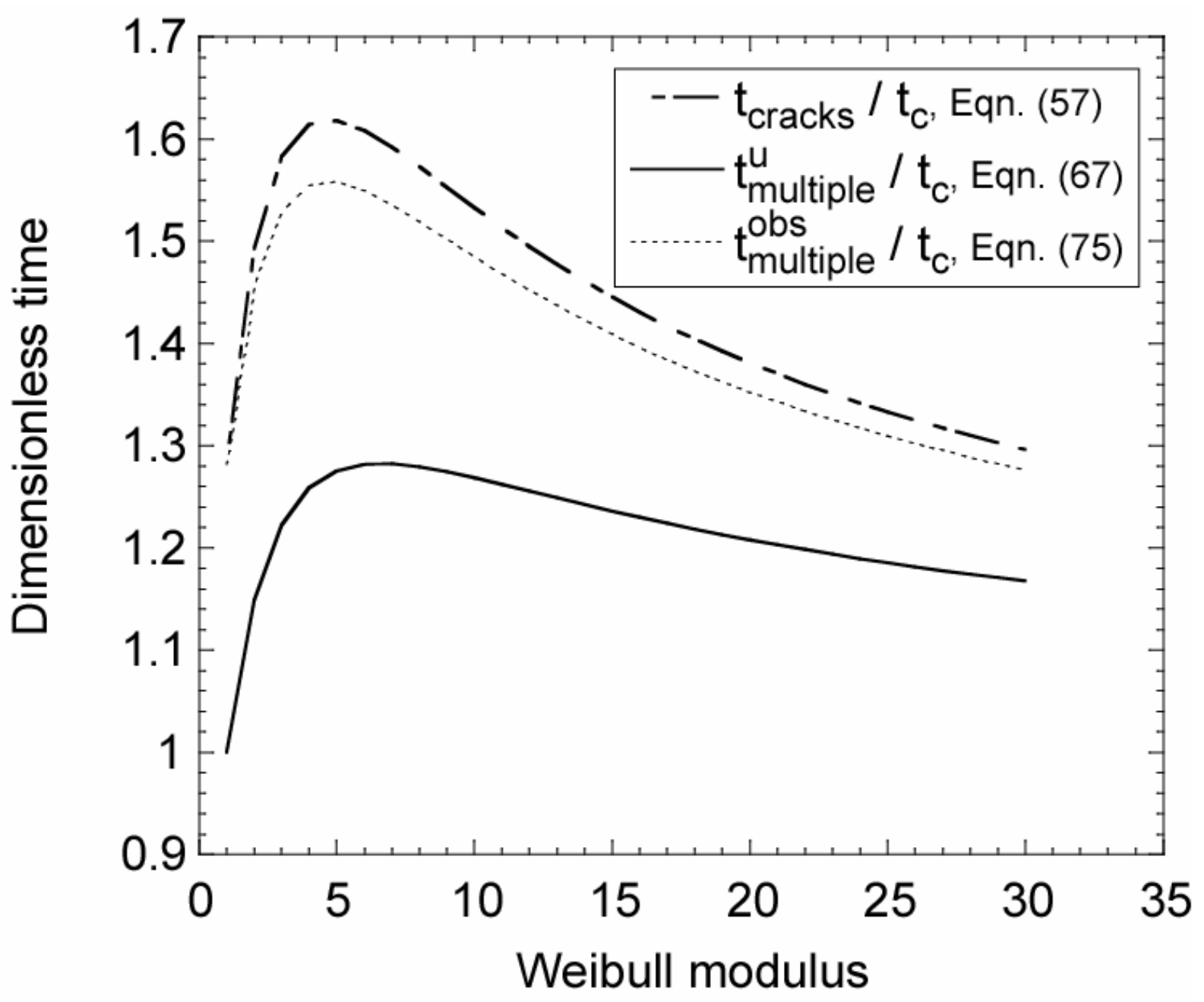

Figure 14. Comparison of three characteristic times of multiple fragmentation $(n=3)$. 


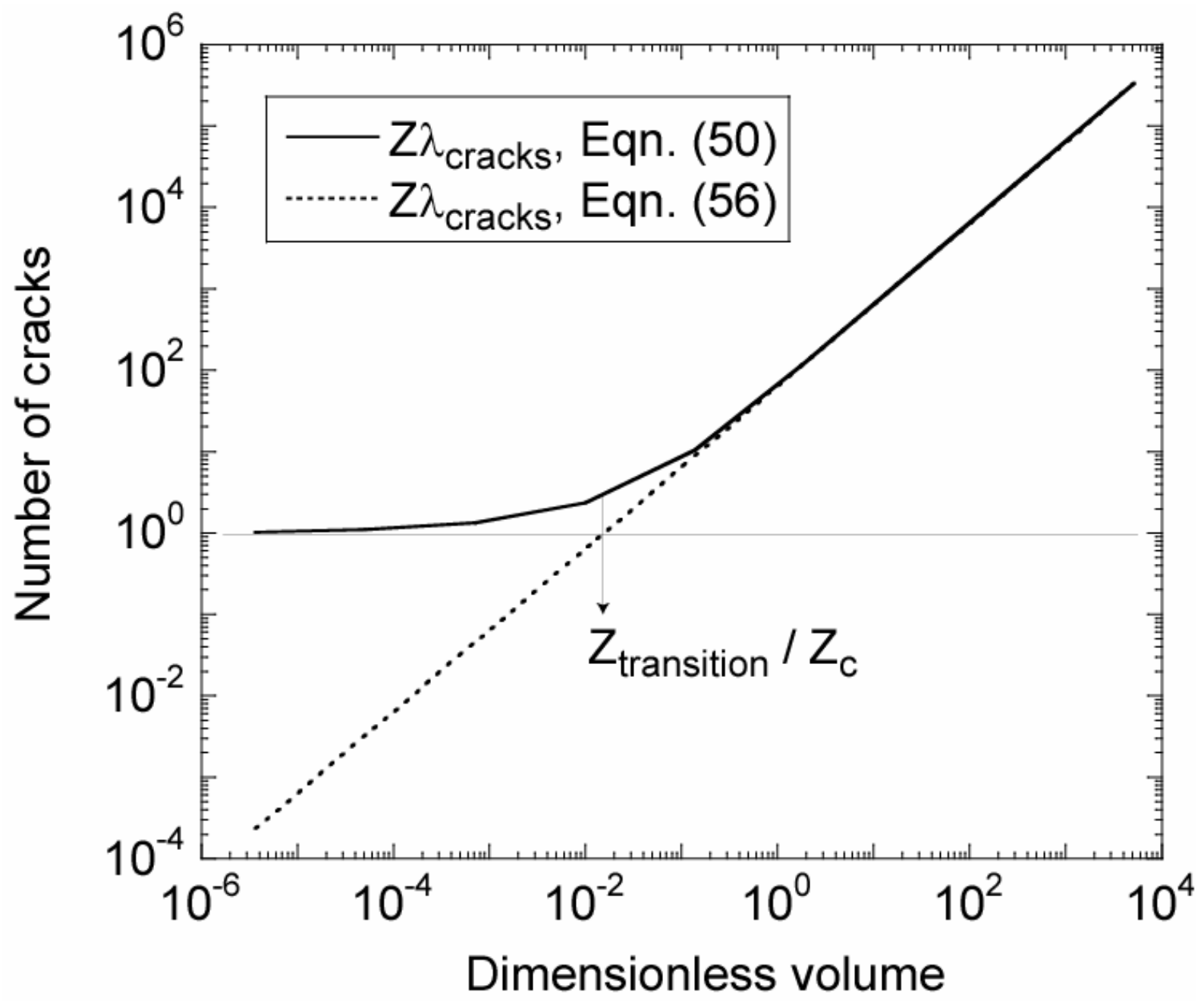

Figure 15. Number of cracks $\left(Z \lambda_{\text {cracks }}\right)$ in $\Omega$ at saturation. Comparison of the general solution (Equation (50)) and that of multiple fragmentation (Equation (56)) for a SiC-100 ceramic (Table 1), when $n=3, S=3.74, k=0.38$. 


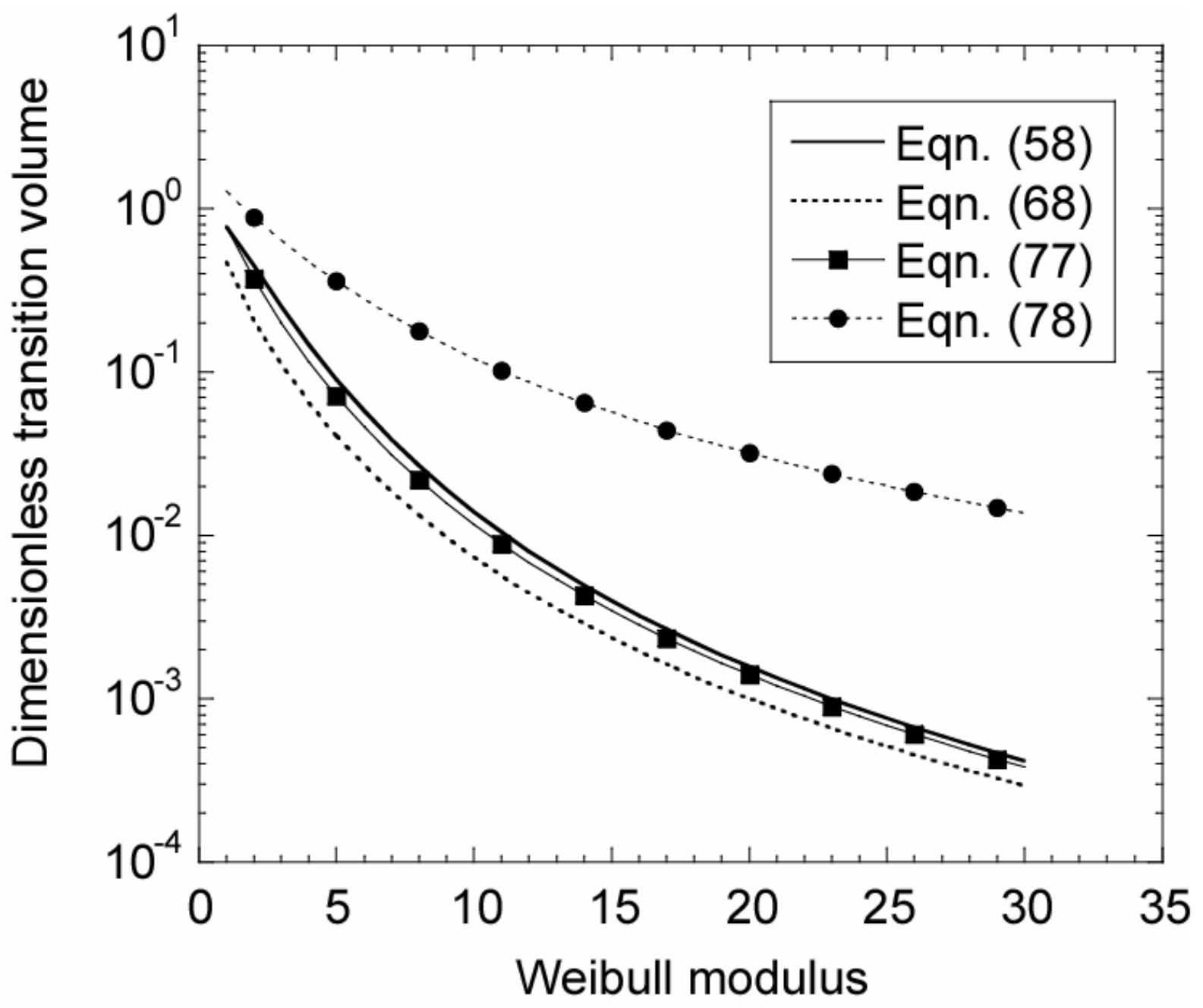

Figure 16. Comparison of four transition criteria $\left(Z_{\text {transition }} / Z_{c}\right)$ for $n=3$. 


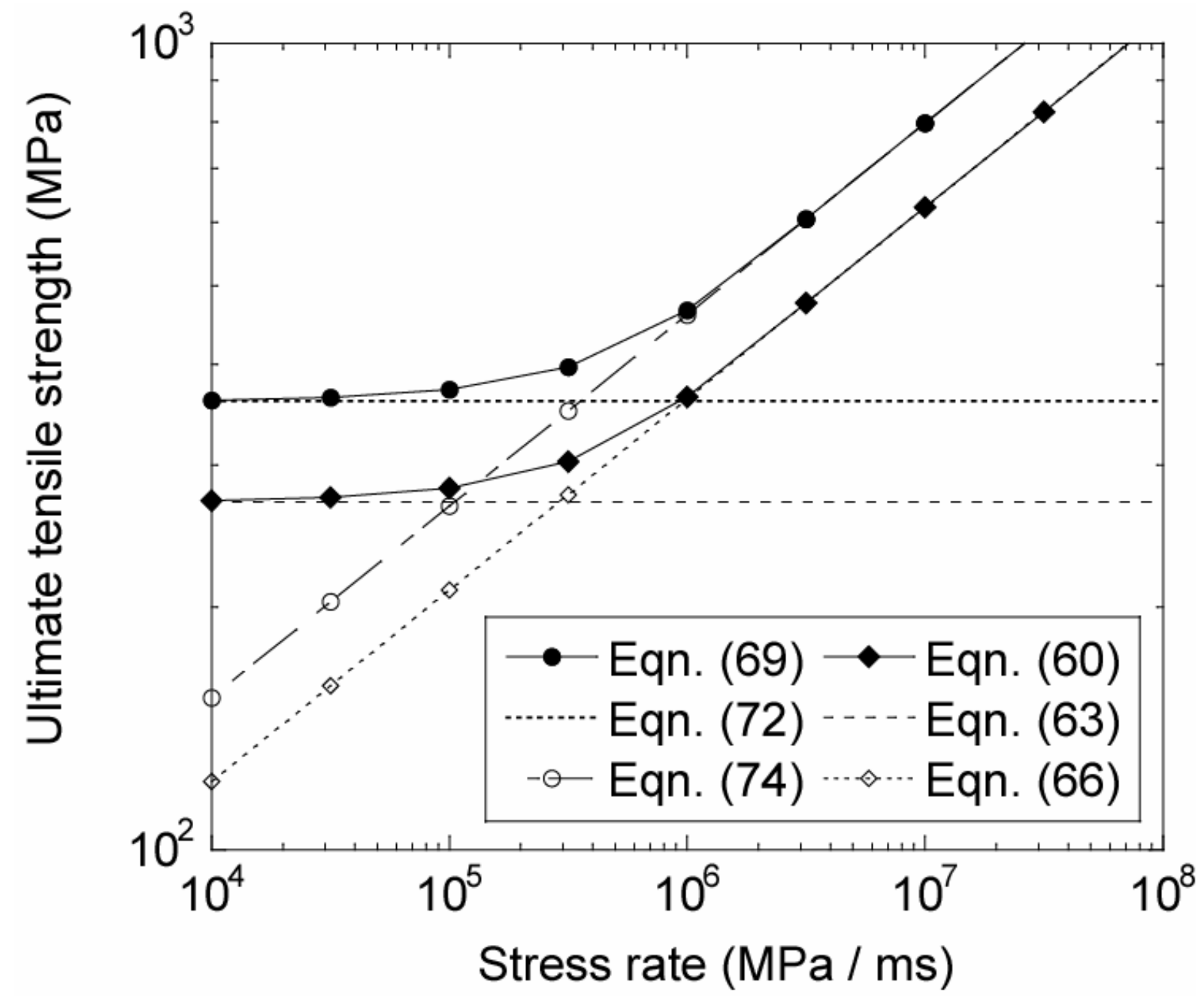

Figure 17. Changes of microscopic and macroscopic stress levels with stress rate for a SiC100 ceramic (Table 1), when $n=3, S=3.74, k=0.38$. 


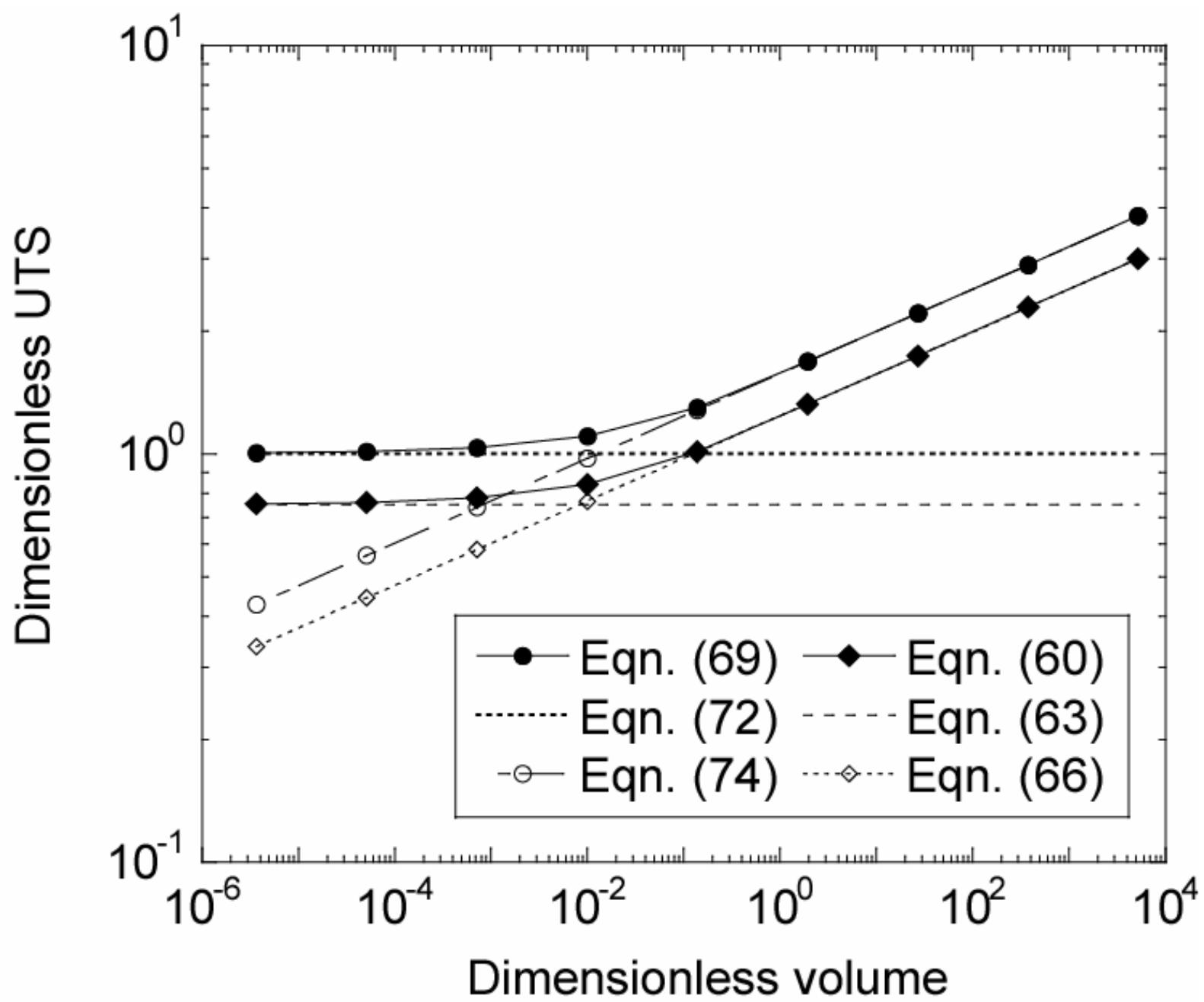

Figure 18. Change of microscopic and macroscopic stress levels normalized by the average failure stress $\left(\sigma_{w}\right)$ with the ratio $\left(Z / Z_{c}\right)$, when $n=3$, and $m=9.6$. 


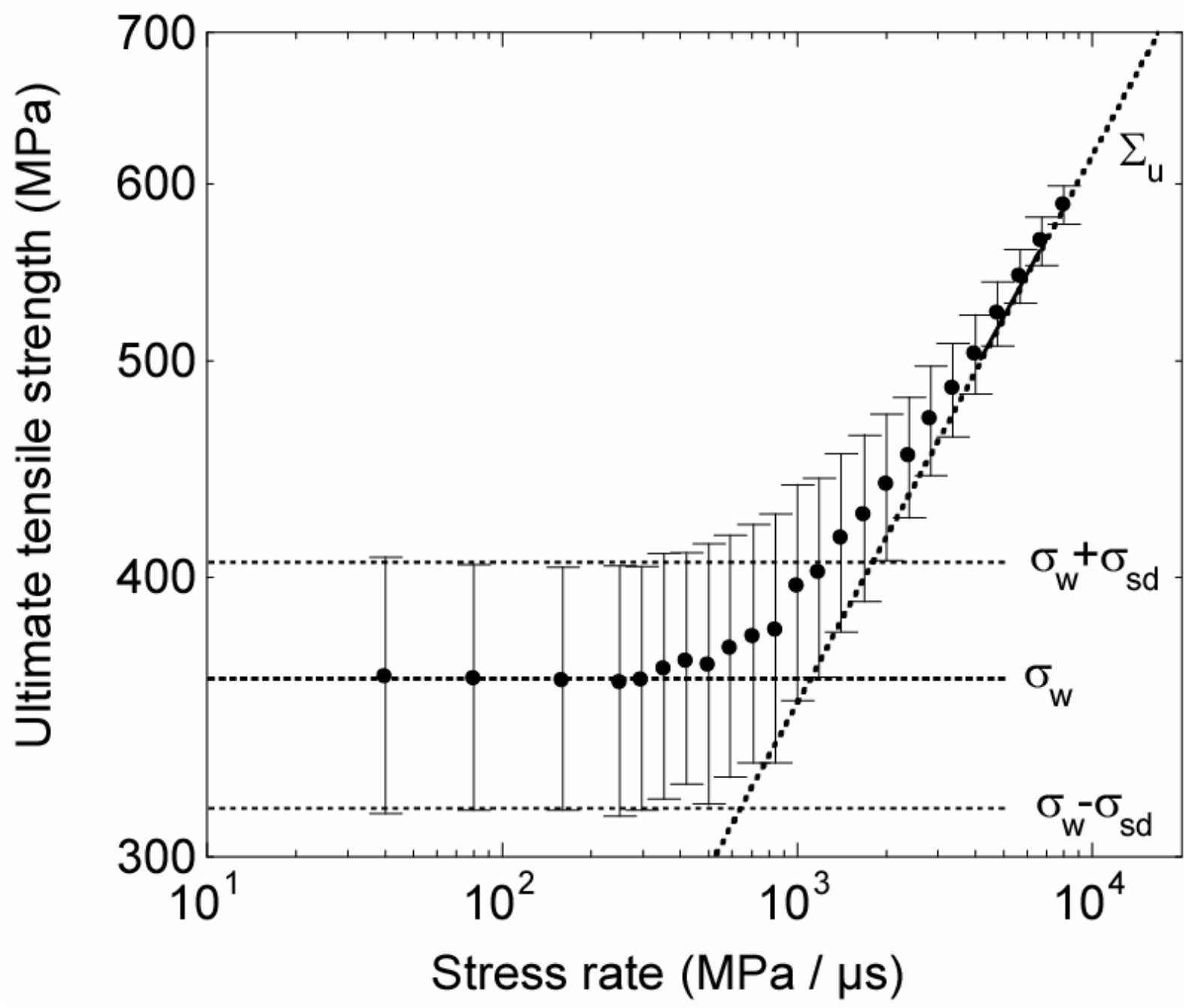

Figure 19. Comparison of microscopic and macroscopic stress levels with results obtained by Monte-Carlo simulations (500 realizations/point) and their standard deviation for a SiC-100 ceramic (Table 1), when $n=3, S=3.74, k=0.38$. 

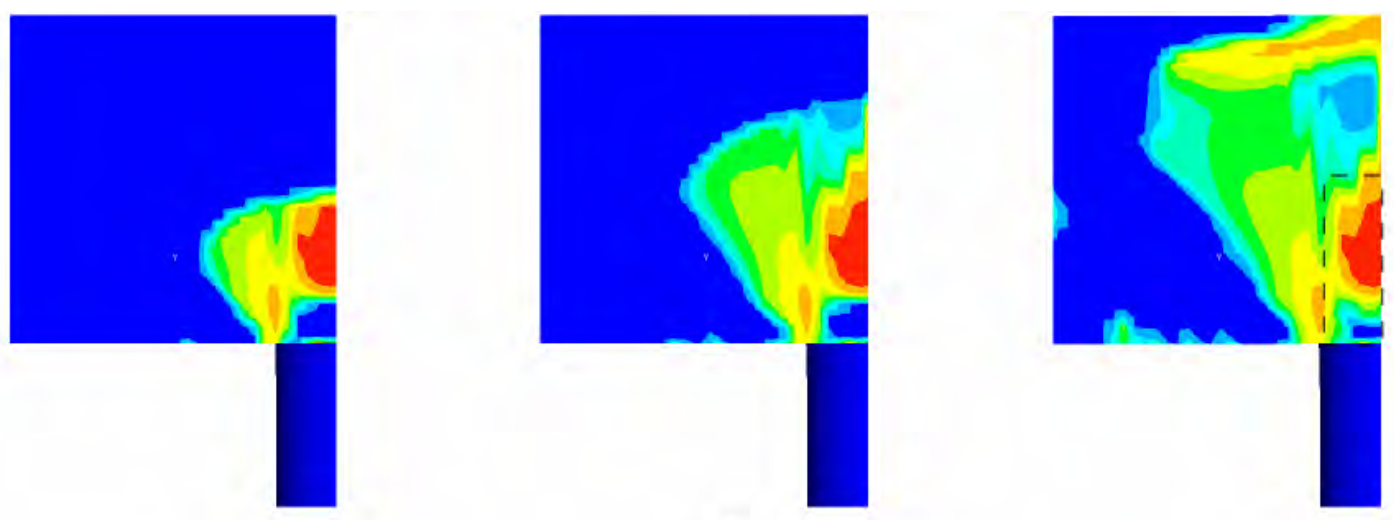

-a-
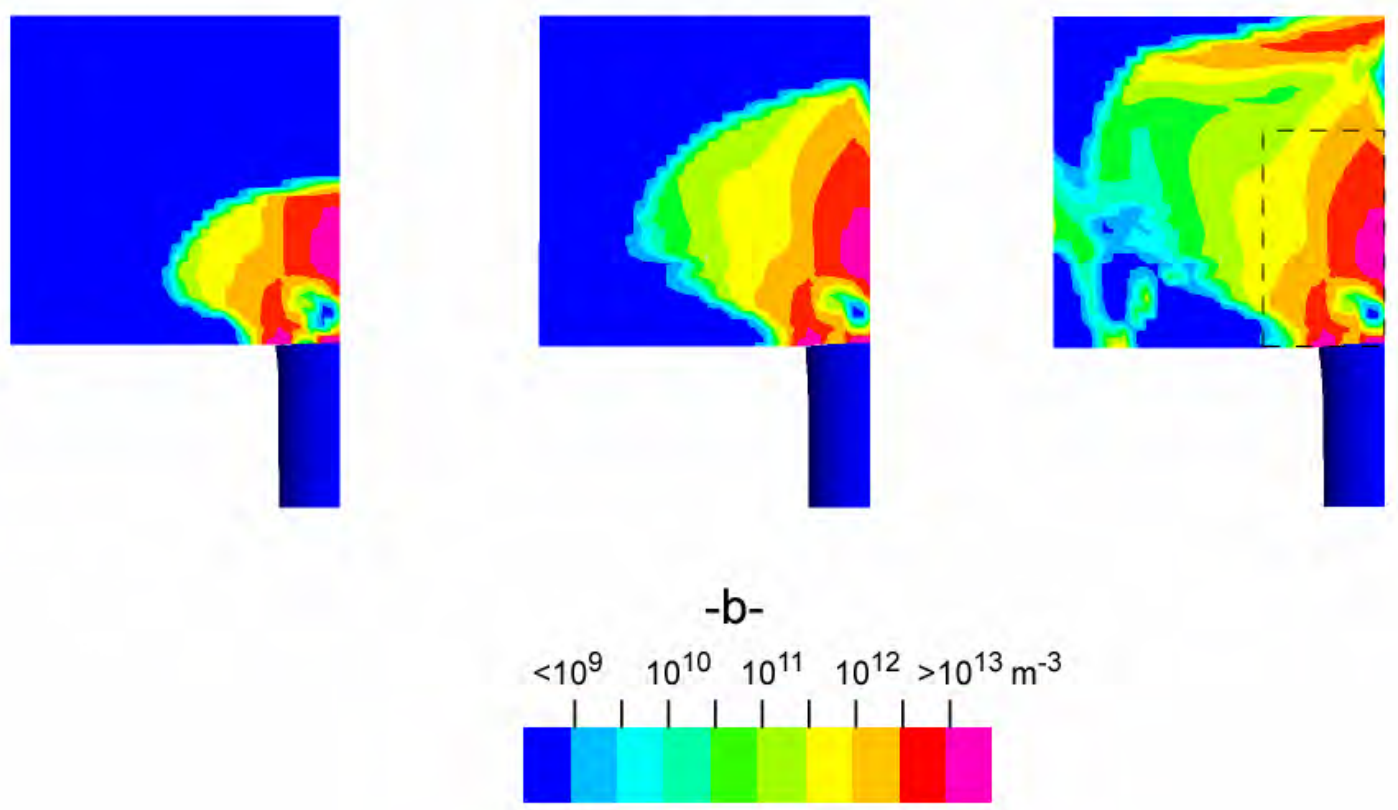

Figure 20. Change of the crack density with time in R-SiC:

$t=2 \mu \mathrm{s}$ (left), $t=3 \mu \mathrm{s}$ (middle), $t=4 \mu \mathrm{s}$ (right) after impact for a projectile velocity of $100 \mathrm{~m} / \mathrm{s}$ (a) and $200 \mathrm{~m} / \mathrm{s}$ (b). 


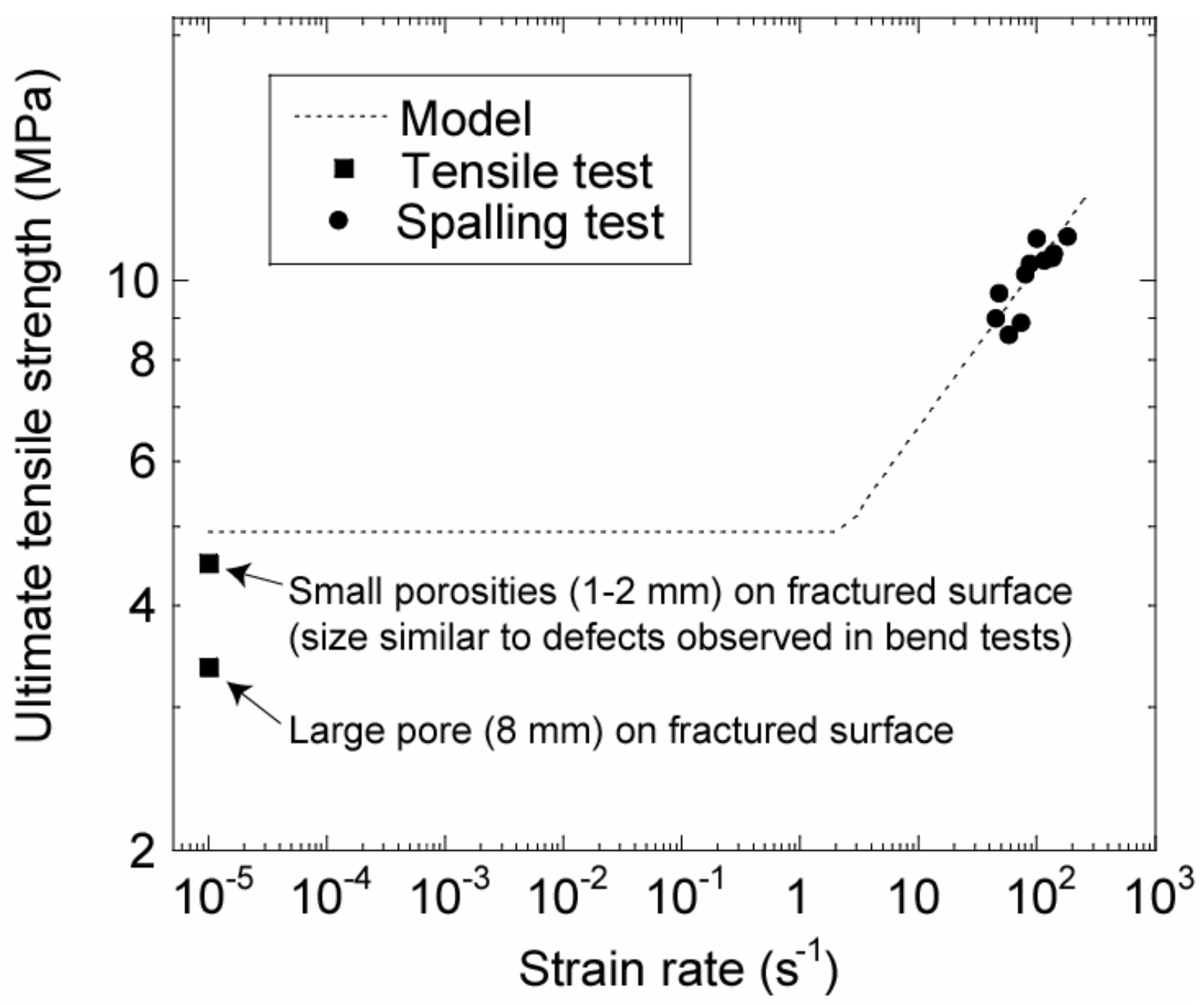

Figure 21. Comparison between experimental results obtained in quasi-static tensile tests and spalling tests (cylindrical specimens $\varnothing 45.7 \mathrm{~mm}, 120 \mathrm{~mm}$ ) and model prediction of the whole range by considering Weibull parameters identified from 20 bend tests on $15 \times 15 \times 60-\mathrm{mm}^{3}$ samples [Forquin and Erzar, 2009]. 


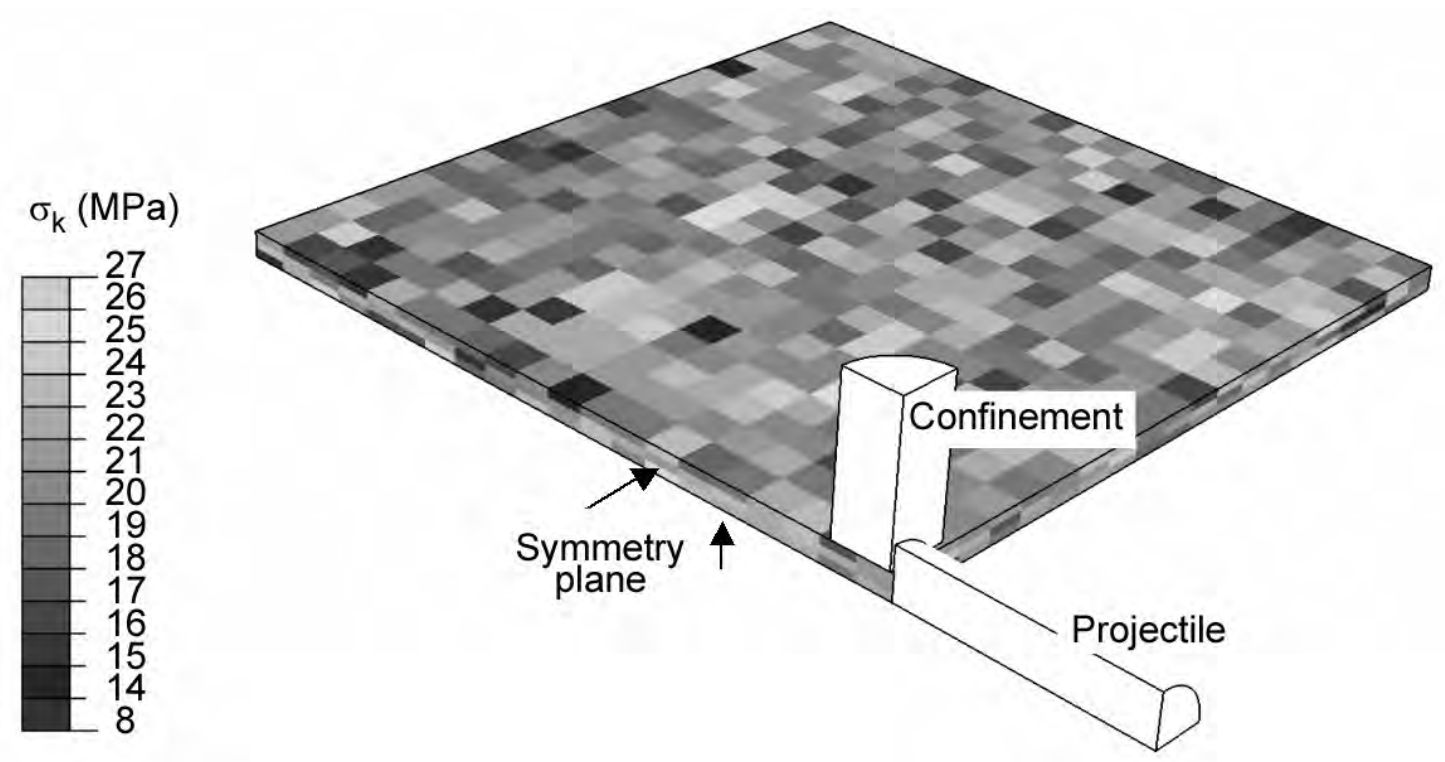

Figure 22. Random failure stresses associated with each finite element (very coarse mesh) and boundary conditions of the numerical simulation. 


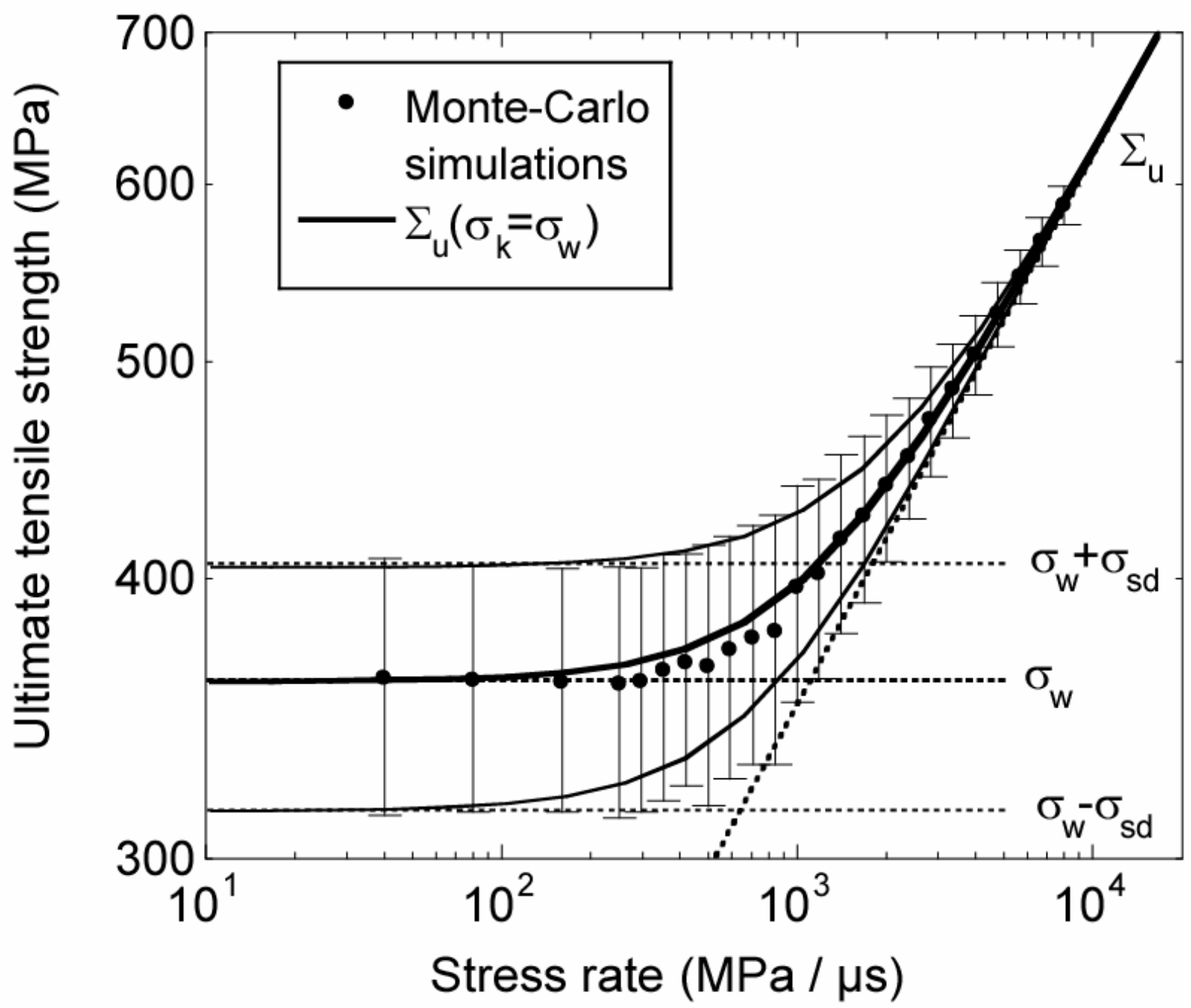

Figure 23. Comparison of the multi-scale model (solid line) and the results obtained by Monte-Carlo simulations (500 realizations/point) and their standard deviation for a SiC-100 ceramic (Table 1), when $n=3, S=3.74, k=0.38$. 


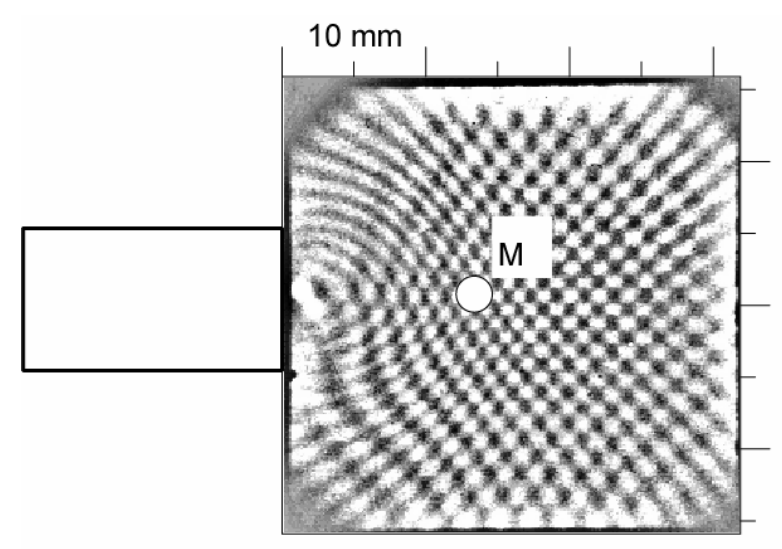

$-a-$

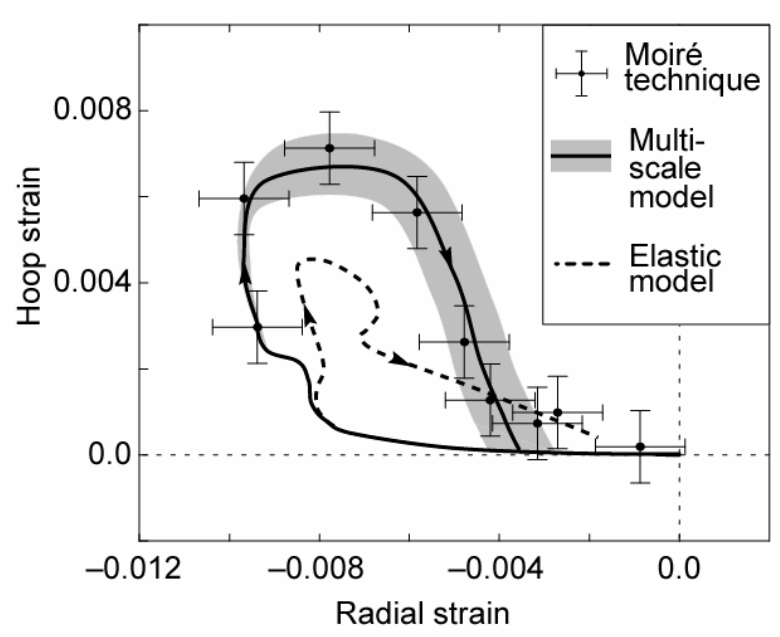

$-\mathrm{b}-$

Figure 24. SiC-100 tile impacted on the edge by a blunt steel projectile $(11 \mathrm{~mm}$ in diameter and $20 \mathrm{~mm}$ in length) with a velocity equal to $330 \mathrm{~m} / \mathrm{s}$ [Denoual and Hild, 2000]. -a-Typical example of moiré fringes.

-b-Strain history given by the moiré technique (dots) and by the multi-scale model (solid line: average, grey bandwidth: \pm standard deviate). 


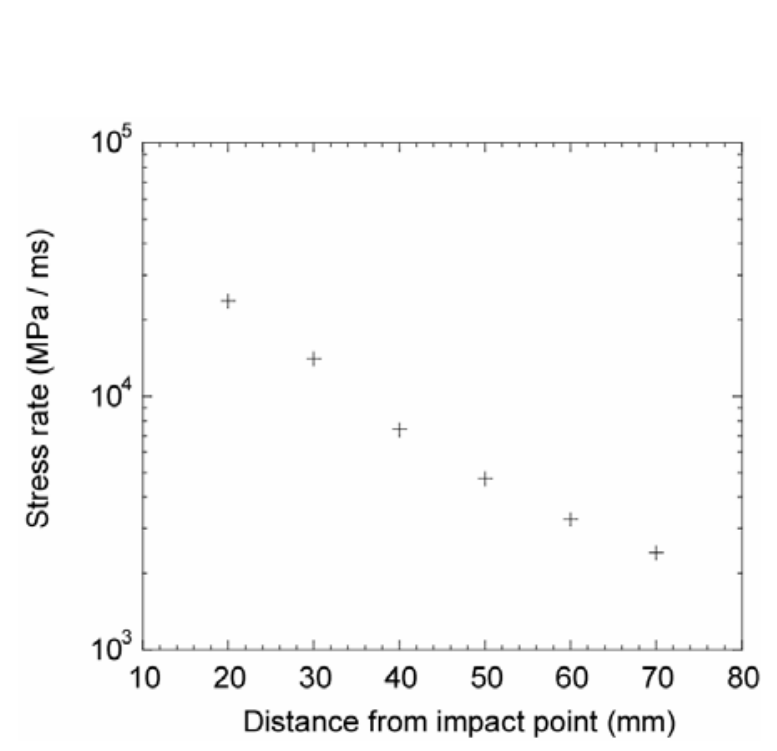

$-a-$

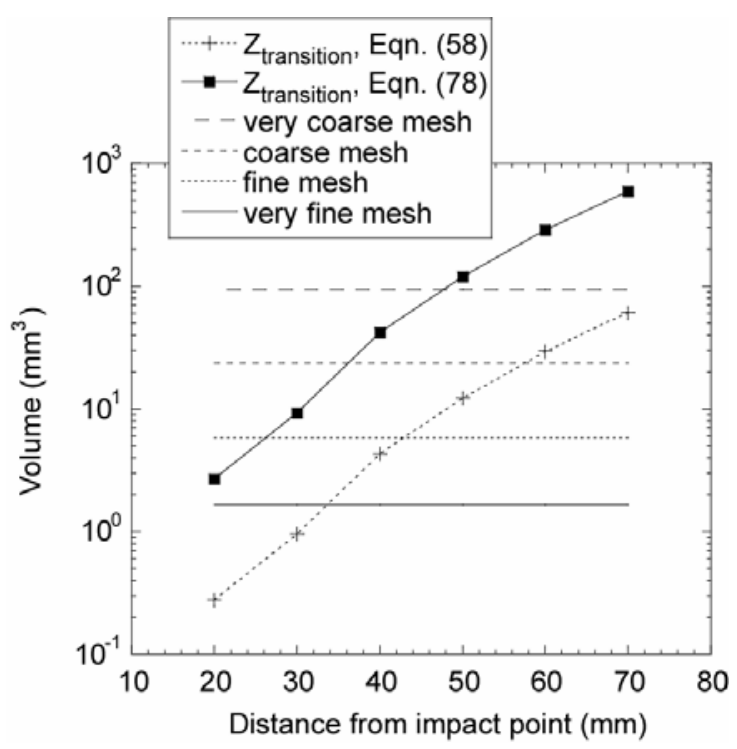

$-b-$

Figure 25. Numerical simulation of EOI test with an aluminium projectile (impact velocity $=88 \mathrm{~m} / \mathrm{s}$ ) against a target of Ductal ${ }^{\circledR}$ concrete (KST model). -a-Stress rate as function of the distance from impact point. -b-Comparison of the volume of finite elements with the volume of transition computed with the stress rates on the left. 


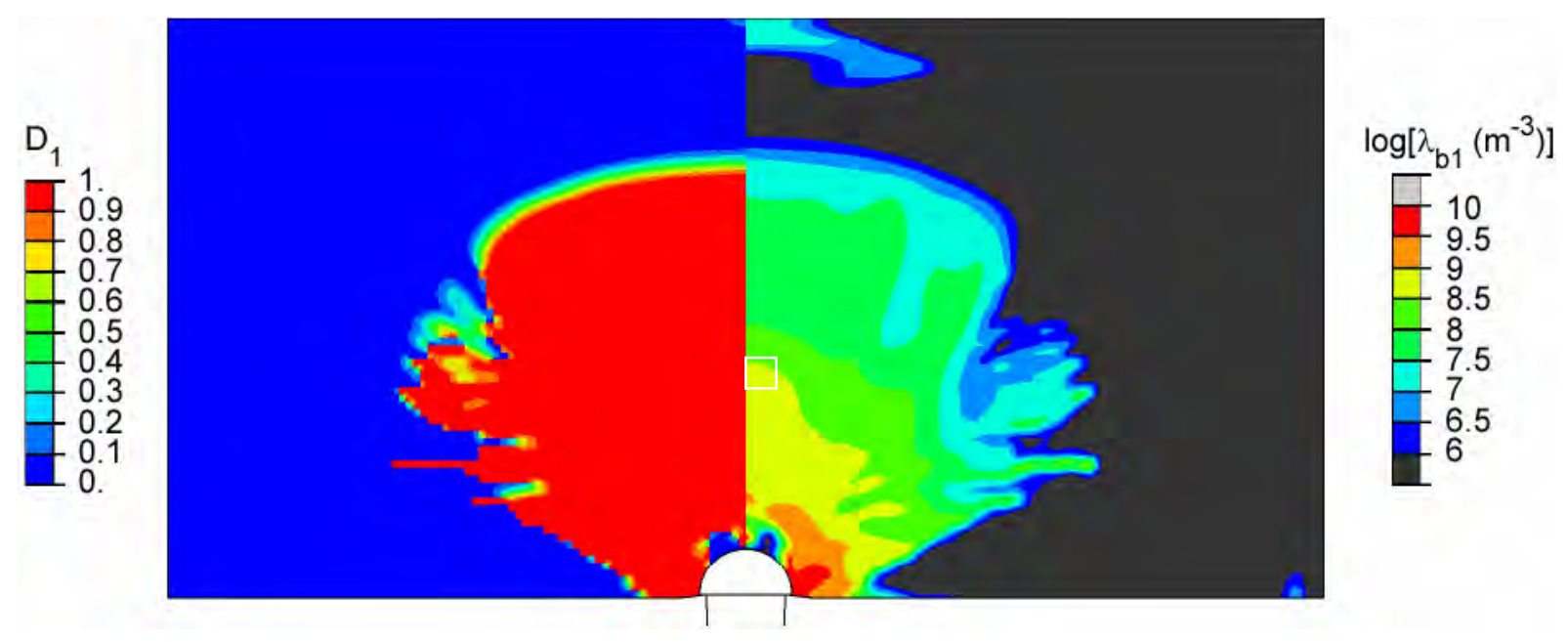

-a-
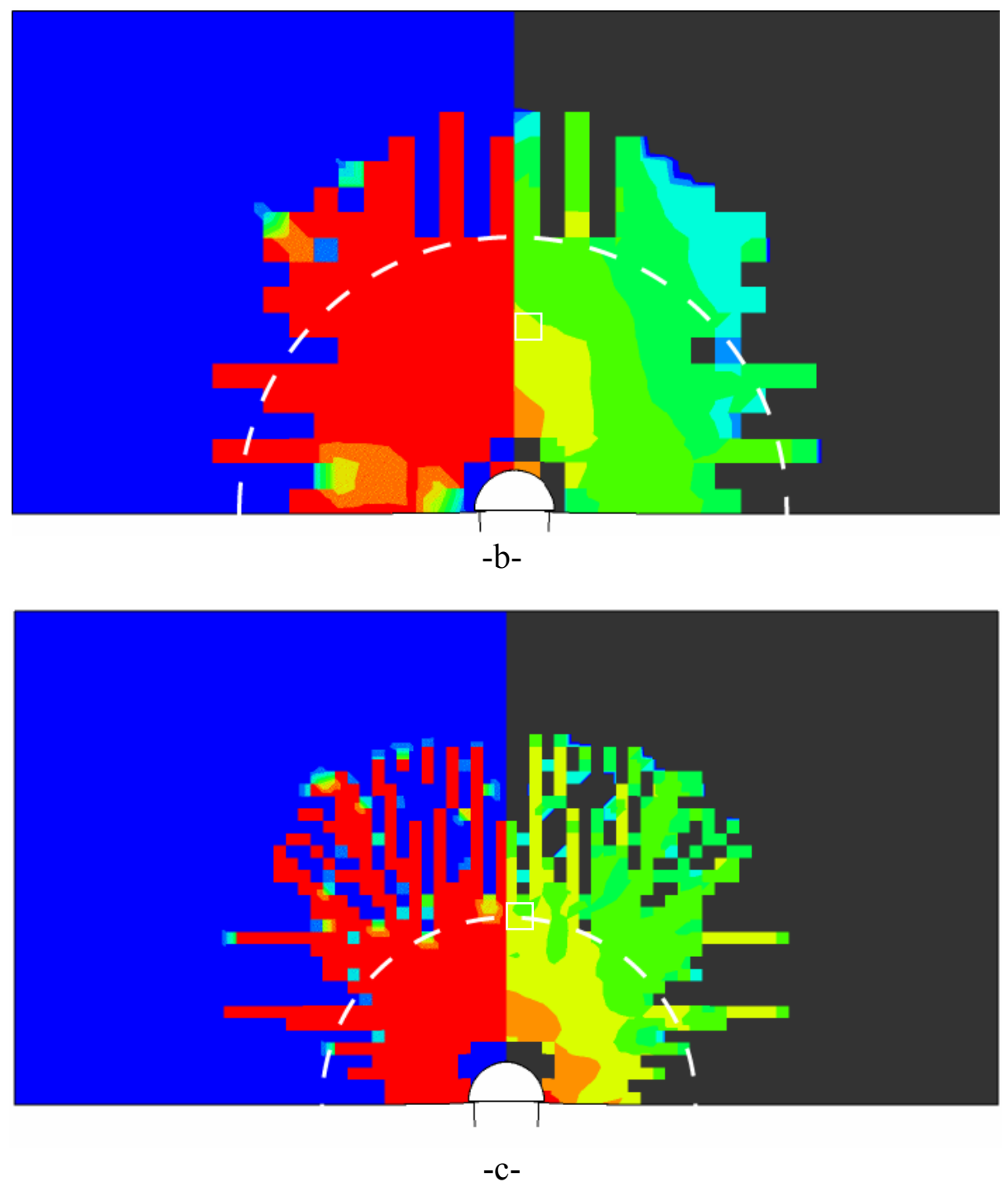


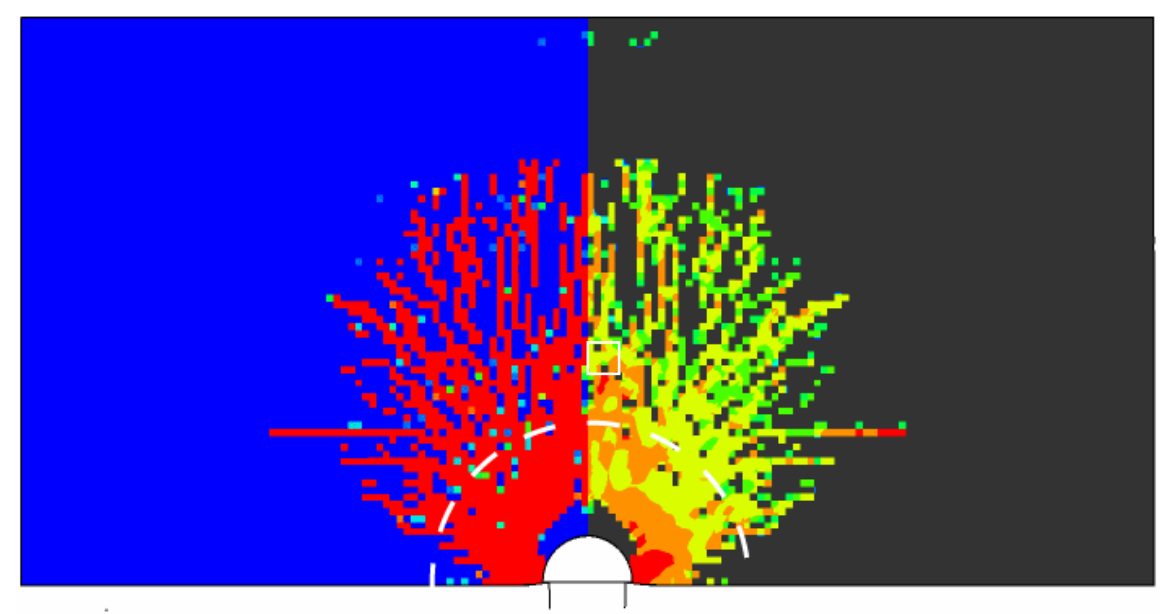

$-d-$

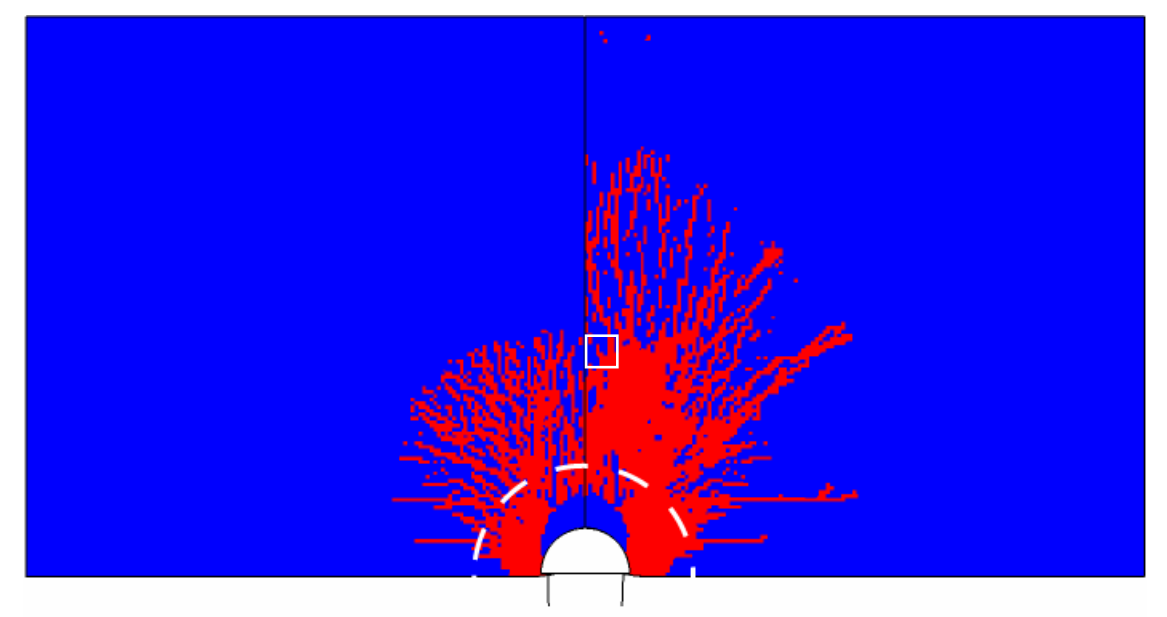

$-\mathrm{e}-$

Figure 26. Damage variable (left, a, b, c, d, e; right, e) and crack density (right, a, b, c, d) associated with the maximum principal stress direction 20 or $35 \mu$ s after impact of an aluminium projectile (impact velocity $=88 \mathrm{~m} / \mathrm{s}$ ). The dashed line depicts the transition from multiple to single fragmentation, and the white box is the volume in which average crack densities are evaluated.

-a-Local (L) model, fine (f) mesh $\left(Z_{F E}=5.86 \mathrm{~mm}^{3}\right), t=35 \mu \mathrm{s}$ (left and right).

-b-Multiscale (MS) model, very coarse (vc) mesh $\left(Z_{F E}=93.8 \mathrm{~mm}^{3}\right), t=35 \mu \mathrm{s}$ (left and right).

-c-Multiscale model, coarse (c) mesh $\left(Z_{F E}=23.4 \mathrm{~mm}^{3}\right), t=35 \mu$ s (left and right).

-d-Multiscale model, fine (f) mesh $\left(Z_{F E}=5.86 \mathrm{~mm}^{3}\right), t=35 \mu$ s (left and right).

-e-Multiscale model, very fine (vf) mesh $\left(Z_{F E}=1.67 \mathrm{~mm}^{3}\right), t=20 \mu \mathrm{s}$ (left), $t=35 \mu \mathrm{s}$ (right). 


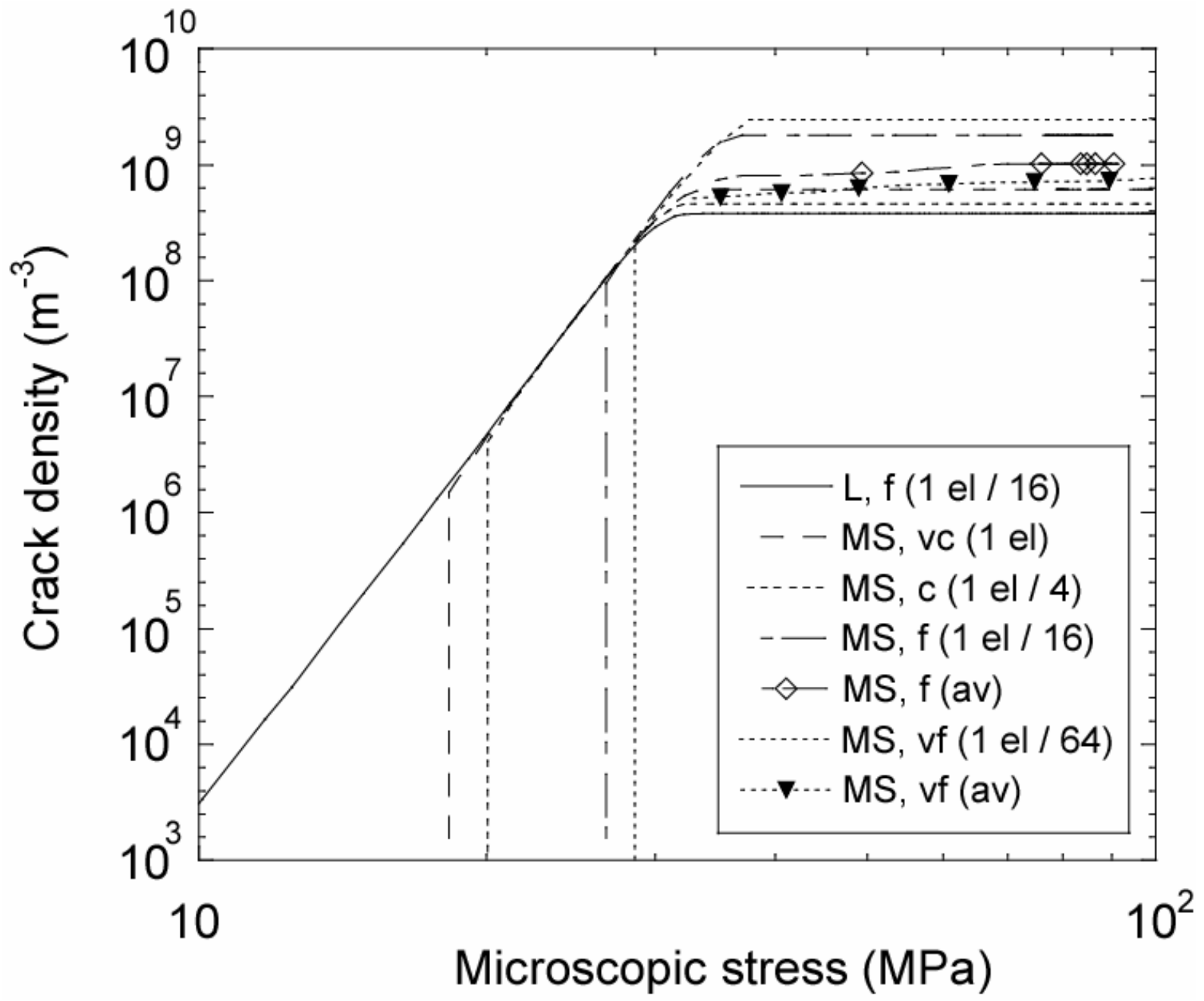

Figure 27. Change of crack density with the microscopic stress in damaged elements located $60 \mathrm{~mm}$ ahead of the impact point for the 5 meshes of Figure 26. For the fine (f) and very fine (vf) meshes, the average (av) crack density is plotted by considering a $93.8-\mathrm{mm}^{3}$ volume. 

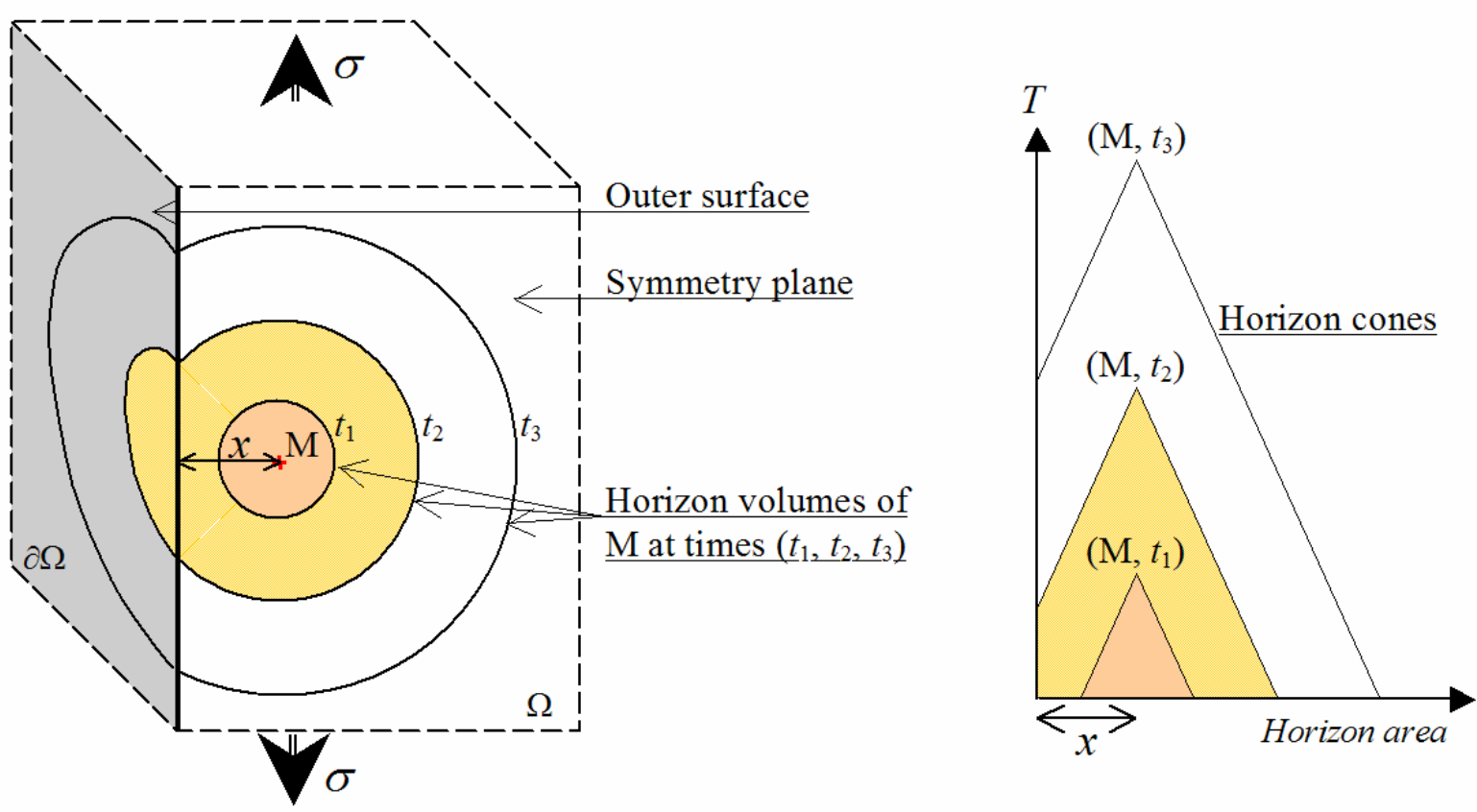

Figure 28. Horizon volumes of a point $M$ placed at a distance $x$ from the outer surface. 


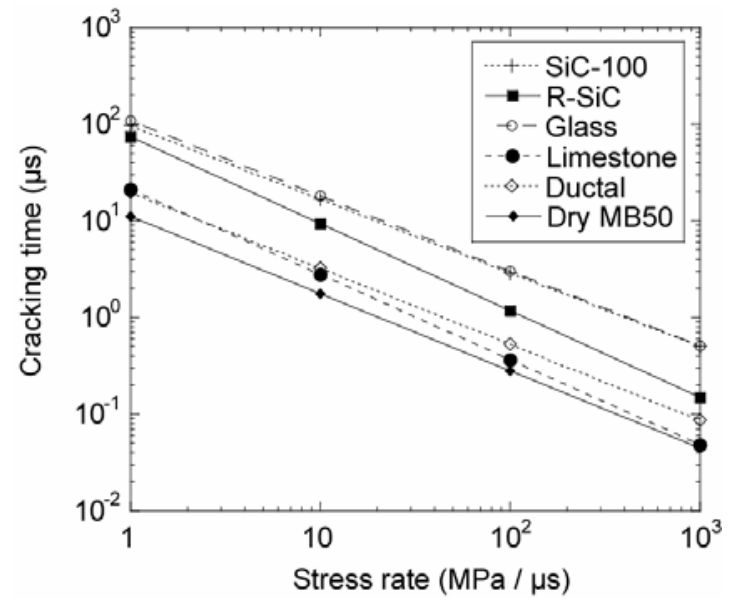

$-a-$

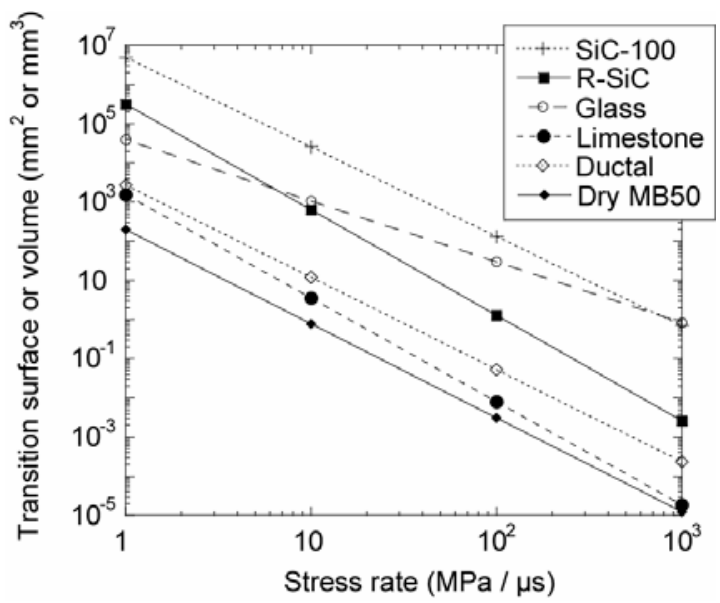

$-\mathrm{C}-$

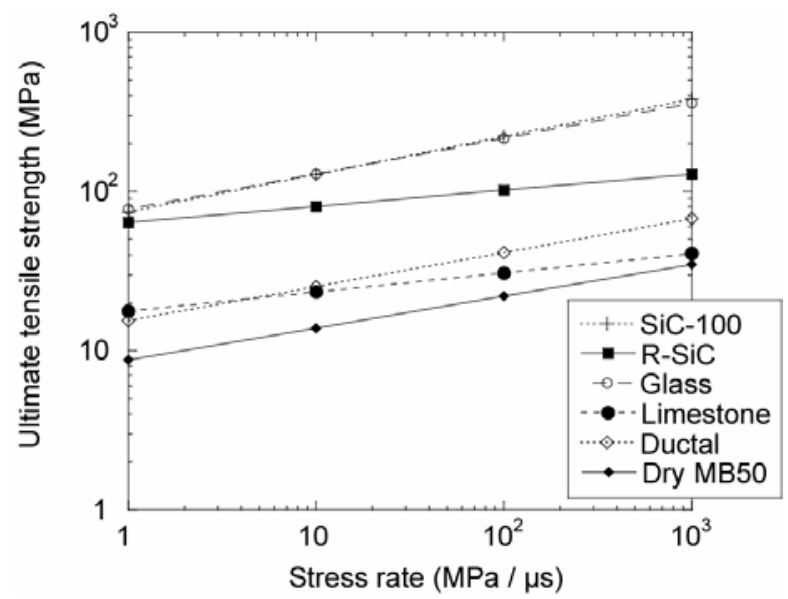

$-b-$

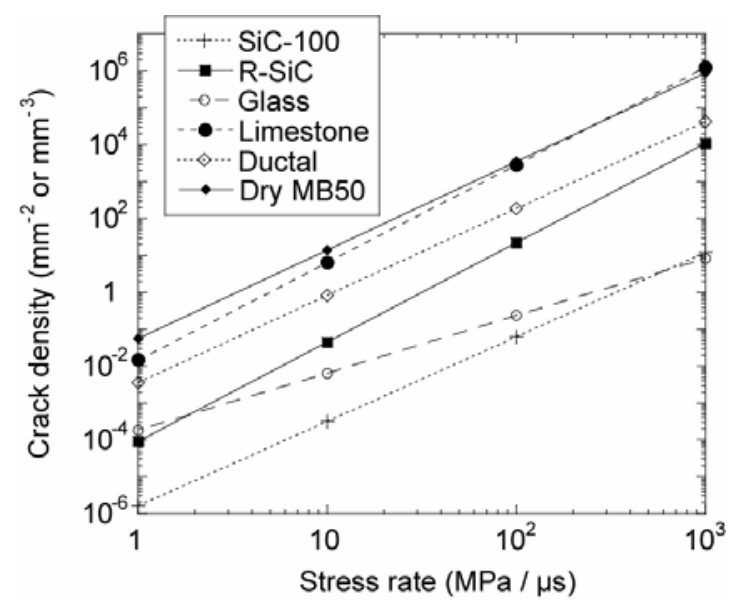

$-\mathrm{d}-$

Figure 29. Comparison of the fragmentation properties of the five reference materials on the outer surface of the domain $\partial \Omega$ :

-a-Time of saturation of crack ( $t_{\text {cracks, }}$ Equation (57)) vs. stress rate,

-b-Ultimate strength ( $\Sigma_{\text {multiple }}^{u}$, Equation (66)) vs. stress rate,

-c-Volume of transition $\left(Z_{\text {transition }}\right.$, Equation (78)) vs. stress rate,

-d-Crack density ( $\lambda_{\text {cracks, }}$ Equation (53)) vs. stress rate. 


\section{Tables}

Table 1. Mechanical properties and Weibull parameters of the six reference materials.

\begin{tabular}{|c|c|c|c|c|c|c|}
\hline Material & $\begin{array}{l}\text { SiC-100 } \\
\text { ceramic }\end{array}$ & $\begin{array}{l}\text { Porous } \\
\text { R-SiC } \\
\text { ceramic }\end{array}$ & $\begin{array}{c}\text { Ductal }^{\circledR} \\
\text { concrete } \\
\text { without fibres }\end{array}$ & $\begin{array}{l}\text { Dry MB50 } \\
\text { micro- } \\
\text { concrete }\end{array}$ & $\begin{array}{l}\text { Crinoidal } \\
\text { limestone } \\
\text { rock }\end{array}$ & $\begin{array}{l}\text { Soda-lime } \\
\text { silicate glass }\end{array}$ \\
\hline \multicolumn{7}{|c|}{ Elastic properties, density, compression tests } \\
\hline $\begin{array}{l}\text { Young's } \\
\text { modulus } E \\
(\mathrm{GPa})\end{array}$ & 410 & 260 & 57 & 31 & 78 & 70 \\
\hline $\begin{array}{l}\text { Poisson's ratio } \\
v\end{array}$ & 0.15 & 0.16 & 0.18 & 0.2 & 0.28 & 0.22 \\
\hline Density $\rho$ & 3.15 & 2.64 & 2.4 & 2200 & 2.7 & 2.5 \\
\hline Porosity & $1.8 \%$ & $17.1 \%$ & $1-2 \%$ & $\approx 12 \%$ & $<1 \%$ & 0 \\
\hline $\begin{array}{l}\text { Compressive } \\
\text { strength }^{1}(\mathrm{MPa})\end{array}$ & $\begin{array}{l}-6500(\mathrm{SC}) \\
\text { [Forquin et } \\
\text { al., 2003b] }\end{array}$ & $\begin{array}{l}\text { Not } \\
\text { measured }\end{array}$ & $-220(\mathrm{SC})$ & $\begin{array}{c}-70(\mathrm{SC}) \\
{[\text { Bernier and }} \\
\text { Dalle, 1998] }\end{array}$ & $-147(\mathrm{SC})$ & $\begin{array}{c}\approx-4000(\mathrm{HEL}) \\
\text { [Cagnoux }, \\
1985]\end{array}$ \\
\hline \multicolumn{7}{|c|}{ Bend tests and Weibull parameters } \\
\hline $\begin{array}{l}\text { Height } \times \text { width } \\
\times \text { span }\left(\mathrm{mm}^{3}\right), \\
\text { number of tests }\end{array}$ & $\begin{array}{c}3 \times 4 \times 30 \\
65\end{array}$ & $\begin{array}{c}3 \times 3 \times 20 \\
19\end{array}$ & $\begin{array}{c}11 \times 10 \times 130 \\
18\end{array}$ & $\begin{array}{c}15 \times 15 \times 60, \\
20\end{array}$ & $\begin{array}{c}50 \times 50 \times 150 \\
40\end{array}$ & $\begin{array}{c}\text { Disk } \\
\text { bending, } \\
400\end{array}$ \\
\hline $\begin{array}{l}\text { Mean tensile } \\
\text { failure stress } \\
(\mathrm{MPa}) \sigma_{w}\left[Z_{e f f}\right]\end{array}$ & 360 & 113 & 21.9 & 9.99 & 19.0 & $\approx 94$ \\
\hline $\begin{array}{l}\text { Effective } \\
\text { volume }\left(\mathrm{mm}^{3}\right) / \\
\text { surface }\left(\mathrm{mm}^{2}\right)\end{array}$ & 1.25 & 0.084 & 53 & 39.9 & 360 & $\begin{array}{c}\mathrm{S}_{\mathrm{eff}}= \\
100 \mathrm{~cm}^{2}\end{array}$ \\
\hline $\begin{array}{l}\text { Mean tensile } \\
\text { failure stress } \\
(\mathrm{MPa})^{[\text {Veff], [Seff] }}\end{array}$ & $31.6^{[1 \mathrm{~mm} 3]}$ & $103^{[1 \mathrm{~mm} 3]}$ & $31.6^{[1 \mathrm{~mm} 3]}$ & $13.6^{[1 \mathrm{~mm} 3]}$ & $24.8^{[1 \mathrm{~mm} 3]}$ & $350^{[1 \mathrm{~mm} 2]}$ \\
\hline $\begin{array}{l}\text { Weibull } \\
\text { modulus } m\end{array}$ & 9.6 & 26.5 & 11 & 12 & 22 & $\approx 7$ \\
\hline References & $\begin{array}{l}\text { [Hild et al., } \\
\text { 2003] }\end{array}$ & $\begin{array}{l}\text { [Forquin et } \\
\text { al., 2003] }\end{array}$ & $\begin{array}{c}\text { [Forquin and } \\
\text { Hild., 2008] }\end{array}$ & $\begin{array}{l}\text { [Forquin and } \\
\text { Erzar, 2009] }\end{array}$ & $\begin{array}{c}\text { [Grange et } \\
\text { al., 2008] }\end{array}$ & $\begin{array}{l}\text { [Oakley, } \\
\text { 1996] }\end{array}$ \\
\hline
\end{tabular}

${ }^{1} \sigma_{\mathrm{SC}}$ : minimum nominal axial stress under simple compression, $\sigma_{\mathrm{HEL}}$ : Hugoniot Elastic Limit (corresponding to the axial stress level during plates impact when the elastic limit is reached) 
Table 2. Parameters of the fragmentation model coupled with the Krieg, Swenson and Taylor model for the unreinforced Ductal ${ }^{\circledR}$ concrete.

\begin{tabular}{|c|c|c|}
\hline Density, Elastic parameters & $\rho ; E ; v$ & $2.390 ; 57 \mathrm{GPa} ; 0.18$ \\
\hline \multicolumn{3}{|c|}{ Parameters of the hydrostatic behaviour } \\
\hline Initial et final bulk moduli & $K_{i} ; K_{f}$ & $29.7 \mathrm{GPa} ; 34.0 \mathrm{GPa}$ \\
\hline \multirow[t]{3}{*}{ Compaction curve ( 3 points) } & $\varepsilon_{v}^{(i)} ; P^{(i)}$ & $-0.013 ; 320 \mathrm{MPa}$ \\
\hline & & $-0.04 ; 600 \mathrm{MPa}$ \\
\hline & & $-0.059 ; 900 \mathrm{MPa}$ \\
\hline \multicolumn{3}{|c|}{ Parameters of the deviatoric behaviour } \\
\hline Coefficient of elliptic equation & $a_{0} ; a_{1} ; a_{2}$ & $10^{4} \mathrm{MPa}^{2} ; 515 \mathrm{MPa} ; 0.384$ \\
\hline Maximum and minimum stresses & $\sigma_{e q}^{\max } ; \sigma_{e q}^{\min }$ & $750 \mathrm{MPa} ; 222 \mathrm{MPa}$ \\
\hline \multicolumn{3}{|c|}{ Parameter of the fragmentation model } \\
\hline Cracks initiation (Weibull) parameters & $\sigma_{w} ; m ; V_{e f f}$ & $22 \mathrm{MPa} ; 11 ; 53 \mathrm{~mm}^{3}$ \\
\hline Cracks propagation parameters & $k ; C$ & $0.38 ; 4880 \mathrm{~m} / \mathrm{s}$ \\
\hline
\end{tabular}

